


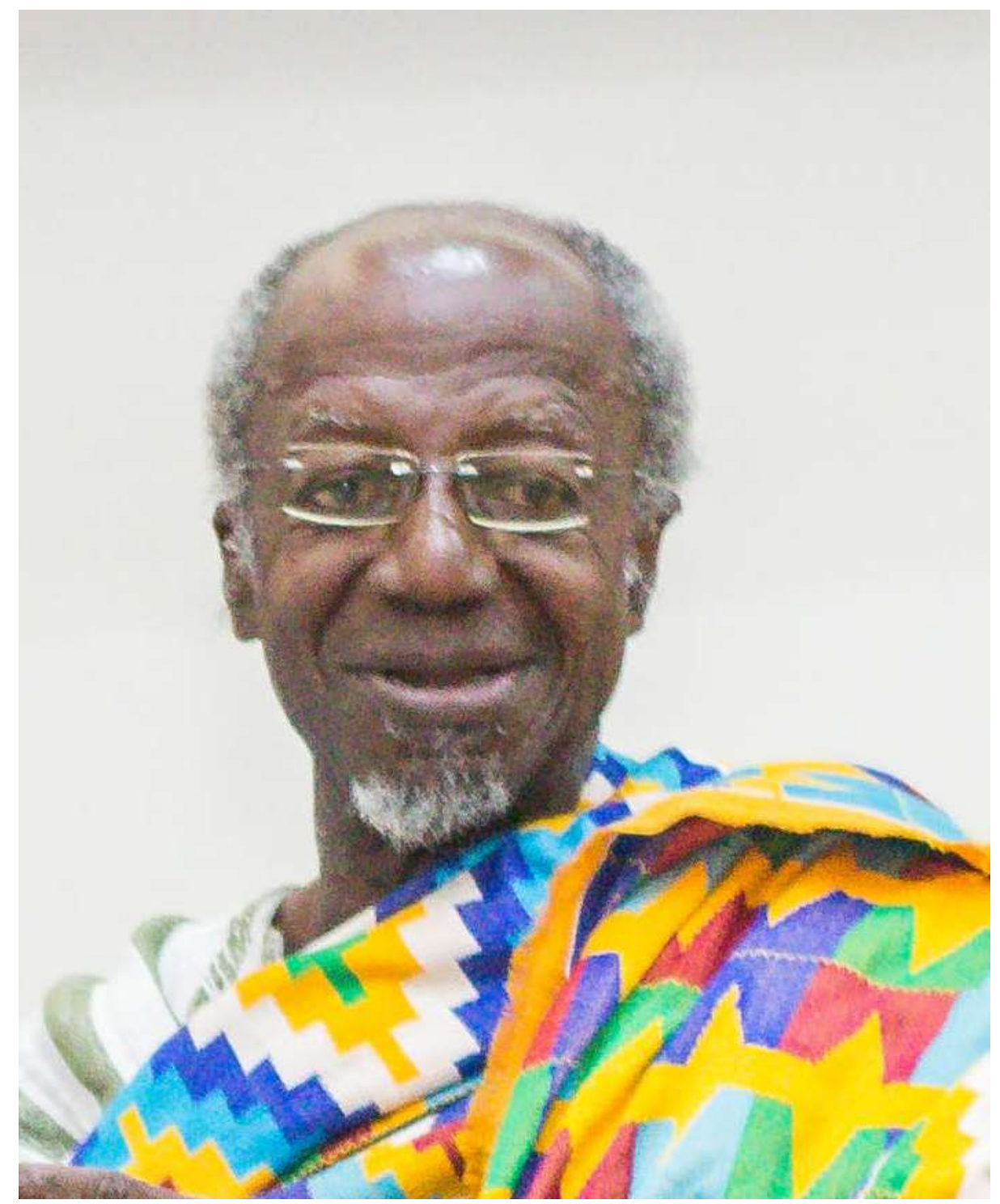

PROFESSOR ATTA GYAMFI BRITWUM 


\section{THE BILINGUAL LITERARY JOURNAL OF THE FACULTY OF ARTS UNIVERSITY OF CAPE COAST}

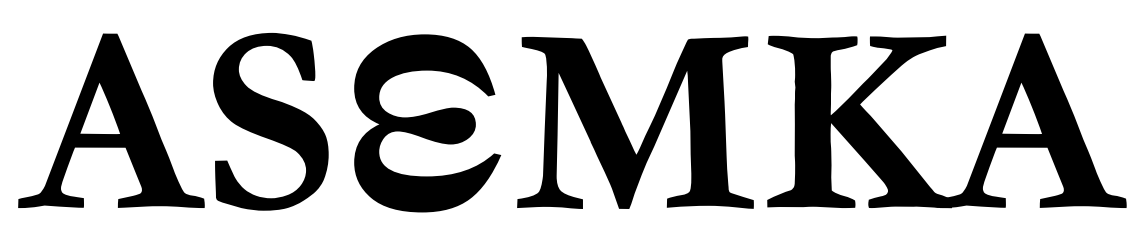

NUMBER 10

SEPTEMBER 2020

\section{EDITORIAL COMMITTEE}

Editor-in-Chief: Prof. Samuel Awuah-Nyamekye (Ph.D.)

Editor: $\quad$ Prof. Mawuloe Koffi Kodah (Ph.D.)

Associate Editors: Dr. Samuel Kwesi Nkansah

Dr. Mrs. Theresa Addai Munumkum

Dr. Isaac Mwinlaaru

Business Editor: Rev. Sr. Dr. Matilda Alice Nsiah

\section{EDITORIAL STAFF}

Mr. Stephen Owusu-Amoh

Mr. Isaac Kweku Grantson

\section{EDITORIAL ADVISORS}

Prof. Kwadwo Opoku-Agyemang, University of Cape Coast.

Prof. Joseph B. A. Afful, University of Cape Coast.

Prof. Raymond N. Osei, University of Cape Coast.

Prof. Richard V. Cudjoe, University of Cape Coast.

Prof. Victor K Yankah, University of Cape Coast.

Dr. Mousa Traore, University of Cape Coast. 


\section{ACKNOWLEDGEMENTS}

We acknowledge the contribution of the underlisted members of the Department of French who did preliminary editorial work on the papers:

Dr. Anthony Y.M. De-Souza (Chairman)

Prof. Raymond N. Osei

Prof. Mawuloe K. Kodah

Dr. Sylvester P. Krakue

Mr. Ofosu Addo-Danquah

Mr. Micheal Donkoh (Secretary)

\section{SUBSCRIPTION}

Assmka is published twice in the Academic year by the Faculty of Arts, University of Cape Coast. The annual out-of-Ghana subscription rate, including air-postage, is US\$29 for individuals, and US\$ 59 for institutions and libraries. Single issue rate for individuals is US\$18. Claims for copies not received must be made within three (3) months following an issue's publication. Correspondence should be addressed to:

The Editor, Assmka

Department of French

Faculty of Arts

College of Humanities and Legal Studies

University of Cape Coast

Cape Coast

Ghana, West Africa

Email: asemkajournal@ucc.edu.gh

\section{ADVERTISING}

Advertising rate, size specifications and related information are available upon request. Please, contact the General Editor for more information.

\section{SUBMISSIONS}

Assmka is an internationally-refereed journal of the Humanities. It publishes scholarly and imaginative articles in Literature, Language, and Culture generally, including, Orature, Film, Theatre, Music and Art. Essays, Interviews, Book Reviews, Poetry, Short Prose Fiction and Drama are welcome. Submitted manuscripts, in English and French, must be prepared in accordance with the most recent of APA or MLA style manual, where applicable. The author's identity and address may appear only on the cover- 
page and nowhere else within the submitted manuscript. All manuscripts should be submitted electronically through:

asemkajournal@ucc.edu.gh

Manuscript will be duly acknowledged within two (2) months of receiving them. Individuals whose works are accepted for publication may provide Assmka with a brief bio-data. The Editors cannot be held liable for lost or damaged manuscripts. Material published by Assmka does not necessarily represent the views of the Journal's Editors, Staff, Financial Supporters or the University of Cape Coast and its affiliates. These parties disavow any legal responsibility related to all submitted material.

\section{BACK ISSUES}

Back issues of Ascmka that are in stock may be ordered from the Editor at US\$20 per copy.

\section{GRANT SUPPORT}

Assmka is funded through grants from the Office of the Dean, Faculty of Arts; the Publications' Board; and the Office of the Vice-Chancellor, University of Cape Coast, Cape Coast, Ghana.

No part of this Journal may be reproduced, stored in a retrieval system, or transmitted in any manner whatsoever without express permission from the Editors, except in the case of brief quotations embodied in critical Articles and Reviews.

Copyright (C2020 by The Editors and The Faculty of Arts, University of Cape Coast. The cover and page design elements were inspired by the Adinkra symbols of Ghana. 


\section{DEDICATION \\ PROFESSOR ATTA GYAMFI BRITWUM}

Professor Britwum is a man of many parts. He is as much at home with Marxist Economic Theory and Feminist Sociological Thoughts, as he is with French and Francophone Literatures. He is a great teacher and Administrator of international acclaim. The Editors dedicate this special issue of Assmka to his honour. 


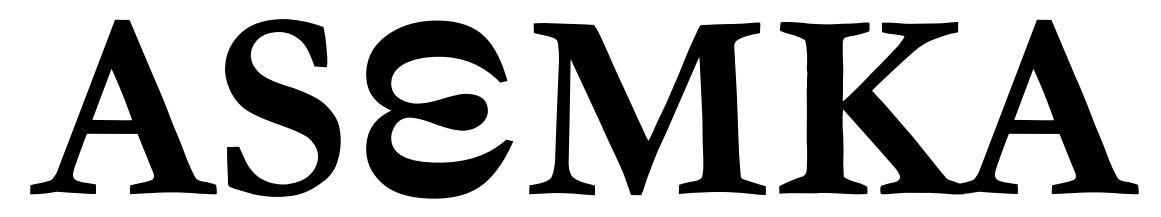

NUMBER 10

SEPTEMBER 2020 


\section{CONTENTS}

$\begin{array}{llll}\text { Editorial Committee } & \sim & \sim & \sim i i \\ \text { Editorial Staff } & \sim & \sim & \sim i i \\ \text { Editorial Advisors } & \sim & \sim & \sim i i \\ \text { Acknowledgements } & \sim & \sim & \sim i i i \\ \text { Subscription } & \sim & \sim & \sim i i i \\ \text { Advertising } & \sim & \sim & \sim i i i \\ \text { Submissions } & \sim & \sim & \sim i i i \\ \text { Back Issues } & \sim & \sim & \sim i v \\ \text { Grant Support } & \sim & \sim & \sim i v \\ \text { Dedication } \sim & \sim & \sim & \sim \\ \text { Foreword } \sim & \sim & \sim & \sim x \\ \text { Assmka: Editorial } & \sim & \sim & x i-x v i i\end{array}$

Articles

First Section - French

Britwum, A. G.

Insuffisances Théoriques Des Damnés De La Terre De

Frantz Fanon

$\sim$

$\sim 2-15$

Kodah, M. K.

Disculpation de Dieu dans le malheur des hommes:

Une lecture critique de Gouverneurs de la rosée de

Jacques Roumain $\sim \sim \sim 16-31$

Addo-Danquah, $O$.

Le récit de pensées: Une analyse comparative de Vol de nuit d'Antoine de Saint-Exupéry et La Condition humaine d'André Malraux

Kodah, M. K. \& Togoh, A. A. X.

Réactions des femmes face au conflit de genre dans C'est le soleil qui m'a brûlée et Tu t'appelleras Tanga de Calixthe Beyala

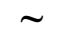

$\sim$

$\sim \quad 45-59$ 
Kudi, M. D.

La Littérature francophone face aux médias de télécommunication : Une nouvelle dynamique de la création romanesque, le cas de L'Énigme de retour et Tout bouge autour de moi de Dany Laferrière $\sim \quad$ 60-72

Gli, $M$.

Les faces du bonheur dans Vol de nuit d'Antoine de Saint-Exupéry $\sim \sim 73-85$

Krakue, S. P.

Christ haïtien : Gouverneurs de la rosée et La Bible $\sim 86-93$

Afari, E. S. K. \& Yegblemenawo, C. A. A.

Apports de la télésérie à l'amélioration de la compétence d'expression orale du FLE à l'école normale $\sim 94-116$

Bationo, J.-Cl.

Didactique de la littérature et littérature didactique:

l'exemple de la littérature africaine francophone en classe de langues étrangères au Burkina Faso

Second Section - English

Krakue, S. P.

Quod erat demonstrandum: A comparative study of narrative technique in Ama Ata Aidoo's Changes and Albert Camus'

Les justes (The Just Ones) 〜 $\sim$ $133-141$

Adjandeh, E. A.

Analysis of Wole Soyinka's Trials of Brother Jero in Relation to Ghanaian Religious Discourse

Sam, C. A.

Decolonizing the Postcolony: Of Men, Spatial Politics and the New Nation in WA Thiongo's Wizard of the Crow.

Kambou, M. K. \& Traore, S. A.

Manipulation and the popular uprising in Burkina Faso in 2014. $\sim \quad \sim 172-189$ 
De-Soura, A. Y.M.

Test-taking Strategies of University of Cape Coast Students of

French as a Foreign Language: a Case Study $\sim 191-216$

Kambou, M. K. \& Soma, L.

Local Culture and EFL Vocabulary Learning $\sim \quad 217-238$

Kabore, A. \& Nazortin, C.

Critical Analysis of the Place and Importance of Literature in the Teaching / Learning of English and in School Leaving Certificate Examination in Burkina Faso from 1985 to 2018

Malgoubri, I., Sawadogo, M. \& Kambou, M. K.

Digital Audio-visuals Aids and Listening in English as a

Foreign Language Classrooms

Osei, R. N. \& Inusah, $H$.

A Critique of the Images of Heaven in the Scriptures of the

Abrahamic Religions: An Existentialist Perspective $\sim$ 270- 282

Negedu, A. K.

Lexical Gaps and Ideological Shift in the Translation of

Chinua Achebe's Things Fall Apart as "Le Monde

S'effondre" in French $\sim \sim 283-297$

Talburt, $T$.

Political Transformation and Development in Africa:

Lessons from Achebe's Things Fall Apart

$\sim 298-313$ 


\section{FORWORD}

All the papers in this Volume were presented at a three-day Conference in honour of Professor Atta Gyamfi Britwum who turns eighty years in March 2021. Most of those years he spent at University of Cape Coast, having cut his teeth as a young lecturer in French language and Literature-in-French in 1974. After many years of an illustrious career in teaching, publication and extension, he bowed out at age seventy, but he didn't get the well-deserved rest he was entitled to; he continues to support his Department and the University as a whole. Today, Professor Britwum's name is associated with high standards of professionalism which earned him the nickname 'L'oracle'. Indeed, it is impossible to find another name universally acknowledged as embodying the excellence in French education offered at the Department of French, University of Cape Coast.

The decision to honour Professor Britwum couldn't have been taken at a more appropriate time. It was planned to coincide with the fiftieth anniversary of the publication of the Beautyful ones are not yet Born, Ayi Kwei Armah's first novel. Britwum never grew tired of reading, teaching and examining it. Such was his respect for Armah's craft. So, the three-day Conference was as much a celebration of Armah's contribution to the shaping of the African novel as it was a tribute to Professor Britwum's work as a teacher of literature of immense influence.

One only has to look at the titles of the papers published in this Volume to get an idea of how deep his influence runs at UCC and beyond. Most of the contributors once upon a time sat at the master's feet, but are now scholars in their own right keeping the flame of French scholarship burning bright (George Cooper: "Polished in a high degree, as each froggie ought to be/Now they sit on other logs, teaching other little frogs.") A good number of the papers are on Literature, nonetheless not limited to Armah's works. No Surprise there. Nevertheless, there are Language papers there too. No surprise here either, for the man to whose honour the Volume is dedicated is equally at home in both Language and Literature

\section{Lawrence $K$. Owusu-Ansah,}

Department of English, UCC.

A Disciple 


\section{$A S E M K A:$ EDITORIAL}

This Special Edition of $A S E M K A$, a bilingual literary journal of the University of Cape Coast, is published in honour of Prof. Atta Gyamfi Britwum, a revered Associate Professor of Francophone African Literature and Civilisation in the Department of French, U.C.C. It contains twenty (20) papers centred on diverse areas of teaching and research in the Humanities and on the theme of the Conference - Literature and the Humanities in the 21 Century: Interdisciplinary Perspectives - held in his honour by the Department of French, University of Cape Coast, Ghana, $13^{\text {th }}-15^{\text {th }}$ Mars, 2019. To reflect Prof. Britwum's area of research interest, the essays are arranged in two sections according to his dominant medium of instruction (French language) and speciality (Literature and Civilisation), followed by those in English language. The first section consists of a set of nine (9) essays in French spanning between themes in Literature and Language. The second section is made up of a set of eleven (11) essays in English which examine issues in literary studies, Language and Didactics, ICT and French Education, Philosophy, and Translation, among others. This special arrangement is however representative of the bilingual nature of the Journal.

\section{First Section}

Britwum, A. G.'s paper titled, “Insuffisances Théoriques Des Damnés De La Terre De Frantz Fanon", presents the Fanonian perspective as a complement to the African nationalism that informed anticolonial struggles. The study posits that African nationalism, populist in nature, for failing to target the capitalist economic base, which defines colonialism, ended up strengthening it. It concludes that Fanon's anticolonialist perspective, despite its overt radicalism, is not designed to allow a "bottom-to-top change" in colonial / capitalist society.

Kodah, M. K.'s paper titled, "Disculpation de Dieu dans le malheur des hommes: Une lecture critique de Gouverneurs de la rosée de Jacques Roumain", puts into question the responsibility of God in the suffering of men on earth and the capacity of man to make and unmake himself. The study aims at absolving God of the guilt of the miseries of men, and also questioning the atheistic or anti-religion denunciation of this narrative 
text since its publication. The study is accomplished through a critical reading and a thoughtful analysis of Jacques Roumain's Gouverneurs de la rosée within the analytical structure of literary studies and sociocriticism.

Addo-Danquah, O.'s paper, "Le récit de pensées : Une analyse comparative de Vol de nuit d'Antoine de Saint-Exupéry et La Condition humaine d'André Malraux", drawing inspirations from theorists such as Léon Edel (1961) and later Dorrit Cohn (1981), examines what Antoine de Saint-Exupéry's Vol de nuit by and André Malraux's La Condition bumaine respectively can offer on the side of representations of the interior life. The study is posited within the framework of narratological theories.

Kodah, M. K. \& Togoh Tchimavor, A. A. in "Réactions des femmes face au conflit de genre dans C'est le soleil qui m'a brûlée et Tu t'appelleras Tanga de Calixthe Beyala" examine the reactions of women to gender conflict in Calixthe Beyala's C'est le soleil qui m'a brulée and Tu t'appelleras Tanga. The study critically reflects on the various ways women in Beyala's C'est le soleil qui m'a brulée and Tu t'appelleras Tanga react to oppression and exploitation resulting from patriarchal domination. It therefore examines the sources and nature of this conflict, and how women react to it in the two novels. The study points to the fact that, much as conflict emanating from patriarchal oppression and male's domination in human societies is inimical to the rights of women, the methods used by the latter to free themselves from this state of being remain questionable, in that, these methods defy rational thinking and are also a kind of reversal oppression and domination which are equally unacceptable.

Kudi, M. D.’s paper, “La Littérature francophone face aux médias de télécommunication: Une nouvelle dynamique de la création romanesque, le cas de L'Énigme de retour et Tout bouge autour de moi de Dany Laferrière", seeks to examine how pertinent painting, photography, television, telephone etc. are to the production of the contemporary Francophone novel. The study focuses on L'Énigme de retour (2009) and Tout bouge autour de moi (2011). The analysis is based on the perspective of literary intermediality propounded by Jürgen E. Muller which is characterised by an interaction between telecommunication media and literary text. The study establishes through these selected novels that these media forms are not simply another form of expression in the novel but rather a lens through which the story is narrated. 
Gli, M.'s paper titled, "Les faces du bonheur dans Vol de nuit d'Antoine de Saint-Exupéry", analyses the faces of happiness in Antoine de Saint-Exupéry's Vol de Nuit. The study is conducted through thematic approach. This approach is complemented by Maslow's theory of human needs. The collection of data or the collection of information is purely documentary. The study therefore seeks to establish a link between individual happiness and collective happiness in Saint-Exupéry's selected narrative text.

Krakue, S. P.'s paper, “Christ haïtien : Gouverneurs de la rosée et La Bible", attempts to question Jacques Roumain's Gouverneurs de la rosée in order to elucidate the novelist's use of the biblical text in his creative activity. The study demonstrates that Jacques Roumain's narrative text turns out to borrow biblical ideas not only to develop his plot but also to design his main character.

Afari, E. S. K. \& Yegblemenawo, C. A. A. in “Apports de la télésérie à l'amélioration de la compétence d'expression orale du FLE à l'école normale." examine the impact examine the impact of the use of serial movies as teaching aid on oral expression of French language learners in Colleges of Education in Ghana with the aid of smartphones. The study discovers that the use of serial movies in teaching French boosts learners' performance in oral communication. It therefore recommends that serial movies could be used in teaching French language lessons in order to enhance the oral communication competencies among learners.

Bationo, J.-Cl.'s paper titled, "Didactique de la littérature et littérature didactique : l'exemple de la littérature africaine francophone en classe de langues étrangères au Burkina Faso", shows not only how to teach literature in language class but also how to use didactic literature to develop social skills among learners to reduce vandalism, school violence, negative stereotypes, misunderstandings of intercultural nature while cultivating social peace and living together in a context of internationalization, globalization and digital revolution. The paper focuses on francophone African Literature and posits that methodological approach used for the didactic transpositions of literary content is based on the new orientation and the redefinition of the objectives of language teaching and on the didactic models of the aesthetic reception of didactics of literature which requires putting the learner in intensive interaction with the text and motivating him/her to express himself/herself on his/her reading experiences. 


\section{SECOND SECTION - ENGLISH}

Krakue, S. P.'s paper titled, “Quod erat demonstrandum: A comparative study of narrative technique in Ama Ata Aidoo's Changes and Albert Camus' Les justes (The Just Ones)", demonstrates through textual analysis, how in Ama Ata Aidoo's Changes and Albert Camus Les justes, the authors resort to a specific form of irony to bring the discussion of issues raised to a conclusion. The technique consists in demonstrating clearly a huge discrepancy between a "fine" idea and its practical usefulness. Both authors successfully use narrative technique. Albert Camus demonstrates the hollowness of the idea of fighting for justice through revolutionary violence and Ama Ata Aidoo similarly demonstrates the fatuousness of the theory of women-emancipation-through-polygamy.

Adjandeh, E. A. analyses selected reports in Ghanaian media in relation to the clergy and identifies how Wole Soyinka's theme is reflected in these media in her paper titled, "Analysis of Wole Soyinka's Trials of Brother Jero in Relation to Ghanaian Religious Discourse". The study seeks to examine the extent to which themes in Soyinka's Trials of brother Jero play out in religious discourses in Ghana. The global nature of the issues problematized by Wole Soyinka also comes out through this study as the work set in Nigeria is analyzed in relation to the selected articles set in Ghana. The paper relies on a content analysis of Trials of Brother Jero and similar themes presented in the selected articles, and makes a few recommendations on how these religious issues could be partially, if not wholly, resolved in Ghana.

Sam, C. A.'s paper, "Decolonizing the Postcolony: Of Men, Spatial Politics and the New Nation in WA Thiongo's Wizard of the Crow", examines how Ngugi Wa Thiongo's Wizard of the Crow blatantly explores Africa's complicity in a seemingly cyclic colonization in the $21^{\text {st }}$ century and its attendant consequences for the total liberation of Postcolonial Africa. The study examines the correlation between masculine representations, spatial reorganization and futurity as alternative ways in thinking about Africa's future through Bakhtin's theory of the carnival and other such concepts as polyphony and the grotesque. The result of the analysis is that the correlation between forms of communities and forms of masculinities is an indication of a vision of hope for Postcolonial Africa. 
Kambou, M. K. \& Traore, S. A. in "Manipulation and the popular uprising in Burkina Faso in 2014", analyse the different discourses in the build-up to the popular uprising in Burkina Faso on the $30^{\text {th }}$ and $31^{\text {st }}$ October 2014. It attempts to clarify how political and civil society leaders use language and other non-linguistic elements to influence the ordinary citizens' minds and, indirectly, their actions. The analysis is premised on Van Dijk's (2006) Sociocognitive approach. The paper analyses the cognitive, the social and the discursive dimensions of manipulation in six political speeches (two speeches from Civil Society, two from the ruling party and two from the political opposition). The results suggest that the three groups manipulated their audiences, and finally, the ruling party lost following the resignation of the then Head of State, making way for a Transition government to take over the reins of governance.

De-Souza, A. Y. M.'s paper “'Test-taking Strategies of University of Cape Coast Students of French as a Foreign Language: a Case Study.” seeks to provide a description of test-taking strategies that may inform teaching and learning of French for better output in tests against the background that Ghanaian students of French as a foreign language deploy strategies that are not adequate enough in answering test items in French. The study examines data gathered right after a French test by level 200 students, using recollective verbalization protocols.

Kambou, M. K. \& Soma, L. examine in their paper titled, "Local Culture and EFL Vocabulary Learning”, the influence of learners' culture on foreign language vocabulary. The paper seeks to demonstrate that there is a link between culture and lexico-semantic errors committed by learners of English as a foreign language among Dioula speaking students in Burkina Faso. A language test composed of two written activities was used as the data collection instrument. The results revealed that the Dioula speakers' English is influenced by their culture. These results have some pedagogical implications. They, therefore, suggest that we adapt the teaching of EFL vocabulary to learners' culture.

Kabore, A. \& Nazortin, C. in "Critical Analysis of the Place and Importance of Literature in the Teaching / Learning of English and in School Leaving Certificate Examination in Burkina Faso from 1985 to 2018", analyse the types of texts given at the "Baccalaureate A" written examination in the last thirty years. In this study, quantitative and qualitative 
data are collected. Baccalaureate written English papers are the main focus of our collection. Teachers and supervisors are interviewed. The study is grounded on "Reader-Response Theory" which stresses the interactions between the reader and the text. The results of the study show that the great majority of texts proposed for "Baccalaureate A" examination, in the last thirty years, are non-literary texts.

Malgoubri, I., Sawadogo, M. \& Kambou, M. K.’s paper titled, “Digital Audio-visuals Aids and Listening in English as a Foreign Language Classrooms", is an experimental study which investigates the potential of digital audio-visuals to improve the listening skills of EFL learners in secondary schools in Burkina Faso. On the assumption that learners born around the year 2000 are digital natives, the researchers try integrating smartphone-friendly audio-visuals in their EFL classrooms in a four-week experiment involving one Experimental Group and one Control Group. The experiment aims at gauging the effectiveness of those aids operated via students' smartphones in improving learners' listening and speaking skills. Independent T-tests were used to compare the groups and Sample Paired TTests to make comparisons within groups. The study suggests that, if appropriately used, smartphones are excellent devices for language teachers and learners in this digitizing world.

Osei, R. N. \& Inusah, H.'s paper, “A Critique of the Images of Heaven in the Scriptures of the Abrahamic Religions: An Existentialist Perspective." Critically examines the scriptural images of heaven as captured in the Abrahamic religions - Judaism, Christianity and Islam - from the existentialist perspective. The paper argues that the idea of life beyond this earthly existence for all human beings in a specially prepared location by God for eternal happiness for those who obey His commands on earth called Heaven, as propounded by the Abrahamic Religions, throws up a lot of problems, especially from the existentialist perspective. The study concludes that the scriptures' constructs of heaven appear self-contradictory and fail to strike a chord with the contemporary image of the ideal society when perused from the existentialist perspective and should, therefore, be discarded.

Negedu, A. K.'s paper "Lexical Gaps and Ideological Shift in the Translation of Chinua Achebe's Things Fall Apart as "Le Monde S'effondre" in French." examines the ideological divergence between the title of the original text and the title of the translation, following an observation 
that in translating Chinua Achebe's Things Fall Apart, Michel Ligny translates directly Igbo terminologies, realities and beliefs into the French language. The paper concludes that the ideology that the translated title projects to French-readers is totally different from the ideology that the original title projects to English-readers.

Talburt, T., in "Political Transformation and Development in Africa: Lessons from Achebe's Things Fall Apart", formulates critical perspectives on the significance of Achebe's novel for the socio-political and economic transformation and development of the African continent. The paper challenges one of the central assumptions in this story that Africa falls apart as soon as it comes in contact with Europe. It questions aspects of political conservatism exhibited in Okonkwo who is suspicious of fundamental changes to his society. The discussion is based on the jollof rice principle of political hybridisation of development which proposes the amalgamation of Westernised and non-Western ideas and systems, in order to achieve economic development, rather than totally rejecting Westernisation in its entirety. The study uses examples of Western-style democracy and State intervention in Africa to demonstrate the significance of embracing some aspects of Westernisation through political hybridisation. 





\title{
Local Culture and EFL Vocabulary Learning.
}

\author{
Moses Kwadwo Kambou \& Lassina Soma \\ Université Joseph Ki-Zerbo, Burkina Faso
}

\begin{abstract}
This paper attempts to investigate the influence of learners' culture on foreign language vocabulary. It seeks to demonstrate that there is a link between culture and lexico-semantic errors committed by learners of English as a foreign language among Dioula speaking students in Burkina Faso. A sample population of 157 of Dioula speaking students from two secondary schools was purposively selected, using the non-probability sampling technique. A language test composed of two written activities was used as the data collection instrument. These activities were translation activities from Dioula into English. A tape-recorder was used during a story-telling session as an oral activity to collect supplementary data. The data were analysed first qualitatively and then quantitatively. The SPSS software version 17.0 (2008) was used to process the quantitative data. The qualitative method was employed to determine the link between Dioula culture and lexico-semantic errors committed by learners of English as a foreign language. Similarly, the quantitative method was used to establish the seriousness of the influence of the Dioula culture on the learning of vocabulary as a foreign language. The results revealed that the Dioula speakers' English is influenced by their culture. These results have some pedagogical implications. They, therefore, suggest that we adapt the teaching of EFL vocabulary to learners" culture.
\end{abstract}

Keywords: Culture; foreign language; lexico-semantic errors.

\section{Résumé:}

Cet article tente d'étudier l'influence de la culture de l'élève sur le vocabulaire de l'anglais comme une langue étrangère. Il cherche à prouver qu'il y a un lien entre la culture de l'élève et les erreurs lexico-sémantiques commises pendant l'apprentissage de l'anglais comme une langue étrangère. 
L'étude a consisté à collecter les données auprès des élèves dioulaphones qui apprennent l'anglais comme une langue étrangère au Burkina Faso. Un échantillon de 157 élèves des classes de 2nde A et de 1ère A sélectionnés dans deux écoles secondaires différentes et dans une localité où l'on parle dioula. L'échantillonnage a été fait de manière ciblée en adoptant la technique de non-probabilité. Comme instrument de collecte de données, nous avons utilisé un test de niveau composé de deux activités écrites. Ces activités étaient basées sur la traduction du Dioula à l'anglais. Nous avons aussi utilisé un enregistreur-audio pour collecter des données supplémentaires lors une activité orale où on avait conté une histoire aux élèves en dioula qu'ils devraient à leur tour raconter en anglais. Les données ont d'abord été analysées qualitativement et ensuite quantitativement. Le logiciel SPSS version 17.0 (2008) a servi au traitement des données quantitatives et présenter les résultats sous forme de tableaux. Nous avons employé la méthode qualitative pour déterminer le lien entre la culture dioula et les erreurs lexico-sémantiques commises en anglais comme une langue étrangère. Pour ce qui est de la méthode quantitative, elle nous a permis de d'établir le degré de l'influence de la culture dioula sur la compréhension du vocabulaire de l'anglais comme une langue étrangère. Les résultats ont montré que l'anglais des apprenants Dioula est influencé par leur culture. Ces résultats ont des implications pédagogiques. De ce fait, ils suggèrent qu'on adapte l'enseignement du vocabulaire de l'anglais comme une langue étrangère à la culture de l'apprenant.

Mots-clés: Culture ; erreurs lexico-sémantiques ; langue étrangère.

\section{Introduction}

Our observation of Dioula speaking students learning English as a foreign language (EFL) reveals that word meanings according to their first language culture interfere in EFL as acknowledged by Yang, Ma and Cao (2013). Cultural interference has positive and negative transfers. The negative transfer pushes learners to commit lexico-semantic errors thus creating frustrating situations for learners of EFL. The most frequent lexico-semantic errors emanate from wrong collocations, wrong selection of words, or wrong connection of meaning to words or phrases.

In a case study, we investigated the influence of Dioula culture on the vocabulary of English as a foreign language by looking at learner lexicosemantic errors. The study consisted in collecting data from students through their writing and speaking. These data were analysed by paying particular attention to lexico-semantic errors in relationship to word meanings in the 
Dioula culture and their equivalent ones in the English culture. Collocation approach to meaning, componential theory of meaning and sense relation framed the work as we wanted to look at learners' lexico-semantic errors in foreign language closely related to Dioula culture.

The results of the study reveal that Dioula culture pushes learners to commit lexico-semantic errors in English as a foreign language and that its influence on the learning of English as a foreign language vocabulary is a serious matter. The results have some pedagogical implications; they, therefore, suggest that we review the methods and approaches of teaching foreign language vocabulary.

The study which is an empirical study has the following research objectives:

1. To find out the link between Dioula culture and learners' lexico-semantic errors.

2. To determine the proportional rate of failure to learn and use English words.

This study endeavours to answer these research questions:

1. Why do lexico-semantic errors occur in learners' English as a foreign language?

2. What is the rate of failure to learn and use words in English as a foreign language?

\section{Literature review}

\section{1. Studies on culture and second or foreign language}

In the literature review, we considered the works on culture and second/foreign language learning. Soma (2014) conducted a study on cultural influence on students' foreign language vocabulary knowledge with ' 1 ìre $A$ ' (SHS2) students as the study population in Burkina Faso. The data were collected using a language test and analysed quantitatively. The results showed that students can succeed in learning foreign language vocabulary if they learn word meanings by referring to their culture. However, these results were limited as the study was not based on a longitudinal experiment with practical teaching of English vocabulary in the culture. A similar study was undertaken by Hamiloglu (2013) who explored the perceptions and views of fourth-year (senior) university pre-service teachers (PTs) on the representations of the target language, local and international culture in EFL course books. The study was conducted at the department of English Language Teaching in a state university in Istanbul, Turkey. A content analysis and a structured interview 
served as the instruments of collecting the data. The results indicated that the majority of the participants desire and prefer to see cultural presentations in EFL course-books and similarly they prefer international cultural elements instead of purely target or local ones in the books. These findings are also limited as the researchers did not extend the study on cultural presentations to the analysis of word meanings in relationship with culture.

\section{2. Studies on lexico-semantic errors}

We also review the related literature by looking at studies on lexicosemantic errors. Jeptarus and Ngene (2016) conducted a study adopting a descriptive survey design. The research population was 7,794 pupils and 180 teachers of English. Three instruments were used for the data collection: essay writing, tape-recorded storytelling and questionnaire. The data were analysed using descriptive and inferential statistics. Descriptive statistics was deployed to describe the standard seven pupils and their teachers of English. The results, according to Jeptarus and Ngene (2016) reveal that there is a relationship between L1 interference and lexico-semantic errors made by learners of English as a second language. This implies that first language interferences have relationship with the lexico-semantic errors in English as a second language in that errors made in word-meaning are also caused by mother-tongue interference. In conclusion, the analysis of the results relevant to the hypotheses testing confirmed that lexico-semantic errors make the learners perform poorly in English. Jeptarus and Ngene (2016) adopted a perfect research design. Although, they dealt with lexico-semantic errors the results are limited. Their study did not take culture into account in the analysis of the lexico-semantic errors. The consideration of culture, as we do in our study, could fill in the gap in Jeptarus and Ngene (2016). Yang, Ma and Cao (2013) analyzed negative Chinese transfer in lexis. Their aim is to help students gain insights into similarities and differences between English and Chinese, to predict and describe the patterns that will cause difficulty in learning and those that will not cause difficulty, and to provide a more effective pedagogy for teaching writing in English. Their results showed errors emanating from the following linguistic elements:

- Word choice as in the sentence * When they got to the summit of the mountain... where summit was used instead of top.

- Derivation as in the sentence * I think I should value my young, instead of youth.

- Collocation as in the sentence, ${ }^{*}$ In the college I learnt knowledge instead of acquired knowledge. Here there is inappropriate co-occurrence between 
learnt and knowledge which is caused by word-to-word translation from Chinese into English.

Tizazu (2014) also carried out a similar study. He wanted to point out the dominant linguistic errors that occur in the written productions of learners of English. After collecting a sample of paragraphs for two years from University students ranging from freshmen to graduating level, the data were analysed. Both quantitative and qualitative analyses were used as methods of analysis. Not only have the results shown that almost all components of the English language (such as orthography, morphology, syntax, mechanics, and semantics) in learners' compositions have been affected by the errors but they also identify two causes which triggered learners' errors: intralingual and interlingual. However, most of the errors are purported to stem from intralingual causes which resulted from the lack of mastery of the basic linguistic elements of the English language. An important aspect of Tizazu's (2014) study is the semantic analysis of learner errors where he pointed errors at three (03) different levels:

- Sense relation in words which sometimes gives rise to semantic confusion, and which eventually leads to lexical errors as in the sentence '*There is nothing that makes me sensational and passionate more than memorizing my child hood life' (sic). There is obviously a semantic confusion between to memorize and to remember in the sentence above.

- Wrong word choice which occurs when a learner chooses a totally wrong word. Such selection of an incorrect word for a particular situation causes misunderstanding as it is the case in the example: '*Sexual intercourse contain many deseases HIV Adis or another dises' (sic). In this sentence, the learner chose contain instead of leads.

- Wrong collocation which derives from the association of two words which is considered inappropriate in native usage. According to Tizazu (2014), wrong collocations tend to affect fluency and sometimes disrupt communication. The following sentence is an illustration of wrong collocation usage: '*The quality of food to bring for the students is also bad'. In fact, instead of serve the learner collocated wrongly food and bring. The findings of these studies cannot serve as answer of our research questions. The studies did not consider learners' culture which may be at the origin of the lexico-semantic errors. To facilitate the understanding of our paper, we invite you to read our research methodology. 


\section{Research method}

We conducted the study in two secondary schools with eligible students of four (04) classes: one $2^{\text {nde }} \mathrm{A}$ (SHS1) and one 1ère A (SHS2) in each school. These two schools are located a Dioula speaking area. In this locality, there are leaners of English skilled at speaking Dioula. Besides, the modern life of the city has less influence on these learners' first language and its culture as many of them come from the country-side.

The consolidation of the background knowledge of the study population raised the issue of the ethnicity of Dioula as they are known to be a caste. We solved this problem by asking the students questions related to their socio-linguistic background. The analysis of the answers provided by the students enabled us to make a list of 157 eligible students who were composed of native speakers and non-native speakers of Dioula. The native speakers are the Dioula who speak Dioula language at home. The non-native speakers have been speaking Dioula for more than ten (10) years.

The 157 eligible students were chosen purposively out of 226 students using a non-probability technique. The socio-linguistic information (number of years spent in speaking Dioula and the frequency of speaking it) indicated that only this number could represent the study population. These 157 students speak Dioula but they cannot write or read it well. There were 08 native Dioula speakers and 148 non-native speakers of Dioula. One of them did not specify whether he/she is a native or non-native Dioula speaker.

The research instrument was a language test based on two writing activities. A tape-recorder was also used to collect supplementary data during a story-telling session based on an oral activity. All the activities were translation activities from Dioula into English. We made copies of these activities in the Dioula version for all the 157 students. We used the tape-recorder with 14 volunteer students for the voice-recording. We also made copies of the text in the Dioula version for the 14 students. We could not take many students as this activity was time-consuming.

To collect the data, we met the students and had them perform the tasks under our supervision. They first dealt with the different activities of the language test. We read each activity at least three times for the students as they were written in Dioula. Then, they retold the story in English individually while we recorded their voices. There was no time limit for the students during all these activities.

After the identification of lexico-semantic errors in the written and recorded data, we analysed the data qualitatively and quantitatively. The qualitative method served to account for the link between Dioula culture and foreign language lexico-semantic errors and the quantitative method enabled 
us to assess the degree of the influence of Dioula culture on the learning of EFL vocabulary.

From the qualitative stand-point, if the following three assumptions are confirmed, then local culture influences the learning of foreign language vocabulary in our study area: (a) students use wrong items in foreign language because the equivalent linguistic items in Dioula language do not exist, (b) lexico-semantic errors occur in students' productions because they wrongly associate foreign language words as they co-occur in Dioula language, and (c) students connect wrong meanings to foreign language words because the meanings of those words are conceived so in Dioula language,

From a quantitative perspective, if the following three assumptions are also confirmed, then the influence of Dioula culture on EFL vocabulary learning is serious: (a) the cumulative percentage of students who use a wrong linguistic item for a specific word is superior to that of those who used the right item, (b) the cumulative percentage of students who wrongly collocate a specific word is higher than that of those who rightly collocate it, and (c) the cumulative percentage of students who connect a wrong meaning to a specific word is higher than that of those who connect a right meaning to it.

We coded the data, labelled the variables and assigned numerical values to the units of measurement. The variables of the data of the first part of the language test were coded as follows: RC for 'right collocation', WC for 'wrong collocation', NRCNWC for 'neither right collocation nor wrong collocation', NA for 'no answer'. The numerical value 1 was used when there was right semantic collocation, the value 2 for wrong semantic collocation, the value 3 for neither right nor wrong semantic collocation, and the value 4 when there is no answer. The variables of the second part were coded as follows: RMC for 'right meaning connected', WMC for 'wrong meaning connected', NCM for 'no corresponding meaning', and NA for 'no answer'. The numerical value 1 was used when respondents connected the right meaning to the lexical item, the value 2 when they connected wrong meaning to it, value 3 when the answer related to the linguistic item was neither right nor wrong, and the value 4 when there was no answer for the linguistic item.

For the recorded data, the variables were coded RLit which stands for 'right linguistic item', WLit for 'wrong linguistic item', NCLit for 'no corresponding linguistic item', and NA for 'no answer'. The numerical value 1 was used when the linguistic item (Lit) was correct, the value 2 when the item was incorrect, the value 3 when it was neither correct nor incorrect, and the value 4 when there was no answer. We used the Statistical Package for Social Services version 17.0 (2008) to process the data quantitatively. 


\section{Results and discussions}

\section{1. Results from a qualitative analysis \\ III. 1. 1. Errors from wrong linguistic item use}

\section{a) Wrong linguistic items used for chicken, mutton, pork and beef}

When we refer to the context, lexico-semantic errors occurred in sentences 1 (a) and 1 (b) (see Appendix below). The expected words are chicken, mutton, pork and beef. The students have used wrong linguistic items for these words by making lexical addition errors. The terms 'sogo' in Dioula and meat in English, as objects of the real world, are pregnant words in the sense that the use of 'sogo' and meat turns out to be vague for the interlocutor. However, with sogo (meat), sense-reference-word relation is well established in Dioula and English. Therefore, the referents with 'sogo' in Dioula and meat in English are the same. Now, with words like 'sisesogo' (chicken), 'sagasogo' (mutton), 'lesogo' (pork) and 'misisogo' (beef), it requires the process of compounding between 'sogo' and the animal concerned for the specific terms in Dioula in order to take away the vagueness. In English, chicken, mutton, pork or beef, which entail both meat and the animal concerned, do not require the process of compounding. Such a difference led the learners to resort wrongly to *hen meat, ${ }^{*}$ sheep meat, ${ }^{*}$ pig meat and ${ }^{*}$ cow meat instead chicken, mutton, pork and beef respectively. The use of the wrong linguistic items is the effect of the absence of these words in Dioula. It is an issue of culture since it is wellestablished in Wardhaugh (1998) that whatever members of a given society value in their culture, they have a word for it.

\section{b) Wrong linguistic item used for sky}

According to the context, there is obviously lexico-semantic error in sentence 2 (see Appendix below). The use of rain in this sentence shows that the students have wrongly learnt the meanings of sky and rain. For the English sky and rain are two different objects of the real world, therefore two different referents, two different references and two different linguistic items/words. The contrast is that, in Dioula, 'sangolo' is composed of the morphemes 'san' (sky) and 'golo' (skin). The word 'sanji' in Dioula also consists of two morphemes 'san' (sky) and 'jii' (water). Now, though 'sangolo' (sky) and 'sanji' (rain) are two different referents, there is no clear-cut distinction between their references in the minds of the Dioula speaker. The morpheme 'san' present in both 'sangolo' (sky) and 'sanji' (rain) enable the Dioula speaker to indifferently use 'san' to refer either to sky or rain. Consequently, this led the learners to believe that the English also use rain and sky indifferently. That is why the 
leaners wrongly used rain instead of sky in English. This is a case of split in the hierarchy of difficulty in Contrastive Analysis proposed by Stockwell, Bowen, and Martin (1965).

\section{c) Wrong linguistic items used for moon}

According to the context, the word month in sentences 3 (a) and (b) (see Appendix below) is a lexical substitution. The students wrongly conceived the meanings of month and moon in English. For the English month and moon are two different objects of the real world, therefore two different referents, two different references and two different words. In Dioula, 'kalo' as moon and 'kalo' as month correlate in meaning even though their referents are different as in English. The contrast is that there is no clear-cut distinction between the reference of 'kalo' as moon and that of 'kalo' as month in the minds of the Dioula. This results in an indifferent use of 'kalo' to refer to either moon or month in Dioula. Consequently, the informants thought that moon and sky also correlate in English. That is why they have wrongly used month instead of moon in English. This is a situation of split in the hierarchy of difficulty and this is confirmed by independent evidence in Ghanaian Pidgin English where end of the month is referred to as moon die in Contrastive Analysis proposed by Stockwell, Bowen, and Martin (1965).

In view of the wrong items used for words in each of the sentences, it is undeniable that learners commit lexico-semantic errors in foreign language. These errors derive from the difference in the sense-reference-word relation between the first language and foreign language. These findings are similar to those of Tizazu (2014) whose study revealed that sense relation in words sometimes gives rise to semantic confusion. The findings of our study show that, on the one hand, sense-reference-word relation creates confusion in the understanding of word meanings. What learners refer to when they use the language element as an object of the real world according to the first language is different from what they should refer to in the foreign language. It is exactly the case with sky and rain in Dioula. On the other hand, these errors occur because the equivalent words are non-existent in the first language. That is the case with chicken (as meat), mutton, pork and beef which are non-existent in Dioula. These kinds of difficulties are the effects of learners ${ }^{\text {ee }}$ local language culture on foreign language. It is known in Wardhaugh (1998) that the organisation of our language is determined by the way our culture allows us to perceive the world. In the same way first language culture influences the learning and organisation of foreign language vocabulary. 


\section{1. 2. Errors from semantic collocation}

\section{a) Wrong semantic collocation between drink and cigarette}

When we refer to the context, students obviously committed lexicosemantic errors in the sentences above. Wrong semantic collocation between drink and cigarette occurred in the sentence 4 (see Appendix below). The Dioula word ' $m i$ ' has both the meanings of drink and smoke. In Dioula drink water and *drink cigarette are correct language usages. There is nothing wrong in the meaning when collocation happens between drink and cigarette in Dioula. This led the students to believe that they can also associate drink and cigarette in English. That is why, instead of smoke a cigarette they wrongly said drink cigarette. These errors occurred because the meaning of the word ' $m i$ ' in Dioula is extended whereas that of drink in English is restricted. As the meaning of the word in first language is not taken into account during its teaching, learners fail to understand that restriction in the word meaning in foreign language. This is an interlingual error between Dioula and English. It is not due to French which has both boire (drink) and fumer (smoke) for the Dioula word 'mi'. This once again is a case of split in the hierarchy of difficulty in Contrastive Analysis proposed by Stockwell, Bowen, and Martin (1965).

\section{b) Wrong semantic collocation between run and bicycle}

According to the context, there is a lexico-semantic error in the translation provided for sentence 5 (see Appendix below). Wrong semantic collocation occurred between run and bicycle. These errors derive from the meaning of the Dioula word 'bori' which has the meanings of run and ride, that is movement. As the meaning of the word is extended it is possible to say run a bicycle in Dioula. The learners established a word-to-word correspondence between first language and foreign language. For them, the meaning of the word is extended in English too. That is why the students translated the sentence by wrongly resorting to run a bicycle instead of ride a bicycle.

\section{c) Wrong semantic collocation between stop and near the house}

When we consider the context, the wrong associations of stop and bouse in the sentences are lexico-semantic errors. The context requires semantic collocation between stand and near the house in English. With regard to the translations provided for sentence 6 (see Appendix below), there is wrong semantic collocation between stop and house. The Dioula word ' $b$ ' means stop (put an end to an on-going action) and stand. As a result, the Dioula can use 
stop to express the idea of putting an end to an on-going action. They can also associate stand and near the house. The extension in the meaning of the word in Dioula led the learners to believe that the meaning of stop in English is also extended. This again is a case of split in the hierarchy of difficulty in Contrastive Analysis proposed by Stockwell, Bowen, and Martin (1965).

\section{d) Wrong semantic collocation between hear/understand/listen and perfume}

Obviously, lexico-semantic errors occurred in sentences 7 (a), 7 (b) and 7 (c) (see Appendix below). The context requires semantic collocation between smell and perfume/fragrance but not between hear/understand/listen and perfume/fragrance. The meaning of the Dioula word ' $m \varepsilon$ ' is also extended as it contains the meanings of the words hear, understand, and listen. The extended meaning of ' $m \varepsilon$ ' increases the number of words that can co-occur with it in Dioula. Learners ignore that the meanings of the English words hear, understand, and listen are restricted. They do not also know that these words cannot co-occur with the same number of words in English. As a result, they wrongly combine hear with perfume, understand with perfume, and listen with perfume. This is once again a case of split in the hierarchy of difficulty in Contrastive Analysis proposed by Stockwell, Bowen, and Martin (1965).

\section{e) Wrong semantic collocation between listen/understand and noise}

It is already mentioned in the section above that the meaning of the Dioula word ' $m \varepsilon$ ' is also extended and that it contains the meanings of the words hear, understand, and listen. The context requires semantic collocation between hear and noise but not between listen/understand and noise in English. Considering students "e translations given for 8 (a) and 8 (b) (see Appendix below), it is undeniable that they committed lexico-semantic errors. The extended meaning of the word in Dioula led them to believe that the meanings of listen and understand are also extended and they could be combined with the same words as in Doula. This again is another case of split in the hierarchy of difficulty in Contrastive Analysis proposed by Stockwell, Bowen, and Martin (1965).

In view of the results, it clearly appears that wrong semantic collocation occurs in foreign language. This shows that learners commit lexicosemantic errors when using some English (foreign language) lexical items. The results are evidence that the local culture influences the organisation of English as a foreign language. This influence may be the effect of the non- 
consideration of local culture during the teaching of foreign language vocabulary.

\section{1. 3. Errors from connecting wrong meaning to words}

\section{a) Wrong meaning connected to wife}

According to the context, the expected word is sister-in-law for sentence 9 (see Appendix below). The students committed lexico-semantic errors. They connected a wrong meaning to the word wife. In the Dioula culture, Salimata is Sidikiees brother Samba "es wife. She is Sidikiies wife, too. This cultural meaning of wife in Dioula made the informants commit lexico-semantic errors by connecting a wrong meaning to wife. That is why they failed to get the expected word in English as sister-in-law.

\section{b) Wrong meaning connected to daughter}

In sentence 10 (see Appendix below) the students committed lexicosemantic errors. According to the context, the expected word is niece. They connected a wrong meaning to the word daughter. According to Dioula culture, Amina is Sidikiees brother Samba "es daughter. She is Sidikiees daughter, too. The informants considered the meaning of the word in the Dioula culture. As a result, they carried that meaning of daughter into English. That is why they failed to get the right meaning of the word as niece in English.

\section{c) Wrong meaning connected to brother}

For sentence 11 (see Appendix below), the expected word is cousin in the English version. In the translations provided, the students committed a lexico-semantic error by using brother instead of cousin. According to Dioula culture, Amina is Moussa "s father"s brother"s daughter. Therefore, Moussa is Amina"s brother. It is what led the informants to take Moussa for Amina "s brother instead of Aminaes cousin.

Considering the results presented, it is undeniable that students connected wrong meanings to words in foreign language because of the differences between local language culture and foreign language culture. This is evidence that local culture interferes in the learning and understanding of foreign language vocabulary. The data in III.1.3 above is an example of semantic restriction from Dioula to English. The data analysis from the qualitative stand-point revealed that Dioula culture influences the learning of vocabulary in English as a foreign language. Let us see from a quantitative 
analysis, the extent to which Dioula culture interferes in the use of vocabulary in English as foreign language.

\section{2. Results from a quantitative stand-point}

\section{2. 1. Rate of failure to use linguistic items}

This section concerns the recorded data which was an oral activity. The story in the Dioula version contained specific words which are: 'san' $(s k y)$, 'sisesogo' (chicken), 'sagasogo' (mutton), 'lesogo' (pork), and 'misisogo' (beef). The tables below show the percentages of cultural interferences in the use of EFL vocabulary among Dioula speaking students in Burkina Faso.

Table 1: Right and wrong words for 'san' as sky

\begin{tabular}{|c|c|c|c|}
\hline 'san' as ‘sky' & Frequency & Validated Percent & Cumulative Percent \\
\hline RLit & 5 & 35.7 & 35.7 \\
\hline WLit & 6 & 42.9 & 78.6 \\
\hline NA & 3 & 21.4 & 100 \\
\hline Total & $\mathbf{1 4}$ & $\mathbf{1 0 0}$ & \\
\hline
\end{tabular}

The Dioula use the morpheme 'san' from 'sangolo' or 'sanji' to refer either to sky or rain. The right use of sky for 'san' depends on the understanding of the meaning of 'sangolo'. According to the results in table 1 above, $42.9 \%$ of the students used rain which is a wrong linguistic item and $35.7 \%$ of them used $s k y$, the right word. The rate of students who failed to get the right word rain is superior to that of those who used sky. These results reflect the high effect of the influence of local culture on foreign language vocabulary.

Table 2: Right and wrong words for 'sisesogo' as chicken

\begin{tabular}{|c|c|c|c|}
\hline 'sisesogo' as chicken & Frequency & Validated Percent & Cumulative Percent \\
\hline RLit & 5 & 35.7 & 35.7 \\
\hline WLit & 7 & 50.0 & 85.7 \\
\hline NA & 2 & 14.3 & 100 \\
\hline Total & $\mathbf{1 4}$ & $\mathbf{1 0 0}$ & \\
\hline
\end{tabular}

The equivalent word corresponding to chicken (as meat) does not exist in Dioula. That is why the Dioula resort to the process of compounding between 'sise' (hen/cock) and 'sogo' (meat) to refer to chicken as meat. According to the results in table 2 above, whereas $35.7 \%$ of the students got 
the right word as chicken, $50 \%$ of them have used a wrong linguistic item (hen meat). The lack of the word in first language, which is a cultural matter, resulted to the wrong use of the word in foreign language with a percentage of success far below that of failure. Once more, these results show how high the influence of local culture is on foreign language vocabulary.

Table 3: Right and wrong words for 'sagasogo' as mutton

\begin{tabular}{|c|c|c|c|}
\hline 'sagasogo' as mutton & Frequency & Validated Percent & Cumulative Percent \\
\hline RLit & 2 & 14.3 & 14.3 \\
\hline WLit & 9 & 64.3 & 78.6 \\
\hline NA & 3 & 21.4 & 100 \\
\hline Total & $\mathbf{1 4}$ & $\mathbf{1 0 0}$ & \\
\hline
\end{tabular}

The interpretation of the results in table 3 is similar to that of table 2 . As there is no corresponding equivalent term for mutton, the Dioula resort to the process of compounding between 'saga' (sheep) and 'sogo' (meat) to refer to mutton. According to the results, $64.3 \%$ of the students used a wrong linguistic item (sheep meat) instead of mutton. Only 14.3\% of the students used the right linguistic item. The absence of the word in the first language prevented the students from getting the right word in English. It is visible from the table 3 that the percentage of students who used a wrong linguistic item is far superior to that of those who got the right linguistic item. These results demonstrate that the influence of local culture on the learning of foreign language vocabulary is high.

Table 4: Right and wrong words for 'IEsogo' as pork

\begin{tabular}{|c|c|c|c|}
\hline 'lesogo' as pork & Frequency & Validated Percent & $\begin{array}{c}\text { Cumulative } \\
\text { Percent }\end{array}$ \\
\hline RLit & 3 & 21.4 & 21.4 \\
\hline WLit & 9 & 64.3 & 85.7 \\
\hline NA & 2 & 14.3 & 100 \\
\hline Total & $\mathbf{1 4}$ & $\mathbf{1 0 0}$ & \\
\hline
\end{tabular}

There is no corresponding equivalent word for pork in Dioula. That is why the Dioula resort to the process of compounding between ' $k \varepsilon$ ' (pig) and 'sogo' (meat) to refer to pork. In Table $464.3 \%$ of students used a wrong linguistic item (pig meat) and $21.4 \%$ got the right word as pork. The use of the wrong word is quite higher than that of right word among respondents, showing evidence of a great cultural influence in the use of vocabulary in EFL. 
Table 5: Right and wrong word for 'misisogo' as beef

\begin{tabular}{|c|c|c|c|}
\hline 'misisogo' as beef & Frequency & Validated Percent & Cumulative Percent \\
\hline RLit & 4 & 28.6 & 28.6 \\
\hline WLit & 7 & 50.0 & 78.6 \\
\hline NA & 3 & 21.4 & 100 \\
\hline Total & $\mathbf{1 4}$ & $\mathbf{1 0 0}$ & \\
\hline
\end{tabular}

The word 'misisogo', from 'misi' (cow/ox) and 'sogo' (meat), is used in Dioula because of the lack of an equivalent term for the word as beef. According to the results in table 5 , whereas $50 \%$ of the students have used a wrong linguistic item (cow meat or ox meat) $28.6 \%$ got it right as beef. The percentage of students who used a wrong word is superior to that of those who got the right word. These results indicate that there is a link between local culture and learners ${ }^{\text {ee }}$ failure to learn foreign language vocabulary.

The results presented in tables 1, 2, 3, 4, and 5 clearly indicate that the percentages of students who got the wrong words are far superior to the percentages of those who got the right words. What is wrong as a language usage according to the English culture is right according the Dioula culture. Therefore, it goes without saying that the influence of local culture on the learning of foreign language vocabulary is a serious matter.

\section{2. 2. Rate of failure in semantic collocation}

Here, we were interested in the percentages of students who rightly or wrongly associated words in English regarding the difference of co-occurrence in words between Dioula and English.

Table 6: Collocations between ride and bicycle 'Karim, nigeso bori!' (Karim, ride the bicycle)

\begin{tabular}{|c|c|c|c|}
\hline 'bori' as 'ride' & Frequency & Validated Percent & Cumulative Percent \\
\hline RC & 3 & 2.2 & 2.2 \\
\hline WC & 92 & 67.6 & 69.9 \\
\hline NRCNWR & 33 & 24.3 & 94.1 \\
\hline NA & 8 & 5.9 & 100 \\
\hline Total & $\mathbf{1 3 6}$ & $\mathbf{1 0 0}$ & \\
\hline
\end{tabular}

In Dioula 'bori' (run) and 'nigeso' (bicycle) can co-occur. In English instead of run and bicycle, it is ride and bicycle that can co-occur. The results in table 6 show that $67.6 \%$ of the students have wrongly combined run and bicycle. Only $2.2 \%$ of them succeeded to rightly associate ride and bicycle. The wrong collocation between run and bicycle is the effect of the meaning of 'bori'. As 
collocation is possible between „borie and 'nigeso' in Dioula, many students thought it is also possible between run and bicycle. That is why the percentage of wrong collocation is superior to that of right collocation. This high percentage of wrong collocation proves that word meanings in Dioula (first language) influence the organisation of English (foreign language).

\section{Table 7: Collocation between ride and motorbike}

Fatogoma, moto bori! = Fatogoma, ride the motorbike!

\begin{tabular}{|c|c|c|c|}
\hline 'bori' as 'ride' & Frequency & Validated Percent & Cumulative Percent \\
\hline RC & 3 & 2.2 & 2.2 \\
\hline WC & 93 & 68.4 & 70.6 \\
\hline NRCNWC & 33 & 24.3 & 94.9 \\
\hline NA & 7 & 5.1 & 100 \\
\hline Total & $\mathbf{1 3 6}$ & $\mathbf{1 0 0}$ & \\
\hline
\end{tabular}

The results in table 7 are similar to those in table 6. In Dioula 'bori' (run) and 'moto' (motorbike) can co-occur. In English instead of run and motorbike, it is ride and motorbike that can co-occur. These results in table 7 indicate $68.6 \%$ of wrong co-occurrence between run and bicycle versus $2.2 \%$ of right co-occurrence between ride and motorbike. Likewise run and bicycle, wrong collocation between run and motorbike resulted from the meaning of 'bori'. As collocation is possible between 'bori' and 'moto' in Dioula, the students deduced that it is also possible between run and motorbike. That is why the percentage of wrong collocation is superior to that of right collocation.

\section{Table 8: Collocation between build and house}

'Kalifa, b boy koro!' (Kalifa, stand near the house!)

\begin{tabular}{|c|c|c|c|}
\hline 'lo' as 'stand' & Frequency & Validated Percent & Cumulative Percent \\
\hline RC & 4 & 2.9 & 2.9 \\
\hline WC & 83 & 61.0 & 64.0 \\
\hline NRCNWC & 18 & 13.2 & 77.2 \\
\hline NA & 31 & 22.8 & 100 \\
\hline Total & $\mathbf{1 3 6}$ & $\mathbf{1 0 0}$ & \\
\hline
\end{tabular}

The word ' $b$ ' in Dioula means build/stand/stop in English. Hence 'boy' (house) and ' $b$ ' can co-occur in Dioula. In English it is only stand and bouse that can co-occur. When we refer to the results in table 8 above, $61 \%$ of the students have wrongly associated either stop and near the house or arrest and near the house. Only $2.9 \%$ of the students have rightly collocated stand and near the bouse. The percentage of wrong collocation is higher than that of right collocation. This is the effect of the meaning of the word ' $b$ ' in Dioula. The 
word ' $b$ ' contains the meanings of stop (partially synonymous with arrest). This meaning led the learners to use either stop or arrest with bouse.

Table 9: Collocation between hear and noise

'Doudou ye moto mankan me' (Doudou heard the noise of the motorbike

\begin{tabular}{|c|c|c|c|}
\hline 'me' as 'hear' & Frequency & Validated Percent & Cumulative Percent \\
\hline RC & 9 & 6.6 & 6.6 \\
\hline WC & 50 & 36.8 & 43.4 \\
\hline NRCNWC & 31 & 22.8 & 66.2 \\
\hline NA & 46 & 33.8 & 100 \\
\hline Total & $\mathbf{1 3 6}$ & $\mathbf{1 0 0}$ & \\
\hline
\end{tabular}

As mentioned above, the word ' $m \varepsilon$ ' in Dioula stands for bear/understand/listen in English. Therefore, 'mankan' (noise) and 'me' can be combined in Dioula. In English, the combination is possible between hear and noise but inappropriate between understand/listen and noise. Table 9 exhibits results with $6.6 \%$ of the students who rightly associated hear and noise. But $36.8 \%$ of them wrongly collocated hear/understand/listen and noise. The percentage of wrong collocation is quite higher than that of right collocation. The high percentage of wrong collocation derives from the meaning of the word ' $m \varepsilon$ '. As this word contains the meaning hear/understand/listen, it led the students to incorrectly combine understand/ listen and noise.

Considering the results in tables $6,7,8$, and 9, it appears clearly that the percentages of wrong collocations are far superior to those of right collocations. The high percentages of wrong collocations are evidence the majority of students follow the structure in Dioula (first language) for the organisation of English (foreign language).

\section{2. 3. Rate of failure to connect right meanings to words}

In this section, we are interested in the percentages of students who connected right or wrong meaning to English (foreign language) words.

Table 10: Meaning of the word 'facefitini' as uncle

\begin{tabular}{|c|c|c|c|}
\hline 'facefitini' as 'uncle' & Frequency & Validated Percent & Cumulative Percent \\
\hline RMC & 34 & 26.2 & 26.2 \\
\hline WMC & 53 & 40.8 & 66.9 \\
\hline NCM & 25 & 19.2 & 86.2 \\
\hline NA & 18 & 13.8 & 100 \\
\hline Total & $\mathbf{1 3 0}$ & $\mathbf{1 0 0}$ & \\
\hline
\end{tabular}


The word 'facefitini' (small father) consists of 'face' (father) and 'fitini' (small). In Dioula 'facefitini' refers to Samba as Moussa's father's brother. According to the context, 'facefitini' stands for father in the Dioula culture. When we refer to the context and the English culture, the expected word for 'facefitini' is uncle. According to the results presented in table 10 above, 26.2\% of the students connected a right meaning to 'facefitini'. They got the right meaning of the word as uncle. $40.8 \%$ of the students connected a wrong meaning to 'facefitini' by using father. There are $19.2 \%$ of no corresponding answer and $13.8 \%$ of no answer. The results clearly indicate that the percentage of the students who connected the right meaning to the word 'facefitini' is far below that of those who connected a wrong meaning to it. These results suggest that many of the students draw the meaning of the word from Dioula (the first language) culture.

\section{Table 11: Meaning of the word 'bamusofitini' as aunt}

\begin{tabular}{|c|c|c|c|}
\hline 'bamuso' as 'aunt' & Frequency & Valid Percent & Cumulative Percent \\
\hline RMC & 22 & 16.9 & 16.9 \\
\hline WMC & 41 & 31.5 & 48.5 \\
\hline NCA & 26 & 20.0 & 68.5 \\
\hline NA & 41 & 31.5 & 100 \\
\hline Total & $\mathbf{1 3 0}$ & $\mathbf{1 0 0}$ & \\
\hline
\end{tabular}

The word 'bamusofitini' (small mother) contains the morphemes 'bamuso' (mother) and 'fitini' (small). In the story 'bamusofitini' stands for Salimata who is Moussa"s uncle Samba"s wife. Based on the context, 'bamusofitini' stands for mother in the Dioula culture. When we refer to the context and the English culture, 'bamusofitini' should be aunt. According to the results presented in table 11 above, $16.9 \%$ of the students connected a right meaning to 'bamusofitini' by using the word aunt while $31.5 \%$ of the students connected a wrong meaning to 'bamusofitini' because they mistook the word for mother. $20 \%$ of no corresponding answer which probably resulted from students ${ }^{\text {ee }}$ poor knowledge of kinship terminologies in English and 31.5\% of no answer. Comparing the percentage of the students who connected a right meaning to the word 'bamusofitini' to that of those who connected a wrong meaning to 'bamusofitini', it is visible that many of them draw English (foreign language) word meanings referring to Dioula, their first language culture. 
Table 12: Meaning of the word 'koroce' as cousin

\begin{tabular}{|c|c|c|c|}
\hline 'korocE' as 'cousin' & Frequency & Validated Percent & Cumulative Percent \\
\hline RMC & 1 & 0.8 & 0.8 \\
\hline WMC & 59 & 45.4 & 46.2 \\
\hline NCM & 5 & 3.8 & 50.0 \\
\hline NA & 65 & 50.0 & 100 \\
\hline Total & $\mathbf{1 3 0}$ & $\mathbf{1 0 0}$ & \\
\hline
\end{tabular}

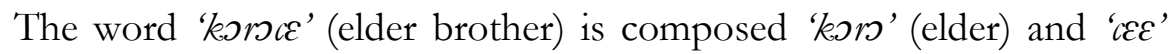
(male). In the story 'korrce' refers to Moussa who is Sidikie"s son. Amina is Sidikie"s brother Sambae's daughter. Considering the context, 'koroce' stands for brother in the Dioula culture. When we refer to the context and the English culture, 'karace' corresponds to cousin. According to the results presented in table 23 above, only $0.8 \%$ of the students connected a right meaning to the word 'karace' by using cousin. $45.4 \%$ of the students connected a wrong meaning to 'karrec'. They used brother instead of cousin. There is $3.8 \%$ of no corresponding answer and $50 \%$ of no answer. It is clear that the percentage $(0.8 \%)$ of the students who connected a right meaning to the word 'karre' is very far below that (45.4) of the students who connected a wrong meaning to 'karce'. Many of the students conceive English (foreign language) word meaning referring to Dioula (the first language) culture.

The results presented in tables 10,11, and 12 reveal that the majority of students draw English (foreign language) word meanings by referring to Dioula culture. These results indicate that the influence of Dioula culture on the learning of English vocabulary is serious.

\section{Conclusion and pedagogical implications}

This paper examined the link between Dioula culture and English (foreign language) lexico-semantic errors. The results, by extrapolation, showed that learners draw foreign language word meanings by referring to the Dioula culture, thus committing lexico-semantic errors. The results may imply weaknesses in the methods and approaches adopted in the teaching of foreign language vocabulary. One of these weaknesses may be owing to the nonconsideration of word meanings in the first language culture during vocabulary teaching. In EFL class, vocabulary is taught considering only word meanings in the foreign culture to the exclusion of meanings of equivalent terms in the first language, the Dioula culture. The paradox is that English learners are much more exposed to the Dioula culture with considerable mismatch in word meanings between Dioula (first language) and English (foreign language). We, 
therefore, suggest the review of the methods and approaches used in teaching EFL vocabulary in non-native countries. One way of doing it is to adapt the teaching of EFL vocabulary to the learners' culture, in our case Dioula. Another technique is to emphasize learners' culture in the writing of textbooks used for foreign language teaching in order to meet their communicative needs as suggested by Namaono (1993). All these strategies necessitate the adoption of learner-culture-based and foreign-culture-based approaches in semantic analysis.

\section{References}

Namaono, H. B. (1993). A Study of English Language Teaching Textbooks for Gème and 5ème Classes in Burkina Faso Secondary Schools with Reference to Cultural Content: Suggestions for Adaptation. Mémoire de Maitrise. Département des Langues Vivantes, Université de Ouagadougou.

Soma L. (2014). Local Culture and Foreign Language Vocabulary Teaching/Learning in the Secondary Schools of Ouagadongou with Reference to Lower-sixth Formers. Mémoire de Maîtrise. Département des Langues Vivantes, Université de Ouagadougou.

Wardhaugh, R. (1998). An introduction to Sociolinguistics. Massachusetts: Blackwell Publishers Inc.

Jeptarus, E. Kipsamo and Ngene K. Patrick (2016). Lexico-Semantic Errors of the Learners of English: A Survey of Standard Seven Keiyo- Speaking Primary School Pupils in Keiyo District, Kenya. In Journal of Education and Practice: Vol.7, No.13. pp. 45-54. Retrieved from https:// files.eric.ed.gov [15/07/2017].

Hamiloglu, K. (2013). Pre-Service Teachers' Views on the Presentation of Culture in EFL Coursebooks. NASED: Educational Policy Analysis and Strategic Research, V 8, $\mathrm{N}^{\circ}$ 1. pp. 38-55. Retrieved from https://www.semanticscholar.org [15/07/2017].

Tizazu, Y. (2014). A Linguistic Analysis of Errors in the Compositions of Arba Minch University Students. In Advances in Language and Literary Studies \& Australian International Academic Centre. Vol. 5 No. 3. pp. 195-205. Retrieved from https:/doi.org/10.4324/9781315842912. 320p. [15/07/2017].

Yang, L., Ma, A., and Cao, Y. (2013). Lexical Negative Transfer Analysis and Pedagogic Suggestions of Native Language in Chinese EFL Writing. Published 
by Atlantis Press: International Conference on Education Technology and Management Science (ICETMS 2013).

\section{Appendix: Identification and classification of the errors}

\section{CORPUS A}

1. (a) O loon togəra, məgəw ye cisesogo, sagasogo, lesogo ni misisogo dumu cama.

On day people chicken meat sheep meet pig meat cow meat eat much. "On that day, people ate a lot of chicken, mutton, pork and beef."

(b) O loon togora, mogow ye cisesogo, sagasogo, lesogo ni misisogo dumu cama.

In, at at this day, people eat chicken meat, sheep meat, pig meat and cow meat.

"On that day, people ate a lot of chicken, mutton, pork and beef."

2. Loon do, sogoma joona, san barila ka fin.

One day morning, the rain become black.

"One day, early in the morning, the sky suddenly became cloudy".

3. (a) Sufe, kalo ni lolow ma bo.

night month star not come out.

"At night, the moon and the stars did not come out"

(b) Sufe, kalo ni lolow ma bo.

Evening, there are not the star and the month.

"At night, the moon and the stars did not come out"

\section{CORPUS B}

4. A ye sigereti fana mi.

He drinks cigarette.

"He also smoked a cigarette."

5. 'Karim, nigeso bori!'

Karim, runs the bicycle.

"Karim, ride the bicycle!"

6. Kalifa, 1 bon korn!

Kalifa, stop in front of the bouse.

"Kalifa, stand near the house!" 
7. (a) Ali ye parifen kasa me.m

Ali heard parfume.

"Ali smelt the perfume/fragrance."

(b) Ali ye parifen kasa me.

Ali has understand parfum ordor.

"Ali smelt the perfume/fragrance"

(c) Ali ye parifen kasa me.

Ali listen some parfum.

"Ali smelt the perfume/fragrance."

8. (a) Doudou ye moto mankan $m \varepsilon$.

Doudou listen the sound of motorcycle.

"Doudou heard the noise of the motorbike"

(b) Doudou ye moto mankan me.

Doudou has understand the noise of motorcycle.

"Doudou heard the noise of the motorbike"

\section{CORPUS C}

9. Sidiki y'a muso Salimata mine kajen.

Sidiki took the care of his wife Salimata.

"Sidiki took good care of his sister-in-law, Salimata"

10. A y'a ka demuso Amina fana mine kanen.

He is also take care of his daughter Amina.

"He also took good care of his niece, Amina"

11. Amina be Samba n'a karre Moussa ko nininga loon be.

Amina is asking her brother Moussa and Samba his information.

"Amina asks about his cousin Moussa every day". 


\title{
Critical Analysis of the Place and Importance of Literature in the Teaching / Learning of English and in School Leaving Certificate Examination in Burkina Faso from 1985 to 2018.
}

\author{
André Kabore \& Charles Nazortin \\ Université Norbert Zongo, Burkina Faso
}

\begin{abstract}
The potentials of literary texts are numerous. Literary texts can be used as basis for the teaching of the four traditional skills. They can also be used to develop learners' cultural competence. In Literature classes preparing for "Baccalaureate A" written examination, literary texts are expected to be used frequently with regard to the profile of students in this section. The purpose of this study is to analyse the types of texts given at the "Baccalaureate A" written examination in the last thirty years. In this study, quantitative and qualitative data are collected. Baccalaureate written English papers are the main focus of our collection. Teachers and supervisors are interviewed. The study is grounded on "Reader-Response Theory" which stresses the interactions between the reader and the text. The results of the study show that the great majority of texts proposed for "Baccalaureate A" examination, in the last thirty years, are non-literary texts. The consequence of this reduction in the use of literary texts may explain teachers' gradual lack of motivation to use them in class, or vice-versa, everything that is likely to have a negative impact on the performance of students from this class.
\end{abstract}

Keywords: enhance; literary text; performance; potentials; skills.

\section{Introduction}

Keeping Literature off the syllabus creates discontentment. Teachers do testify that many learners want and love literary texts and are also keen to familiarize with the English patterns of social interactions (Collie and Slater, 
1987; Hall, 2005). Queries from pupils to their teachers, like "could you recommend a novel that I might read to improve my English? I need more vocabulary and reading helps a lot" (Collie and Slater, 1987, p. 1) show English learners' love for Literature. In response to this desire for Literature, pedagogues, such as Joanne Collie and Stephen Slater (1987), Geoff Hall (2005), the contributors to Literature in Language Teaching and Learning (2006), have devised ways of making Literature a more significant instrument of English teaching programme to help English learners in the mastery of the four basic areas of listening, speaking, reading and writing. They have tried to illustrate the relationship between Literature and language learning and to offer practitioners ways to integrate Literature into English classes. They offer highly valuable pieces of advice on adding Literature to language classes and show how learning English can be a pleasurable experience if some degree of literariness is used to flavour the process.

Yet, nowadays, there is much questioning of the relationship between Literature and the study of Language. There is a debate on whether Literature should be taught in the English language teaching classroom in Secondary School and even at University. In the Burkinabe context especially, Kaboré (2017), through a comparative study of three English textbooks used in the Burkinabe education system, has highlighted the decrease in the use of Literature in teaching English language, which led to pupils' lack of proficiency in written English, owing to the adoption of "functional" didactics by Burkinabe Education policy makers. In fact, in view of helping students achieve communicative competence and relying on modern Linguistics which lays emphasis on the primacy of the spoken language, Burkinabe Department of National Education issued a new Language Policy in 1983, and revised the syllabi of English as a Foreign Language (EFL) in the first cycle in 2010. Yet, Somé-Guiébré's study (2018), based specifically on a critical analysis of the syllabi of quatrième (4e) in Burkina Faso education system, and interviewing stakeholders, concludes that despite tremendous efforts invested in the conception of syllabi, these tools hardly help implement communicative language teaching (CLT) in English language classrooms in Burkina Faso. Expectations are then not met despite the change of teaching strategies. As the African saying goes, "The better broth is made in an old pot." But why do English teachers not resort to Literature in the teaching of English as a foreign language? Is there a reciprocal influence between the types of texts-literary or non-literary-given at the School Leaving Certificate examinations and the teachers' motivation for Literature as a tool for the acquisition of language? In other words, since it is the teachers who propose examination questions, would the prevalence of non-literary texts proposed in examination papers be the expression of teachers' disgust for Literature and, alternatively, would this 
prevalence discourage lovers of Literature from using the latter for the teaching of English in classes preparing for the School Leaving Certificate Examinations? The present study analyses the texts used for the written tests of "Baccalaureate A" from 1985 to 2018 to determine whether the lack of use of Literature in the teaching of English in classes is caused by the use of nonliterary texts in the final examinations and whether the rare literary texts used are expressive of nostalgia for the use of Literature in the teaching/learning of English in view of making recommendations on the use of Literature in the teaching/learning of English as a foreign language.

To successfully carry out this study, Baccalaureate A English written examination papers in Burkina Faso are collected. The period concerned goes from 1985 to 2018. This time sequence is chosen to include the time spent at secondary school and the years the School Leaving Certificate examination is taken and the time spent by teachers. The identification of the place of literary texts in these examinations in the last thirty years is our main focus. The population involved in this study includes 20 teachers and 04 supervisors from Ouagadougou and Koudougou. Questionnaires, interview protocols are used for the collection of data. Teachers and supervisors are identified using a nonprobability convenience sampling. Teachers answer questionnaires. Supervisors are interviewed. The texts and questions are examined using the reader-response theory which lays emphasis on communicative performance.

\section{Theoretical Framework}

The study is conducted using reader-response theory. Theorists of this criticism, according to Lois Tyson (1999, p. 154), share two beliefs: (1) that the reader's function in the process of reading, cannot be omitted from the understanding of Literature, and (2) that the reader does not passively consume the meaning provided by an objective literary text. This theory mainly argues that readers, as much as the text, play an active role in a reading experience (Rosenblatt, 1994). It asserts that readers draw on their personal experiences to create meaning in a given text.

This theory focuses then on the way readers receive texts. As Culler (2011) puts it, reader-response criticism can be seen as the description of the reader's progressive movement through a text, analysing how he/she produces meaning by "making connections, filling in things left unsaid, anticipating and conjecturing and then having their expectations disappointed or confirmed." (p. 137).

There are many approaches in reader-response criticism: subjective reader-response theory, affective stylistics, transactional reader-response theory, psychological reader-response theory, and social reader-response 
theory (Tyson, 1999, p. 157). The first approach will be used in this study because its emphasis on communicative performance makes it a convenient tool for assessing teachers and candidates. It is a theory that is laid down by David Bleich according to whom readers' responses are the text in a double sense: first, in the sense that there is no literary text beyond the meanings created by readers' interpretations; second, in the sense that the text subjected to critical analysis is the written responses of readers and not the literary text per se. Bleich differentiates between what he calls "real objects," namely the printed pages of a literary text, and "symbolic objects", that is, the experience created in the reader's mind from reading the text (Tyson, 1999, p. 164). According to Bleich, the meaning of a text for an individual reader depends on a process of "symbolization" that occurs in the mind of the reader, in which the reader progresses from developing a "response" to an "interpretation" of that text (Bleich, 1978, pp. 34-36). For Bleich, the individual reader's initial response and his or her more developed interpretation are less constrained by the particular features of the text. Bleich places a greater emphasis on the social context, the "interpretive community" (Bleich, 1978, p. 38) in which responses and interpretations are formed, a community which includes the teacher and the students in the classroom.

If teaching Literature is to accommodate students' role in making interpretation, it is supposed to place them as the active readers to interpret and shape the meaning of literary works; it is not teaching them a specific meaning previously decided. Therefore, by applying reader-response theory in this study, the objective is to examine the texts given at the "Baccalaureate A" examinations and the questions to see if they are in the open-form format as required in reader-response criticism and make recommendations accordingly.

\section{Result and Analysis}

Our participants are half male and half female and all have attended Literature classes during their University training. $62.5 \%$ are aged between 31 and 40 and have less than ten years teaching experience. $25 \%$ are over 40 but less than 50 years old and have between 11 and 20 years' experience in the teaching profession. $12 \%$ are over 51 years old and has been teaching for more than 21 years. The hobby of $62.5 \%$ of them is the reading of literary works. $50 \%$ of them said they have not studied English through Literature in Secondary School. All of them study texts in class with their pupils but half of them resort to either literary or non-literary texts without any reason, while the other half combines literary and non-literary texts. Half of them also select their texts according to current issues, while the other half does it either according to learners' profile and interests or combining those interests with 
current issues. $62 \%$ answered that from their experience, it is literary texts that usually come at the School Leaving Certificate Examinations. 70\% expect literary texts to be given at the "Baccalaureate A" written examination. Half of the respondents thinks that literary texts can best develop learners' performance because they are authentic materials and are more complete in terms of language skills and vocabulary. $37.5 \%$ think without giving a reason that any text can be used to best develop learners' performance in the English language.

The interview with four supervisors of English teachers reveals that the type of texts teachers study during reading-comprehension lessons is nonliterary texts. According to them, the reasons are (1) the lack of curricula and the absence of current issues in books; (2) the fact that teachers have not been trained to use literary texts, hence their lack of confidence to do so; (3) the fact that non-literary texts are mostly used at the School Leaving Certificate Examinations. Three out of the four supervisors see a link between "Baccalaureate A" written examination papers and the ones used by teachers in classrooms but they all expect that literary and non-literary texts be given during the School Leaving Certificate examinations because they are all useful for language learning and variety is the spice of life.

The combination of the answers from the teachers and the supervisors predicts and helps understand the avalanche of non-literary texts at the "Baccalaureate A" written examinations. It can be noticed that prior to Kaboré's article (2017) in which he deplores the minimal use of Literature in English teaching textbooks and raises awareness on the importance of Literature in English learning/teaching in 2017, most of the excerpts for "Baccalaureate A" Examinations were taken from non-fiction books, at the ratio of 59 against 06. From 1988 to 2016, only one literary text was used out of 59 examination papers. Yet, from 1985 to 1987, five literary texts were used out of a total of six examination papers. Figure 1 gives a visual picture of the overall percentage of non-literary texts used in "Baccalaureate A" examinations from 2018 to 1985.

Figure 1 also shows that, an average of 15\% of literary texts against $85 \%$ of non-fiction texts were used in Burkina Faso School Leaving Certificate examinations in the last thirty years. Conspicuously, the literary texts are concentrated at the beginning, that is, the first two years from 1985 to 1987 with three literary texts. The use of literary texts in recent years can be explained as a positive impact of Kaboré's 2017 paper whereas the use of literary texts from 1985 downwards may be due to the use of literary-based English texts books like Anglais en Afrique et à Madagassar (1972), for the teaching of English as a foreign language. $37.5 \%$ of teachers in our sample 
who said they studied English through Literature in secondary school may have used this textbook.

The non-fiction texts in turn can be divided in two: excerpts taken from books and formal reports $(35 \%)$ and the others taken from speeches and newspapers $(50 \%)$, in addition to the $15 \%$ literary texts, as shown in figure 2 .

The various texts cover a variety of themes, as can be seen in reading the different excerpts: Apart from the first, as well as the last two titles, the others are about daily common issues which are likely to be developed in the popular media (radio, TV, internet). The implication is that students who follow the daily news in English may be able to understand them successfully thanks to the communicative qualities they might have acquired from communication with native speakers through the different media. However, the issues are most often old, not current, as shown in figure 3.

Figure 3 actually shows the discrepancy that exists between the dates of issue of the texts in comparison to the year of examination. Most of the texts are older than the candidates who sit for the exams. No text given is from the same year. The age gap goes from 60 to 1 year. Apart from two literary texts, at least eight of the non-fiction texts are at least 20 years old. The use of such old and non-literary texts is a matter of debate and discussion.

\section{Discussion}

The discussion will be first around the place and importance of Literature in the objectives set up in the secondary school programme for the teaching of the English language. Then, the implementation of these objectives will be discussed. Finally, the questions following the texts given at School Leaving Certificate Examination papers will be examined.

\section{Objectives of the Teaching of English in Secondary School}

An undated document of the Ministry of Education enumerates the objectives for using Vocabulary and texts of Civilisation and Literature in the English language teaching programme in Secondary School. It argues that, in addition to reinforcing the English acquired at the first cycle of education, the syllabus of the second cycle aims at "deepening pupils' knowledge in the cultural domain through the study of any type of documents that is representative of English civilisation and culture" (Ministère, n.d., p. 1) as well as "giving pupils the means for self-development and the desire and possibility for an in-depth study of the English language" (Ministère, n.d., p. 1).

The objectives are clear but the means to achieve them need further explanation. The use of any type of documents certainly includes literary and 
non-literary ones. But the debate would be about the "type of documents that is representative of English civilisation and culture." The second part of the document which is about "vocabulary" and the third part on "Civilisation and Literature" suggest that teachers are free to use literary as well as non-literary materials. They are encouraged to make pupils acquainted with original forms of expressions in English, with materials from newspapers, journals, radio, television, cinema to help them gain a variety of vocabulary. Teachers are also invited, in their choice, "to prefer, in general, contemporary register of everyday communication to any other" (Ministère, n.d., p. 2). Pupils should be encouraged to read newspapers and listen to foreign radios. This part, therefore, lays emphasis on the use of non-literary materials.

The third part of this official document on English language teaching programme in Secondary School strongly recommends teachers to often use authentic texts and materials from all cultural domains: literature, plastic arts, cinema, music, television, radio, technology, etc. (Ministère, n.d., p. 3). It stresses that excerpts from Literature should be taken from the works of modern and contemporary British, American, and African writers. It encourages personal reading and group discussion of plays, short stories, novels, and newspaper articles. Therefore, this part lays emphasis on the use of excerpts from contemporary Literature without excluding the resort to modern non-literary works.

So, in a nutshell, the whole syllabus for the teaching of English recommends the use of literary and non-literary texts equally, provided they are contemporary and understandable to the pupils. There is then a problem when teachers focus only on non-literary texts. Literature should take the pride of place in English language teaching Secondary School.

\section{Place of Literature in the Teaching of English in Secondary School}

Literature is integrated in English learning from first to third-year University Education in Burkina Faso, which is not the case everywhere (Butler 2006). All the teachers in our sample acknowledge having attended Literature classes in their training at University. 37.5\% of them even studied English through Literature at Secondary School.

At the University Joseph Ki-Zerbo, in the Department of Anglophone Studies, the subjects where there is literature are as follows: ANG 1003 (Introduction to English Literature), the aim of which is to develop language awareness, with Literature being used to introduce concepts and ideas; ANG 1502 (Anglophone Literatures: African, American and British), which is meant to introduce learners to different types of genres, where Literature provides a 
variety of registers; ANG 2003 (British Literature from $16^{\text {th }}$ to $18^{\text {th }}$ Centuries), which focuses on specific works from that period, at the same time providing rich input for language analysis. The following courses also concur to the same objective: ANG 2004 (American Literature from its origins to the $19^{\text {th }}$ Century), ANG 2505 (African Literature in English from its origins to the independence), ANG 3005 (British Literature from the $19^{\text {th }}$ to the $20^{\text {th }}$ Centuries), ANG 3006 (20 $0^{\text {th }}$ Century American Literature), and ANG 3007 (Post-independence African Literature in English). The last semester, students have the possibility of choosing four genres (novel, short story, poetry and drama) in African, American or British Literatures to gain an in-depth knowledge of the English Language used in Literature.

It is astonishing then that after so many years of learning English through Literature, the student, once he/she becomes a teacher, cannot use Literature in the teaching of English as a Foreign Language, but has to resort to newspaper articles. One of the supervisors contends that the reason is that teachers have not been trained to use literary texts. Another one evokes the influence of the prevalence of non-literary texts at School Leaving Certificate Examinations. Another reason may be the fact that print newspapers (discarded past issues of American cultural Centre or NGO's) or online materials are easily available. Concerning texts in electronic format, "cut and paste" makes the work easier than typing the text from a printed novel, which is often difficult to find in a French speaking country. This may explain the fact that though having learned English through the use of Literature, teachers use non-literary texts in their teaching.

Yet Literature is a crystallisation of ordinary speech and cultural practice in a memorable way. Even though common sense traditionally makes the difference between a stereotype of 'literary' language and ordinary language, viewing literary language as flowery or elevated, unusually figurative and symbolic, and so difficult to understand, unlike the language used and encountered in everyday life, such criticism, however, overlooks the performative aspect of Literature in the reading process. As Michael Riffaterre (1978) puts it, "readers make the literary event" (p. 116), laying emphasis on the role of readers in the performance of literary texts. A literary work's meaning and interpretation are composed by the readers who successfully manage to interpret the literary work based on their responses. The teaching of Literature in the classroom requires from teachers a different teaching method that lays emphasis on communicative performance. Literature, culture, and language should thus be approached as naturally intertwined (Barnett, 1991).

The interview with supervisors reveals that teachers have not been trained to use literary texts in the classrooms. It is a weakness that the Department of Education should address because the teaching of the English 
language with literary texts has some requirements. For example, teachers should make it possible that a literary work's interpretation is composed by the students, based on their responses. They should place students as the learners of a discussed literary work, as the core of studying Literature as they are the actors shaping the literary work's meaning. In so doing, teachers are also the ones who encourage students to express their opinions, and eventually help them develop a critical mind. Hence, teaching and studying Literature could become an interactive and collaborative process. The opinion question in all the test papers is very relevant in this sense. Language and Literature are interrelated entities, with teachers as users of Literature rather than as teachers of it.

Another important requirement for the use of Literature in the teaching of English is the choice of texts. As McKay (2001) emphasises it, "students will enjoy reading Literature only if the text is accessible to them. Hence, it is important in selecting literary texts to ensure that the theme of the text is engaging for the students, and that the text itself is not difficult on either a linguistic or conceptual level" (p. 322). Students' needs, age, interest and the ability to read fluently, as well as texts' length, lexis and syntax, should be taken into account in the choice of texts so as to boost the appetite of learners to read literary texts (Hill, 1986; Bibby, 2014). Even other criteria such as learners' cultural and literary background should be taken into consideration in the choice of texts for study (Lazar, 1993). The implementation of these criteria in the selection of a literary text will contribute to sharpen the desire of learners to always enjoy reading Literature. In "Baccalaureate A" examination papers, for example, the examiners have actually adapted the different texts to the students' age and context; hence, the phrase "adapted from" which accompanies most excerpts of School Leaving Certificate examination papers.

Many other reasons have been given for the use of Literature in language class. Showalter (2003) says that though nowadays there is no agreement on the goals of teaching literary texts, in the past, "most educators agreed that teaching Literature was a way of making people better human beings and better citizens" (p. 22). For example, Literature in England in the 1820 s aimed at moralizing, civilizing and humanizing people. In the United States too, after the Civil War, the purpose of Literature was to promote moral and spiritual values. During the Negritude movement in Africa, Literature was a means to promote African values. The post-colonial Literature aimed at depicting the wrongs done to Africans and encouraging Africans to take their destiny into their own hands. Showalter (2003) asserts that today Literature is taught for learners' education and life.

Literature also helps recognize subtle and complex differences in language use, giving access to cultural background (Lazar, 1993; McKay, 2001; 
Showalter, 2003; Bo and Li, 2007). It enables learners to make the distinction between literal and metaphorical meaning (Showalter, 2003; Liu and Yin, 2007). The use of Literature in language class contributes to developing students' interpretive abilities as regards the literary work, its author and its content, educating the whole person (Lazar, 1993; McKay, 2001; Showalter, 2003; Bo and Li, 2007). Another benefit is that, literary texts are a means of raising students and teachers' cross-cultural awareness. In reading literary texts, students learn about other people's culture and this helps students understand them (Lazar, 1993; McKay, 2001; Showalter, 2003). Literature is a language that is worked out that it becomes interesting material that motivates and encourages learners in language acquisition (Lazar, 1993). It is the reason why it constitutes a source of teaching the four skills: reading, writing, speaking and listening (McKay, 2001).

All these authors acknowledge the paramount importance of literary texts in the teaching of English as a foreign language in classrooms. They show that Literature can be used for linguistic acquisition, cultural awareness, and the development of learners' creativity, moral values and human qualities. Yet, there is no means of evaluating all these impacts on learners. Examination questions do not cover all these aspects.

\section{Questions on the texts}

What is missing in the syllabus is the way the evaluation of the pupils should be done. The type of assessment shows whether the objective of deepening "pupils' knowledge in the cultural domain through the study of any type of document that is representative of English civilisation and culture" (Ministère, n.d., p. 1) has been reached. What is usually evaluated at examinations is the comprehension of texts.

Analysing the "Baccalaureate A" examination papers from 1985 to 2018, we find out that the questions following the texts fall into two kinds: "Guided Commentary" and "Translation". The guided commentary is usually made up of three questions of comprehension of the text and one opinion question. Except the examination papers of the normal sessions of 1989, 2000 and 2004 and the resit sessions of 1986, 1990, 2003 and 2006 where the questions are directed to the writer- "According to the writer / the author"- all the other years, the comprehension questions are about the text, hence the use of different wordings of the following formulations of questions: "In / According to / Basing on / On the basis of / Referring to / Relying on... the text,...?" But even though there is a difference between the writer and the text, this difference may have not been perceived by the 
committee that prepared the questions. In other words, "according to the writer" is understood as being equivalent to "according to the text."

One important remark is in most of the examination questions from 1985 to 2000 there are more questions directed to the reader in addition to the opinion question that is found in all papers. Whereas the examination questions from 2001 to 2018 are focused on the text, the questions of previous years are targeted on the reader with questions like "according to you", "do you think", "do you agree", "do you share this point of view." Such questions respond to the demands of reader-response theory.

In reader-response criticism, the questions should be opinionorientated, in the sense of "according to you / in your opinion", as there are as many understandings as there are readers, in this theory. As Culler (1997) puts it, in reader-response criticism, "the work is not something objective... but is the experience of the reader" (p. 123). Individual answers should be valued in terms of overall consistency and coherence to candidates' own ideas instead of "objectivity" or conformity to the writer's intention. In this way, Literature could be of better profit in the examinations than any other texts.

\section{Conclusion and Recommendations}

The study confirms our hypothesis that the great majority of texts proposed for "Baccalaureate A" examinations, in the last two decades, are non-literary texts. The consequence of this reduction in the use of literary texts is that it may explain teachers' gradual lack of motivation to use Literature in class, which is likely to have a negative impact on the performance of students from this class. This paper, therefore, calls for an integration of literary and linguistic studies in a full awareness of the historical tensions between what has often been perceived as two distinct fields, 'Language' and 'Literature'. It also requires that teachers be trained first, to select literary texts as classroom teaching material, and second to use them in such a way as to let "readers make the literary event" (Riffaterre, 1978, p. 116), encouraging students to express their opinions so that teaching and learning Literature could become an interactive and collaborative process in which teachers rather appear as users of Literature instead of teachers of it.

\section{Notes}

1. All translations are ours. The original versions are: «d'élargir l'information des élèves dans le domaine culturel, par l'étude de documents de toute nature, représentatifs de la civilisation et de la culture anglaise» «de donner aux élèves les moyens d'un 
développement autonome ultérieur, le désir et la possibilité de poursuivre et d'approfondir l'étude d'anglais »

2. The original French version is: «préférer, en general, le registre comtemporain de la communication courante à tout autre »

\section{References}

Bleich, D. (1978). Subjective Criticism. Baltimore: Johns Hopkins UP.

Collie, J. and Slater, S. (1987). Literature in the Language Classroom: A Resource Book of Ideas and Activities. Cambridge: Cambridge University Press.

Culler, J. (1997). Literary Theory: A Very Short Introduction. Oxford: Oxford University Press.

Hall, G. (2005). Literature in Language Education. London: Palgrave MacMillan.

Jauss, H. R. (1997). Literary History as a Challenge to Literary Theory. In Newton K.M., eds. Twentieth-Century Literary Theory. London: Palgrave.

Iser, W. (1989). Prospecting: From Reader Response to Literary Anthropology. Baltimore: Johns Hopkins University Press.

Kaboré, A. (2017). Didactique de la littérature dans l'enseignement de l'anglais au Burkina : Etude comparée de trois manuels scolaires. In Bationo J. C. (dir.), Didactique de la littérature dans l'enseignement et l'apprentissage des langues étrangères en Afrique au Sud du Sahara: Regards croisés (pp. 211-242). Ouagadougou: L'Harmattan.

Lazar, G. (1993). Literature and Language Teaching: A Guide for Teachers and Trainers. Cambridge: Cambridge University Press.

Liu, B and Yin, B. (2007). Pourquoi intégrer la littérature dans la didactique des langues. Synergies Chine. No 02, 149-157.

McKay, L. S. (2001). Literature as Content for ESL/EFL. In Celce-Murcia, M. (Ed), Teaching English as a second or foreign language (pp. 319-332). $3^{\text {rd }}$

Edition. Boston: Heinle \&Heinly.

Ministère de l'éducation nationale. (n.d.) Programmes d'anglais au second cycle. Ouagadougou: n.p.

Paran, A., ed. (2006). Literature in Language Teaching and Learning. Virginia: Tesol.

Richards, J. C. (2006). Communicative Language Teaching Today. Cambridge: Cambridge University Press.

Riffaterre, M. (1978). Semiotics of Poetry. Bloomington: Indiana University Press. 
Rosenblatt, L. M. (1994). The Reader, the Text, the Poem: The Transactional Theory of the Literary Work. Illinois: Southern Illinois University Press.

Showalter, E. (2003). Teaching Literature. Victoria: Blackwell Publishing.

Somé-Guiébré, E. (2018). EFL Syllabus Design: Challenges of Implementation in Burkina Faso. International Education Studies. Vol. 11, No. 6, 73-78.

Tyson, L. (1999). Critical Theory Today: A User-Friendly Guide. New York and London: Garland.

Figure 1

Percentage of Literary and non-Fiction Papers Used in School Leaving Certificate Examinations in Burkina Faso between 1985 and 2018

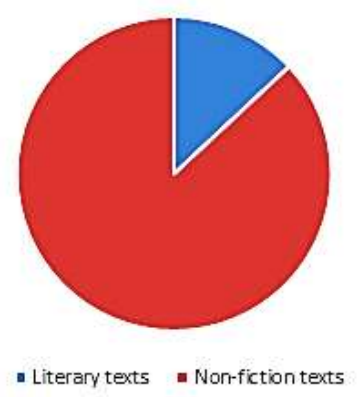

Figure 2

Percentage of Non-Fiction Papers Used in Burkina Faso School Leaving Certificate Examination from 1985 to 2018

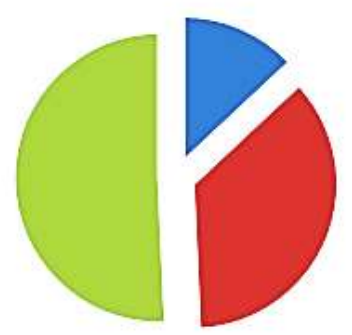

- Excerptsfrom literary texts

- Excerpts from books and reports

" Excerpts from \$peches and journal articles a 


\section{FIGURE 3}

GAP BETWEEN EXAMINATION YEAR AND ISSUE DATE OF TEXTS USED FOR EXAMINATIONS

- Correlation between year of exam and year of publication of texts

- Agegap

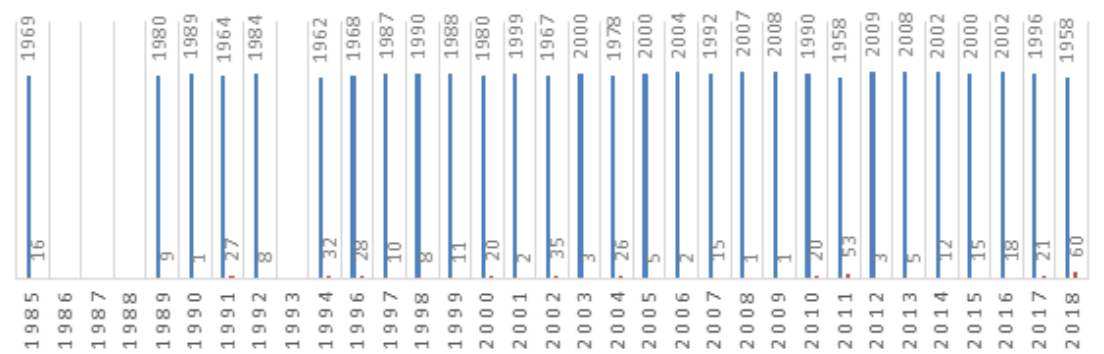




\title{
Digital Audio-visuals Aids and Listening in English as a Foreign Language Classrooms
}

\author{
Inoussa Malgoubri, Mahamadou Sawadogo \& Moses Kwadwo Kambou \\ Université Joseph Ki-Zerbo, Burkina Faso.
}

\begin{abstract}
Many scholars and language practitioners have stressed the importance of listening and speaking in language learning and teaching particularly in formal contexts. However, learners of English as a Foreign Language (EFL) in Burkina Faso appear to perform very poorly in those basic language skills. This experimental study investigates the potential of digital audio-visuals to improve the listening skills of EFL learners in secondary schools in Burkina Faso. Assuming that learners born around the year 2000 are digital natives, we have tried to integrate smartphone-friendly audio-visuals in their EFL classrooms in a four-week experiment involving one Experimental Group and one Control Group. The experiment aimed at gauging the effectiveness of those aids operated via students' smartphones in improving learners' listening and speaking skills. Independent T-tests were used to compare the groups and Sample Paired T-Tests to make comparisons within groups. Furthermore, Cohen's $d$, an effect size formula, was used to measure the effect size. The findings show that the listening skills of the students exposed to the digital audio-visual aids improved on average from 10.2 to 18.5. It was noticed incidentally that their speaking skills improved as well. The study suggests that, if appropriately used, smartphones are excellent devices for language teachers and learners in this digitizing world.
\end{abstract}

Keywords: audio-visual aids; control group; English as a Foreign Language (EFL); experimental group; Information and Communication Technology (ICT); listening comprehension. 


\section{Introduction}

As the international language mostly used around the world in business, science and technology, and international relations, English has logically made its way into the educational system of Burkina Faso, a francophone country. English is taught in secondary schools as a foreign language, and allotted 5 hours per week in 6è and 5è (Junior High School 1 and 2) and 3 hours a week fin 4è, 3è, 2nd, 1ère and Tle classes (Junior High School 3, 4 and Senior High School 1, 2, and 3) regardless of whether English is a compulsory subject or not.

The inclusion of Information and Communication Technology (ICT) in education is no longer a luxurious thing but a necessity as learners from one country may find themselves in another country during the schooling/learning period and use this tool to follow the courses back home. Therefore, teachers have the responsibility to continue updating their teaching methods and teaching aids, in the same line, Perraton et al. (2001) say that teaching is becoming more and more demanding as knowledge is expanding rapidly and much of it is available to students as well as teachers at the same time. As far as learning concepts evolve, teachers should facilitate learning and make it meaningful to individual learners rather than to just provide knowledge and skills. As new concepts of learning evolve, teachers are expected to facilitate learning and make it meaningful to individual learners rather than to provide knowledge and skills.

"Modern developments in innovative technologies have provided new possibilities to the teaching professions, but at the same time have placed more demand on teachers to learn how to use these new technologies in their teaching" Robinson \& Latchem (2003) quoted in Jung (2005:01). Unfortunately, most teachers are left to fend for themselves in the midst of many technologies to find the most appropriate ways for their specific teaching environment. Combining new technologies with effective pedagogy has become a daunting task for both teachers and teacher-training colleges.

The education authorities of Burkina Faso set the following language policy, "Every learner at the end of a given cycle should be able to hold a regular communication with a native peer of the same level" (Ministry of education, 1983) ${ }^{1}$. This goal is unrealistic owing to the materials available and the teaching environment which allows very little or no exposure of the students to English as spoken by their native peers of the same level.

There is a huge gap between the goal expected by the Ministry of Education and the observation of education supervisors. The English Inspectorate (2011:3) observed that "during class visits and inspections, most English teachers in Burkina Faso teach grammar and reading basically, and 
those teachers who tried [sic] productive activities did something else." This observation reveals that EFL teachers and learners are not doing enough to achieve the expected outcome of teaching/learning EFL. Dramé (2008) conducted a survey where $100 \%$ of respondents said their teachers used printed texts to conduct listening comprehension activities. When we compare the observations made by the English inspectorate of Burkina Faso and current practices, it can be inferred that this situation does not help attain the objectives of teaching/learning EFL. In order to help reach the EFL teaching/learning objectives, we have a wide range of resources such as digital audio-visuals which can help through the use of ICT resources for English learning. ICTs "include technologies such as desktop and laptop computers, software, peripherals, and connections to the internet that are intended to fulfil information processing and communications functions" (Statistics Canada, quoted by Amjad et al., 2016: 2). Singh, Cheok, and Ng (2005: 237) define audio-visual aids as "any device which by sight and sound increases the individuals' experience beyond that acquired through reading". They can be downloaded/uploaded and shared with other devices through file sharing systems. ICT provides online digital audio-visual aids which allow great choices and controls which can be adapted to the learners' needs. These audiovisual aids (AVs) are not only useful resources for the EFL teacher but a must since learners born around and after the year 2000 are "digital natives" as coined by Prensky (2001). This study tries to find out if digital AVs can help EFL teachers better than common teaching aids such as printed texts and tape recorders. Secondly, it aims at assessing the effectiveness of digital audio-visual aids in the EFL classes to enhance EFL learners' listening skills.

\section{Listening comprehension in the literature}

Definitions of listening comprehension have been provided by many scholars around the world, basically describing it as the ability to comprehend native speech at normal speed. Morley (1972) quoted in Cheug (2010:04) specifies that it "involves auditory discrimination, aural grammar, selecting necessary information, remembering it, and connecting it to the process between sound and form of meaning". It appears that listening is not a passive skill as assumed in the heyday of the Audio-Lingual Method. Hamouda (2013:117) also defines listening comprehension as "an interactive process in which listeners are involved in constructing meaning". In addition to these definitions, Nadig (2013) as quoted by Pourhosein (2016:124) says that "listening comprehension is the various processes of understanding and making sense of spoken language." Listening comprehension consists of the 
ability to make sense of what is heard and perform an inferred action i.e. doing something that the speaker asked to.

\section{Listening processes}

The listener resorts to two processes to make sense of the incoming information known as bottom-up and top-down listening. When the learner decodes the incoming sounds starting from the smallest unit to the complete text, it is called top-down processing. Top-down processing is explained as employing background knowledge in comprehending the meaning of a message. It requires background knowledge and a good command of the phonetics, grammar, and syntax of the language being listened to. Bottom-up processing is when the listener starts from the phonemes to complete texts. These processes are not mutually exclusive, and the listener may resort to checking or asking for clarification in an interactive mode. So, good listeners resort to different strategies and processes to make sense of the incoming data. Digital audio-visuals provide learners with visual effects such as gestures, facial expressions, and proxemics, kinetic clues which assist the learner in the processing of the message they hear.

\section{Listening strategies}

Comprehending listening passages requires processes and strategies so as to clearly grasp what is said. Learners resort to cognitive, meta-cognitive and socio-affective strategies as identified by Rost and Ross (1991). Cognitive strategies are related to understanding and gathering input in short-term memory or long-term memory for later use. Comprehension begins with the received information. Then, the listener examines the piece of information following levels of formation and a process of decoding the meaning. In the decoding process, the listener may use meta-cognitive strategies. These are strategies deployed when the listener uses extra knowledge to make sense of the incoming data. They can easily be used by proficient learners of the language. Salataci (2002) indicates that the use of metacognitive strategy in the listening process increases learners' self-confidence, motivation, and ability to complete the activities. Vandergrift (2003) and Abdalhamid (2012) define socio-affective strategies as techniques that listeners use to cooperate with others, to check their comprehension, and to reduce their apprehension. Apart from these strategies, there are listening strategies that Nunan (1999) identified and referred to as purposive listening strategies. For instance, we have listening for main idea, for specific information, listening for tone, listening for inference, etc. 


\section{ICT and listening}

Previous studies showed that students know about or use ICT and teachers must take advantage of it to improve students' performance by using them because today's students are "digital natives" and their teachers "digital immigrants” (Prensky, 2001:1-2).

The use of digital AVs in the classroom has been a subject of study for many linguists and educational researchers. Stempleski \& Arcario (1991) reveal five major tendencies in the use of video: (a) integration of video with other content; (b) teacher-made support materials; (c) teacher-house video production; (d) emphasis on aural/oral skills; (e) on cultural content. (Lonergan, (1992) and Forrest (1993).

In Burkina Faso, the integration of the digital audio-visuals in teachertraining dates back to the 90s with the National Institute of Education Science (INSE), Béogo (2016). It consisted in recording a teacher in a classroom. This recorded video was then used in the teacher-training college. It was used for in-service training to allow participants to reflect on their peers' weaknesses and strengths, to build on those strengths and attend to their weaknesses.

Furthermore, Nikièma (2016) conducted a survey to have insights on the impact of the digital audio-visuals on the new pedagogical approach called "Approche Intégratrice" (API), that is Integrative Approach which allows learners to gather and process without barriers between, study subjects. He found that teachers appreciate digital AVs, but this research was about digital audiovisuals in primary school teacher-training and aimed at helping teachers reflect on their peers' weaknesses and strengths to improve their daily classroom activities.

Some studies on listening comprehension were conducted in Burkina but they hardly ever involved an experimental approach to the use of digital AVs as undertaken in this one.

\section{Design and Methods}

\section{Study population}

The target population is art-oriented students of 2ndeA (Senior High School 1). Purposive sampling was used for this study. Students of 2 ndeA have been studying English for at least four years and can do some complex listening activities. Secondly, English is a compulsory subject for them. Furthermore, English is the third subject in terms of weighting in this level with a factor ${ }^{2}$ of 4 , after philosophy and French which have a factor of 5 each. 
The age range is $18-20$ according to the normal schooling system and they may be allowed to use cell phones.

\section{Sampling}

The students selected for this study were 18 years old or above and had smartphones or access to other devices which support digital AVs: students can use their parents', friends' or siblings' laptops, desktop or smartphones. According to the statistics of the 2016/2017 school year, the Région du Centre (Center Region) counts 65,194 second cycle students regardless of their options. This study involved students of Senior High School 1 (2ndeA) divided into two groups: a control group (CG) of 10 students and an experimental group (EG) of 11 students.

\section{The experiment}

The experiment consisted of a pre-test and a post-test used to gauge the impact of the intervention (experiment). It is divided into three phases: the situation before the experiment, the experiment itself and the situation after the experiment.

\section{The design of the experiment}

The research design is quasi-experimental. It is a term used to describe a research design that uses the same design and process as the experimental approach but which, for practical reasons, cannot meet one or the other essential element conditions (Denscombe, 2014).

In this study, students were randomly divided into two groups - one control group and one experimental group. Both groups had the same teacher and took the same activities in a Pre-test-Post-test designed for their level. The pre-test served as a baseline for comparison purposes. The post-test was used to see how the students performed after the experiment.

\section{Pre-test-Post-test}

A pre-test and a post-test were used i.e. tests before and after the treatment in order to gauge the impact of the experiment or treatment. Both tests consist of gap filling, multiple choice, and true/false questions to measure the learners' listening skills. Objective test items were used as they have intragrader and inter-grader reliabilities. They measure the extent to which the use of digital AVs improves the students' listening abilities. They test the students' ability to comprehend spoken discourse related to various language functions. 
There were 25 items subdivided into three different competence levels and each level covered two situations and language functions - asking for permission, asking for personal information, offering and ordering, advising, asking for people's activities, describing free time activities.

\section{Evaluation of the Pre-test-Post-test}

At the Post-tests, an improvement from the Pre-tests of the experimental group was expected. The experimental group was expected to outscore the control group by having medium to large effect according to Cohen's $d$. It is only when the effect size is medium and above, that it could be said that the use of digital audio-visuals was effective in improving EFL learners' listening skills.

\section{Findings and Discussion}

In this section, we have the findings of the Pre-test and the Post-test, the discussion of the results, and their implications. Two types of t-test were used. Independent T-tests are used when we compare two groups, that is between group comparison i.e comparing CG and EG. Paired Sample T-tests are employed when we compare the pre-test and post-test of the same group, that is within group comparison i.e. comparing the performances before and after the experiment of the same group.

\section{Findings of the Pre-test}

In order to control variables prior to the experiment, the pre-test was administered to serve as a baseline to find out whether there were statistically significant differences between the control and the experimental groups in terms of listening comprehension.

\section{Comparison between the performance of the students in Control Group and Experimental Group}

Table 1: Group statistics CG vs EG

\begin{tabular}{|l|c|c|c|c|c|}
\hline \multicolumn{7}{|c|}{ Group Statistics } \\
\hline Group & & $\mathrm{n}$ & Mean & $\begin{array}{c}\text { Std. } \\
\text { Deviation }\end{array}$ & $\begin{array}{c}\text { Std. Error } \\
\text { Mean }\end{array}$ \\
\hline Pre-test & CG & 10 & 11.400 & 1.1738 & .3712 \\
\cline { 2 - 6 } & EG & 11 & 10.182 & 1.8340 & .5530 \\
\hline
\end{tabular}

Source: Field data, 2018 
Table 2: Independent Samples Test CG vs EG

\begin{tabular}{|c|c|c|c|c|c|c|c|c|c|c|}
\hline & \multicolumn{2}{|c|}{$\begin{array}{c}\text { Levene's } \\
\text { Test for } \\
\text { Equality of } \\
\text { Variances }\end{array}$} & \multicolumn{7}{|c|}{ t-test for Equality of Means } \\
\hline & & \multirow[t]{2}{*}{$\mathrm{F}$} & \multirow[t]{2}{*}{ Sig. } & \multirow[t]{2}{*}{$\mathrm{T}$} & \multirow[t]{2}{*}{$\mathrm{df}$} & \multirow[t]{2}{*}{$\begin{array}{l}\text { Sig. (2 } \\
\text { tailed) }\end{array}$} & \multirow[t]{2}{*}{\begin{tabular}{|c|} 
Mean \\
Dif.
\end{tabular}} & \multirow[t]{2}{*}{$\begin{array}{c}\text { Std. } \\
\text { E } \\
\text { Dif. }\end{array}$} & \multicolumn{2}{|c|}{$\begin{array}{c}95 \% \\
\text { Confidence } \\
\text { Interval of the } \\
\text { Difference }\end{array}$} \\
\hline & & & & & & & & & Lower & Upper \\
\hline \multirow[b]{2}{*}{$\begin{array}{l}\text { Pre- } \\
\text { test }\end{array}$} & \begin{tabular}{|l} 
Equal \\
variances \\
assumed
\end{tabular} & 5.330 & .032 & 1.791 & 19 & .089 & 1.2182 & 6801 & -.2053 & 2.6417 \\
\hline & \begin{tabular}{|l} 
Equal \\
variances \\
not \\
assumed \\
\end{tabular} & & & 1.829 & 17.169 & .085 & 1.2182 & .6660 & -.1859 & 2.6223 \\
\hline
\end{tabular}

\section{Source: Field data, 2018}

Table 1 shows Independent T-Test result of Control Group (CG) and the Experimental Group (EG). We can see that the means of the Control Group (CG) and the Experimental (EG) are close. Table 2 shows the Levene's Test of Equality of variances where the groups are homogenous as Equal variances are assumed. The p-value, that is (sig. tailed), is .089 is well above 0.05 . We can infer that there is no statistically significant difference between both groups at the pre-test.

\section{Findings of the Post-test}

After the experiment, the same test was administered. When the pvalue (sig. tailed) is less than 0.05 , it can be inferred that the difference between the pre-test and the post-test is statistically significant. When it is above 0.05 , it means that the treatment had no significant impact on the students from the pre-test to the post-test and therefore the digital audio-visual aids do not help to improve EFL learners' listening skills. In case the mean scores of the pre-test and the post-test are statically significant, the effect size (d) was calculated according to the formula provided by Cohen: $d=\frac{\text { Mean }}{\text { SD }}$ to calculate the $d$ value. 
The referential framework to identify the effect size is as follows:

Table 3: The referential framework for identifying the effect size

\begin{tabular}{|l|l|}
\hline The d value (effect size) & Interpretation \\
\hline 0.2 till less than 0.5 & Small \\
\hline 0.5 till less than 0.8 & Medium \\
\hline 0.8 or more & Large \\
\hline
\end{tabular}

Source: Field data, 2018

Comparison between Control Group (CG) and Experimental Group after the treatment

Table 4: Group statistics CG vs EG

\begin{tabular}{|l|l|l|l|l|l|}
\hline \multicolumn{2}{|l|}{ Group } & $\mathrm{n}$ & Mean & Std. Deviation & Std. Error Mean \\
\hline \multirow{3}{*}{ Pre-test } & CG & 10 & 11.400 & 1.1738 & .3712 \\
\cline { 2 - 6 } & EG & 11 & 10.182 & 1.8340 & .5530 \\
\hline \multirow{2}{*}{$\begin{array}{l}\text { Post- } \\
\text { test }\end{array}$} & CG & 10 & 12.700 & 1.7670 & .5588 \\
\cline { 2 - 6 } & EG & 11 & 18.455 & 4.2039 & 1.2675 \\
\hline
\end{tabular}

Source: Field data, 2018 
Table 5: Independent Samples Test CG vs EG

\begin{tabular}{|c|c|c|c|c|c|c|c|c|c|c|}
\hline & \multicolumn{2}{|c|}{$\begin{array}{l}\text { Levene's } \\
\text { Test for } \\
\text { Equality of } \\
\text { Variances }\end{array}$} & \multicolumn{7}{|c|}{ t-test for Equality of Means } \\
\hline & & \multirow[t]{2}{*}{$\mathrm{F}$} & \multirow[t]{2}{*}{ Sig. } & \multirow[t]{2}{*}{$\mathrm{T}$} & \multirow[t]{2}{*}{ df } & \multirow[t]{2}{*}{$\begin{array}{l}\text { Sig. (2- } \\
\text { tailed) }\end{array}$} & \multirow[t]{2}{*}{$\begin{array}{c}\text { Mea } \\
\mathrm{n} \\
\text { Diff. }\end{array}$} & \multirow[t]{2}{*}{$\begin{array}{l}\text { Std. } \\
\text { Error } \\
\text { Diff. }\end{array}$} & \multicolumn{2}{|c|}{$\begin{array}{c}95 \% \\
\text { Confidence } \\
\text { Interval of } \\
\text { the } \\
\text { Difference }\end{array}$} \\
\hline & & & & & & & & & Lower & Upper \\
\hline \multirow[t]{2}{*}{$\begin{array}{l}\text { Pre- } \\
\text { test }\end{array}$} & $\begin{array}{l}\text { Equal } \\
\text { variances } \\
\text { assumed }\end{array}$ & 5.330 & .032 & 1.791 & 19 & .089 & 1.2182 & .6801 & -.2053 & 2.6417 \\
\hline & $\begin{array}{l}\text { Equal } \\
\text { variances } \\
\text { not } \\
\text { assumed }\end{array}$ & & & 1.829 & 17.169 & .085 & 1.2182 & .6660 & -.1859 & 2.6223 \\
\hline \multirow[t]{2}{*}{$\begin{array}{l}\text { Post- } \\
\text { test }\end{array}$} & $\begin{array}{l}\text { Equal } \\
\text { variances } \\
\text { assumed }\end{array}$ & 6.419 & .020 & -4.011 & 19 & .001 & -5.7545 & 1.4346 & -8.7572 & -2.7519 \\
\hline & $\begin{array}{l}\text { Equal } \\
\text { variances } \\
\text { not } \\
\text { assumed }\end{array}$ & & & -4.154 & 13.690 & .001 & -5.7545 & 1.3852 & -8.7319 & -2.7772 \\
\hline
\end{tabular}

\section{Source: Field data, 2018}

Tables 4 and 5 show Independent T-Test results of Control Group and the Experimental Group (EG). The means of the Control Group (11.4) and the Experimental (10.2) are close at the pre-test whereas the EG scored better than CG at the post-test (18.5 vs. 12.4). The Levene's Test of Equality of variances shows that the groups are homogenous as Equal variances are assumed. The p-value was .085 at the pre-test and 0.001 at the post-test. Since there was no significant difference between both groups at the pre-test, the difference at the post-test is considered to be due to the treatment. It can, therefore, be concluded that EG outscored CG at the post-test and the treatment was effective. In the next tables, Paired Samples statistics will be used to show how well each group did compared with its performances at the pre-test and post-test. 
Comparison between the pre-test and post-test of each group Performance of Control Group (CG)

Table 6: Paired Samples Statistics CG

\begin{tabular}{|l|l|r|r|r|r|}
\hline \multicolumn{2}{|c|}{} & \multicolumn{1}{c|}{ Mean } & $\mathrm{n}$ & \multicolumn{1}{c|}{$\begin{array}{c}\text { Std. } \\
\text { Deviation }\end{array}$} & $\begin{array}{c}\text { Std. Error } \\
\text { Mean }\end{array}$ \\
\hline $\begin{array}{l}\text { Pair } \\
1\end{array}$ & Pre-test & 11.400 & 10 & 1.1738 & .3712 \\
\cline { 2 - 6 } & Post-test & 12.700 & 10 & 1.7670 & .5588 \\
\hline
\end{tabular}

Source: Field data, 2018

Table 7 : Paired Samples Correlations CG

\begin{tabular}{|l|l|r|r|r|}
\hline \multicolumn{2}{|c|}{} & $\mathrm{n}$ & Correlation & Sig. \\
\hline Pair 1 & $\begin{array}{l}\text { Pre-test \& Post- } \\
\text { test }\end{array}$ & 10 & .118 & .746 \\
\hline
\end{tabular}

Source: Field data, 2018

Table 8: Paired Samples Test CG

\begin{tabular}{|c|c|c|c|c|c|c|c|c|c|}
\hline & \multicolumn{5}{|c|}{ Paired Differences } & \multirow[t]{3}{*}{$\mathrm{t}$} & \multirow[t]{3}{*}{$\mathrm{df}$} & \multirow{3}{*}{\begin{tabular}{|c|} 
Sig. \\
$(2-$ \\
tailed)
\end{tabular}} \\
\hline & & \multirow[t]{2}{*}{ Mean } & \multirow[t]{2}{*}{$\begin{array}{c}\text { Std. } \\
\text { Deviation }\end{array}$} & \multirow[t]{2}{*}{$\begin{array}{l}\text { Std. } \\
\text { Error } \\
\text { Mean }\end{array}$} & \multicolumn{2}{|c|}{$\begin{array}{c}95 \% \\
\text { Confidence } \\
\text { Interval of the } \\
\text { Difference }\end{array}$} & & & \\
\hline & & & & & Lower & Upper & & & \\
\hline Pair 1 & $\begin{array}{l}\text { Pre-test } \\
\text { - Post- } \\
\text { test }\end{array}$ & -1.3000 & 2.0028 & .6333 & -2.7327 & .1327 & -2.053 & 9 & .070 \\
\hline
\end{tabular}

Source: Field data, 2018

Tables 6, 7, and 8 show that students who were not exposed to the use of the audio-visual aids during the experiment did not improve after the experiment as there is no statically significant difference in scores on both tests. The pvalue is .070 and it is above the $0.05,(p>0.05)$.

\section{Performance of Experimental Group (EG)}

Table 9: Paired Samples Test EG

\begin{tabular}{|c|c|c|c|c|c|}
\hline \multicolumn{2}{|c|}{} & Mean & $n$ & Std. Deviation & $\begin{array}{c}\text { Std. Error } \\
\text { Mean }\end{array}$ \\
\hline \multirow{2}{*}{ Pair 1 } & Pre-test & 10.182 & 11 & 1.8340 & .5530 \\
\cline { 2 - 6 } & Post-test & 18.455 & 11 & 4.2039 & 1.2675 \\
\hline
\end{tabular}

Source: Field data, 2018 
Table 10: Paired Samples Correlations EG

\begin{tabular}{|l|l|l|l|l|}
\hline \multicolumn{2}{|l|}{} & $\mathrm{n}$ & $\begin{array}{l}\text { correlati } \\
\text { on }\end{array}$ & Sig. \\
\hline Pair 1 & Pre-test \& Post-test & 11 & .559 & 0.74 \\
\hline
\end{tabular}

Source: Field data, 2018

Table 10: Paired Samples Test EG

\begin{tabular}{|c|c|c|c|c|c|c|c|c|c|}
\hline & \multicolumn{5}{|c|}{ Paired Differences } & \multirow[t]{3}{*}{$\mathrm{T}$} & \multirow[t]{3}{*}{$\mathrm{df}$} & \multirow{3}{*}{$\begin{array}{l}\text { Sig. } \\
(2- \\
\text { tailed })\end{array}$} \\
\hline & & \multirow[t]{2}{*}{ Mean } & \multirow[t]{2}{*}{\begin{tabular}{c|} 
Std. \\
Deviation
\end{tabular}} & \multirow[t]{2}{*}{$\begin{array}{l}\text { Std. } \\
\text { Error } \\
\text { Mean }\end{array}$} & \multicolumn{2}{|c|}{$\begin{array}{l}95 \% \text { Confidence } \\
\text { Interval of the } \\
\text { Difference }\end{array}$} & & & \\
\hline & & & & & Lower & Upper & & & \\
\hline ir 1 & \begin{tabular}{|l} 
Pre-test \\
- Post- \\
test
\end{tabular} & -8.2727 & 3.5239 & 1.0625 & -10.6401 & -5.9053 & -7.786 & 10 & .000 \\
\hline
\end{tabular}

\section{Source: Field data, 2018}

Tables 9, 10, and 11 show that the Experimental Group (EG) students who were exposed to the use of the digital audio-visual aids during the experiment did something different at the post-test. This difference in score shows that EG students performed better than those of the Control Group who were not exposed to the digital AVs. The observed level of significance for the test is 0.00 ( $\mathrm{p}<0.05)$. This points to the fact that the performance of the Experimental Group (EG) which took part in the experiment is statistically more significant than that of the Control Group. Therefore, it can be concluded that they improved after the experiment thanks to the use of digital audio-visuals. For more reliability and to measure the extent to which the experiment was effective, the effect size on students' listening skills was computed according to the formula suggested by Cohen (2013). The calculated effect size for the Experimental Group is (2.34) $>0.8$. Therefore, it can be inferred that the use of digital AVs had a very large effect on the students' listening performance at the post-test. 
Figure 1 shows the improvement of each group after the experiment and the Mean scores of the CG and EG at Pre-test and Post-test.

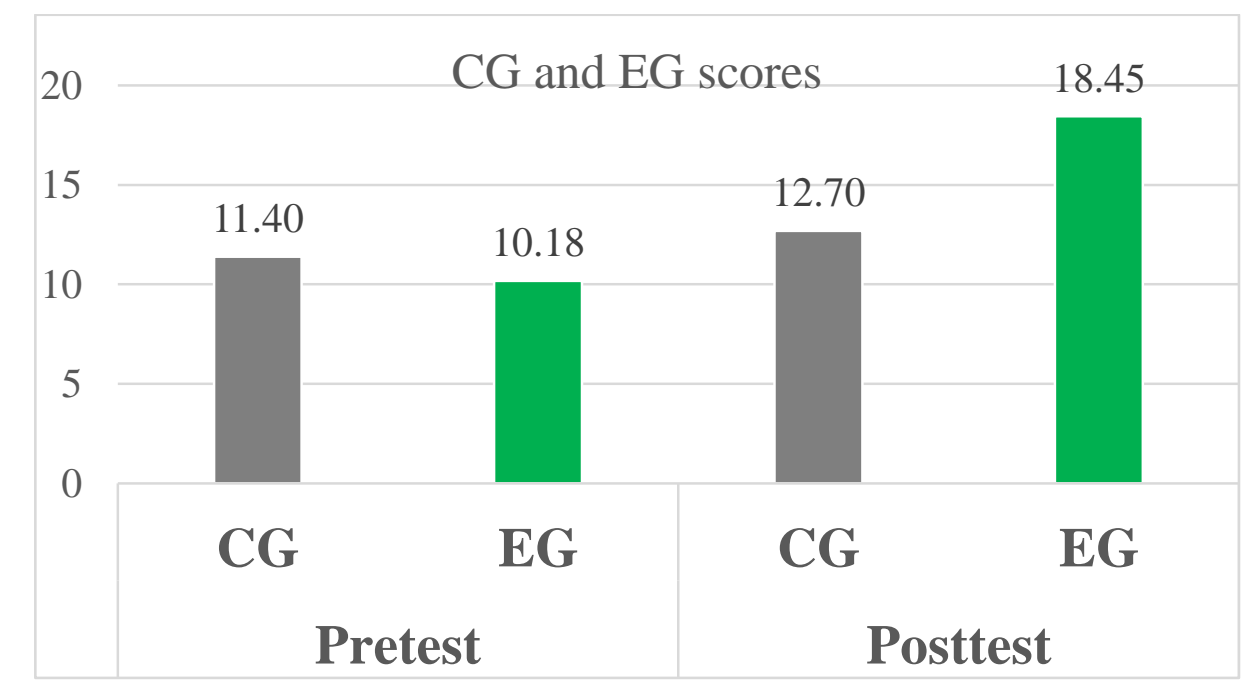

Source: Field data, 2018.

\section{Discussion}

The analysis of the results shows that the use of digital audio-visual aids in the EFL classroom is beneficial to the learners. At the Pre-test, all the students regardless of their groupings were similar. The equalities of variances were assumed in the two groups from each class and there were no significant differences between all the groups at each level (See Tables 1-2).

The experiment revealed that the listening skills of students have improved. For instance, the mean score of the Control Group of (CG) at the pre-test was 11.4 and their mean score at the post-test was 12.4. The sample paired test showed that both groups made some progress when we look at the mean scores of the groups. The paired samples statistics using SPSS v.21.0 showed that the progress made by the Control Group was not statistically significant. The difference from pre-test to post-test is statistically significant in the Experimental Group. EG moved from 10.82 to 18.45. The progress they made was large according to the effect size calculated using Cohen's $d$. The effect size calculation helped to measure the strength of each teaching aid/method.

The experiment revealed that the use of digital AVs is effective with the students as the results were significant in the experimental group. This study revealed that the use of the digital AVs is effective in enhancing EFL learners' listening skills. Students may have access to other learning 
opportunities but the smartphone friendly AVs constitute stimulus for permanent learning as reported by students themselves. Once home, students resort to people around them to make sense of what they watch. It leads students to use Socio-affective strategies. Digital AVs provide students with linguistic clues to better understand the spoken passage. Purdy (1997) once observed that listeners do not passively absorb the words, but actively attempt to grasp the facts and feelings in what they hear by attending to what the speaker says, to how the speaker says it, and to the context in which the message is delivered.

As the digital AVs greatly impacted students' listening, it was also observed that they significantly impacted on their speaking as well. This shows that using digital AVs is very important in listening and speaking as the feeling, setting and the context are clear in the audio-visual. Dike (1993:87) stated that "once the phenomenon is visualized, the picture and knowledge become very clear and permanent".

Doosuur \& Sandra (2013: 45) said that:

audio-visual materials when effectively used have these advantages: they lessen major weaknesses, provide verbalism, humanize and vitalize subject matter, provide an interesting approach to new topics, give initial correct impressions, save time in learning, supply concrete materials needed, and stimulate listeners' initiative.

Natoli (2011:102) once added that "audio-visual materials are rich opportunities for students to develop communication skills while actively engaged in solving meaningful problems". The statistical analysis gives evidence that the use digital AVs enhances EFL learners' listening skills and this also infers that digital AVs have positive effects in the listening process and lessen difficulties and impediments that the learners encounter.

Swank (quoted in Akinwole, 2015:54) said that digital audio-visuals "are effective in learning as $40 \%$ of our concepts are based upon visual experience, $25 \%$ upon auditory, $17 \%$ upon tactile, $15 \%$ upon miscellaneous organic sensation and 3\% upon taste-smell". This buttresses the opportunity of permanent learning that digital AVs offer. Moreover, Fawcett (1994) quoted in Akinwole (2015:54) pointing the contributing role of audio-visual materials in stimulating interest stated that "A friendly, accepting group climate is important in any learning situations, especially those materials that require students to reveal their ignorance and confront their fellow students". When there is a climate of acceptance for learning, then learning is stimulated. The statistical analysis gives evidence that the use of digital AVs enhances EFL 
learners' listening skills. The effectiveness in listening comprehension showed that digital AVs have positive effects in the listening process of the learners. This effectiveness also impacted students' speaking throughout the experiment.

\section{Conclusion}

This study showed that digital AVs are effective in alleviating factors affecting EFL learners' listening comprehension. While students' listening skills were improving, it was noticed that, listening was pivotal in the acquisition of other skills and learners used diverse strategies to process it. After all, speaking is the skill which combines with listening to open doors wherever good communication is a prerequisite such as job interviews and business doing. The integration of ICT and digital in the language classroom allows teachers to keep pace with the fast digitalizing world and adapt to learners' learning styles. The findings imply that the ongoing teaching aids improve students' listening skills but it is very limited when compared to the digital audio-visuals. With digital natives as coined by Prensky (2001), the EFL curricula and syllabi should include the digital AVs to help learners improve their listening skills and provide opportunities for permanent learning. This study purported to investigate the effectiveness of digital AVs in improving EFL students' listening comprehension. From the results obtained after the experiment we can conclude that Smartphones are ICT materials which are helpful in the teaching and learning of listening comprehension and digital AVs are good alternatives to printed texts, reading aloud and tape recorders in listening comprehension.

\section{Notes}

1. Our translation of an excerpt of Circular 1983-105/MENA/ICESD of Ministry of education and culture of Burkina Faso on Foreign Language Teaching

2. Weight of grades in a given study subject. It ranges from 2 to 5 in Senior High School Year 1(2ndeA).

\section{References}

Abdalhamid, F. (2012). Listening comprehension strategies of Arabic-speaking ESL learners. (Master's Thesis). Colorado State University, USA.

Amjad, A., Ahmad, R. Jafar , I. (2016). ICT applications and user satisfaction in Aligarh Muslim University, Aligarh: a survey. Library Philosophy and 
Practice. Retrieved from https://go.galegroup.com/ps/i.do?id=GALE $\% 7 C A 471851640 \&$ sid $=$ googleScholar\&v $=2.1 \& \mathrm{it}=\mathrm{r} \&$ linkaccess $=\mathrm{abs} \& \mathrm{i}$ $\mathrm{ssn}=15220222 \& \mathrm{p}=\mathrm{AONE} \& \mathrm{sw}=\mathrm{w}$ on June 15, 2018.

Akinwole, O. I. (2015). The Effects of Audio-Visual Materials in the Teaching and Learning of the Speaking Skill in Junior Secondary Schools. International Journal of Social Science and Humanities Research, Vol. 3(Issue 3,), 50-58.

Béogo, J. (2016). Continuing Professional Training of Teachers in Burkina Faso: The Movie as a Fundamental Alternative System. Revue de Philosopbie, Littérature et Sciences Humaines, 003(007), 564-577.

Cohen, J. (2013). Statistical power analysis for the behavioral sciences. Routledge.

Denscombe, M. (2014). The good research guide: for small-scale social research projects: McGraw-Hill Education (UK).

Dike, V. W. (1993). Library resources in education: Abic Publishers.

Doosuur, A.\& Sandra M. I., (2013). The Use of Audio-Visual Materials in the Teaching and Learning Processes in Colleges of Education in Benue State-Nigeria. Journal of Research \& Method in Education. Vol 1(6), 44-55.

Dramé, S. (2008). Teaching Listening Comprehension. (Dissertation submitted for Advanced certificate for teacher supersvision), University of Koudougou, Koudougou.

Forrest, T. (1993). Technology and the language classroom. Available technology. TESOL quarterly, 27(2), 316-318.

Hamouda, A. (2013). An Investigation of Listening Comprehension Problems Encountered by Saudi Students in the EL Listening Classroom. International Journal of Academic Research in Progressive Education and Development, 2(2), 113155.

Lonergan, J. (1992). Using a video camera to evaluate learners' classroom performance. Video in second language teaching: Using, selecting, and producing video for the classroom, 93-105.

Natoli, C. (2011). The Importance of Audio-Visual Materials in Teaching and Learning. Retrieved from https://www.helium.com/channels/224-earlychildhood-edu on February, 20, 2016. 
Nikièma, N. J. (2016). Apport des supports audio-visuels dans la formation continue des enseignants de l'éducation de base primaire au Burkina Faso : cas de la vidéo intitulée "calcul : décomposition soustractive du nombre 15 au CP1 » utilisée en vue de l'expérimentation de l'Approche Pédagogique Intégratrice(API). (TeacherTraining), University of Koudougou, Koudougou, Burkina Faso.

Nunan, D. (1999). Second Language Teaching \& Learning. Heinle \& Heinle Publishers, 7625 Empire Dr., Florence, KY 41042-2978.

Retrieved from https:// eric.ed.gov/?id=ED441344 on June 30, 2017.

Perraton, H., Robinson, B., \& Creed, C. (2001). Teacher Education through Distance Learning: Technology, Curriculum. Evaluation, Cost. Paris. UNESCO.

Pourhossein Gilakjani, A. (2016). English pronunciation instruction: A literature review. International Journal of Research in English Education, 1(1), 1-6.

Pourhosein Gilakjani, A., \& Sabouri, N. B. (2016). How can students improve their reading comprehension skill. Journal of Studies in Education, 6(2), 229-240.

Prensky, M. (2001). Digital natives, digital immigrants part 1. On the horizon, 9(5), 1-6.

Rost, M., \& Ross, S. (1991). Learner use of strategies in interaction: Typology and teachability. Language learning, 41(2), 235-268.

Salataci, R. (2002). Possible effects of strategy instruction on L1 and L2 reading. Reading in a foreign language, 14(1), 1.

Singh, S., Cheok, A., \& Ng, G. (2005). Mobile platform. In: Google Patents.

Stempleski, S., \& Arcario, P. (1991). Video and ESL in the US: Pilot survey results. TESOL Video News, 10.

The English Inspectorate of Burkina Faso (2011). Gè to 3è Class Syllabuses. Ministry of Education, Burkina Faso.

Vandergrift, L. (2003). Orchestrating strategy use: Toward a model of the skilled second language listener. Language learning, 53(3), 463-496. 


\title{
A Critique of the Images of Heaven in the Scriptures of The Abrahamic Religions: An Existentialist Perspective.
}

\author{
Raymond Nonnatus Osei \& Husein Inusah \\ University of Cape Coast, Cape Coast, Ghana.
}

\begin{abstract}
In this paper, we critically examine the scriptural images of heaven as captured in the Abrahamic religions from the existentialist perspective. The three dominant Abrahamic religions: Judaism, Christianity and Islam opine that there is life beyond this earthly existence for all human beings and that God (their object of worship) has prepared a special place of eternal happiness for those who obey His commands on earth. This place is frequently referred to as the Kingdom of God, Heaven or Paradise. We argue that the above construct of heaven throws up a lot of problems, especially from the existentialist perspective. Some of these problems include the fact that these constructs of heaven eliminate all the challenges that stimulate human existentiality, throw into oblivion the scourging evils of boredom arising from the eternal passivity of existence in heaven and fail to lay down exactly the political structure and the legal status of the earthlings in heaven since a Kingdom presupposes a feudalist structure where there are kings, lords and serfs. We conclude by showing that the scriptures' constructs of heaven appear self-contradictory and fail to strike a chord with the contemporary image of the ideal society when perused from the existentialist perspective and should, therefore, be discarded.
\end{abstract}

Keywords: Abrahamic Religions; Boredom; Christianity; Existentialism; Heaven; Islam; Judaism; Kingdom; Scriptures.

\section{Introduction}

On this occasion of celebrating the life and achievements of our illustrious Professor and friend, we deem it appropriate to spend a few moments to reflect on a phenomenon that is all too familiar to us, and yet we 
wish it to be at least at arm's length. After all our dear Professor and friend is at the twilight of his life and death is a looming reality that he can't ignore.

As human beings, we are condemned to bite the bullet but we shudder at the prospects, and we do all that we can to escape, alas in vain, that finality. Hence, we have risen rich and soothing narratives that assure us of an afterlife that reduces the harsh finality into a transition: from the brutish human existence here on earth to a life of perpetual bliss bereft of pain and anguish. This is the incentive that the mainstream Abrahamic religions: Judaism, Christianity and Islam dangle before our eyes. It is a powerful motif that has urged the mass of the human population over time and across diverse cultures to endure brutish experience and senseless pain with equanimity. Their endurance and resilience are built on the hope that all this suffering is not for nothing; that there will be a just reward after this hardship. Otherwise, the world will be unfair, that your maker, Yahweh, God, Allah will be unjust.

So there is a powerful motivation for humans through their religious expression to hold up a form of existence befitting them even if that life happens to elude them here on earth. That, of course, is the hereafter life popularly known as Paradise, Heaven or the Kingdom of God. Let us then gaze into this imagined life of post-mortem existence and see what awaits us. We must warn you that the texture of the narratives of the hereafter life is rich and diverse, not only across the different religions but even within the same religion across epochs and geography. But due to lack of space, we will pick from each of the three religions the most popular and enduring images in contemporary times. But before then let's quickly take a look at some of these imagined conceptions of afterlife for the purposes of clarification and delimitation.

\section{The Concept of Afterlife}

The terminology "afterlife" may seem an ambiguous phraseology, given that its connotation is diverse across religious and demographic divide and even individual religions. Therefore, a suitable definition is needed in order to develop a meaningful discourse on any subject matter of the concept of an afterlife. One of the meaningful ways of defining the term is to construe it as the prolongation of life after biological or bodily death. This construal refers to a folk definition of the afterlife and has roots in the scriptures of the three Abrahamic religions. Another means of defining the afterlife is to construe it as the direct vision of God - what St. Thomas Aquinas calls "Visio beata" or the "beatific vision" of God. ${ }^{1}$ This also has roots in the scriptures. The third way of defining the concept of the afterlife is to suggest a neardeath-like experience where human consciousness and all sensory experiences 
are retained. This is what scholars have called the theory of natural afterlife (Ehlmann 2016: 2). ${ }^{2}$ Let us for the purpose of this presentation construe the term "afterlife" to mean the prolongation of consciousness after biological death or the continued existence of the self after bodily death. There are reasons for going on this trajectory - the second and the third ways of construing the concept of the afterlife, as shown above, are quasi-natural of some sort. For instance, the beatific vision is not necessarily meant to occur in the afterlife; it can also manifest when one is alive on earth in the form of direct self-communication with God. Hence, the way it is sketched fails to strike a chord with the picture we have of the eternal and self-direct communication with God in the hereafter. That is to say, it fails to capture St. Thomas Aquinas' intuition about eternal happiness when one is directly experiencing God after bodily death. The beatific vision is said to be an intellectual conception because it cautions believers from imagining the afterlife. It places in the minds of people a kind of perpetual suspense to prevent believers from trying to imagine what the afterlife would be like. ${ }^{3}$ This picture of heaven as beatific vision digresses from the way we intend to conceive of an afterlife, especially the heavenly portion of it that finds expression in the scriptures. Our focus is on examining the images of the heavenly portions of the afterlife to see if they are consistent with human existentiality.

In a similar vein, conceiving the afterlife in a natural sense is also not consistent with our position since we are examining some sort of supernatural afterlife - an imagined post-mortem existence after biological death - the one that occurs after the body and the soul are reunited for judgment in the hereafter. This latter version of the afterlife is consistent with some of the images of heaven depicted in the scriptures of the Abrahamic religions that we intend to examine. It depicts a kind of image that signifies the prolongation of life on earth after our bodily death. This to us raises an existential concern: if the afterlife is a continuation and manifestation of our earthly life, how would it accommodate human existentiality? Imagine a life without its usual and familiar challenges: making awkward choices, making decisions, the freedom to choose and take responsibility, the sense of achievement or failure, the fear of the unknown and the future. These are the challenges that stimulate human existentiality. In the absence of these challenges, the greatest existential evil that stares us in the face is boredom. Life without challenges is inevitably boring. Imagine a life that knows no needs, where efforts have no value or motivation. Is it any different from the life of a vegetable? What will be the normal life circle of the earthlings in this paradise? Is life worth living in Abrahamic heaven? 
Another crucial aspect we will explore in the scriptures' images of heaven concerns its political structure. Routinely referred to as the Kingdom of Heaven, one wonders what would be the political structure and legal status of the earthlings in this Kingdom. What rights and freedoms would they be entitled? For a kingdom evinces a feudalist structure of state where there are Kings, Lords/Barons and Serfs - each class having differing rights to property and other freedoms including political power. What then would be the status of the earthlings in God's Kingdom?

These are some of the things this presentation seeks to explore. We will show that the scriptural image of Heaven in the Abrahamic religions is: 1) self-contradictory when analyzed from the existentialist perspective and 2) strikes no chord with the contemporary image of the ideal society and should, therefore, be jettisoned.

As noted, we shall focus only on the heavenly aspect of the hereafter, what is usually referred to as the heaven or paradise - a place prepared by God for those who obey His commands while on earth. Now, let us take a brief look at some of these images of heaven in the three Abrahamic Religions.

\section{The Description of Heaven in Judaism}

Jews do not have a comprehensive description of heaven in the Torah. However, evidence abounds in the Judaist scriptures about the heaven and the nature of the hereafter, popularly known in Judaism as "Olam $\mathrm{Ha}-\mathrm{Ba}$ " "the world-to-come” (Wright 2000 p. 203).

Whoever contemplates four things, it would have been better for him if he had not come into the world - that which is above, that which is beneath, that which is before time, and that which will be hereafter (Mishnah, Hagiga 2:1).

As pointed out, the construal of heaven in Judaism is not that spectacular like that of the other two Abrahamic religions, Christianity and Islam. One does not encounter splendour and beauty of heaven in the Torah as we see in the Bible and the Quran. However, the Judaist text of Shi 'ur Qomah depicts heaven, the world-to-come, as a place that offers security from the tribulation of this world. The following are a few passages from the Judaist text of Shi 'ur Qomah that detail the description of the heaven in Judaism:

All who know this secret are certain to enter the world-tocome. The Holy One, Blessed be He, will rescue him from every evil thing - all kind of sorcery, the evil eye, the evil 
inclination, evil thoughts, all kinds of destroyers, all kind of damages, poverty and evil plans (Sepher HaQomah 24-27).

Whoever knows this measurement of his Creator and the glory of the Holy One, blessed be he, is secured in this world and in the world to come. He lives long in this world, and he lives long and well in the world-to-come. He does good in this world and in the world-to-come. Rabbi Ismael said, 'I and Rabbi Aqiba guarantees this, that in this world such a one has a good life and in the world-to-come a good name, but only if he recites this as Mishnah every day (Spher HaQomah 121-127). "Rabbi Jacob said, 'this world is like a foyer to the world-tocome; prepare yourself in the foyer so that you may enter into the banquet hall." (Mishnah, Avot 4:16).

The lesson drawn from the above literature is that the Judaists envisage a world that comes after this world where dwellers of this world-to-come will enjoy total security from the harsh troubles of this world, a place where one will enjoy a life of perpetual bliss.

\section{The Description of Heaven in Christianity}

For most Christians, heaven is the final goal of life. Hence, heaven is seen as an eternal abode of life where every comfort can be afforded without personal effort; where time ceases and where the righteous are rewarded for their good deeds. For instance, we find one of such descriptions of heaven in the Revelations, The final book of the New Testament. It reads:

Then one of the elders asked me, "These in white robes-who are they, and where did they come from?" I answered, "Sir, you know." And he said, "These are they who have come out of the great tribulation; they have washed their robes and made them white in the blood of the Lamb. Therefore, - they are before the throne of God and serve him day and night in His temple; and He who sits on the throne will shelter them with His presence. - Never again will they hunger; never again will they thirst. The sun will not beat down on them, nor any scorching heat. For the Lamb at the center of the throne will be their shepherd; He will lead them to springs of living water. And God will wipe away every tear from their eyes. (Revelation 7:14-17). 
Another verse of the Revelation offers a description of an eternal life devoid of sunlight in a timeless environment. It says the following: "There will be no more night. They will not need the light of a lamp or the light of the sun, for the Lord God will give them light. And they will reign forever and ever". (Revelation 22:5)

In Isaiah, there is a description of heaven showing life without bloodshed where human beings and wild animals live together in peace. This verse reveals an eternal abode devoid of all life challenges and tribulations; it reveals an environment bereft of competition, wants, and desires. It reads: "nations shall beat their swords into plowshares, and their spears into pruning hooks; nation shall not lift up sword against nation, neither shall they learn war anymore." (Isaiah 2:4).

One may find in the Bible two speculations about the Christian heaven in the New Testament. In one of such speculations, heaven is located in the clouds. This description is seen in the Thessalonians:

According to the Lord's word, we tell you that we who are still alive, who are left until the coming of the Lord, will certainly not precede those who have fallen asleep. For the Lord himself will come down from heaven, with a loud command, with the voice of the archangel and with the trumpet call of God, and the dead in Christ will rise first. After that, we who are still alive and are left will be caught up together with them in the clouds to meet the Lord in the air. And so we will be with the Lord forever. Therefore encourage one another with these words. (1 Thessalonians 4:15-18).

In contrast to this construal of heaven as beyond the sky, there is another speculation of heaven, The "New Jerusalem that comes down from heaven". The writer of the Revelations reports the following:

I saw the Holy City, the New Jerusalem, coming down out of heaven from God, prepared as a bride beautifully dressed for her husband. And I heard a loud voice from the throne saying, Look! God's dwelling place is now among the people, and he will dwell with them. They will be his people, and God himself will be with them and be their God. He will wipe every tear from their eyes. There will be no more death or mourning or crying or pain, for the old order of things has passed away (Revelation 21:2). 
This shows that God will not transport the righteous to heaven as suggested in the Thessalonians but will remodel the earth into an Edenic paradise where righteous Christians will have an eternally joyous and comfortable life.

\section{The Description of Heaven in Islam}

Like Judaism and Christianity, heavenly speculations are an integral part of a Muslim's spiritual life. Generally, Muslims believe that at death, people will be judged on the basis of their deeds on earth. Those found to be righteous will inherit paradise, "Al-Jana" and those found to be impure will be transported to the hell of perpetual flame, "Jaha' nam." Pious Muslims are told to envisage a paradise adorned with every stripe of beauty one could imagine. The Quran depicts the dwellers of heavens as royals robed in royal garments according to ranks who enjoy every comfort without any effort:

"They will recline (with ease) on Thrones (of dignity) arranged in ranks..." (52: 20).

They and their associates will be in groves of (cool) shade, reclining on Thrones (of dignity). Every fruit (enjoyment) will be there for them; they shall have whatever they call for (36:5657).

In a lofty Paradise, where they shall neither hear harmful speech nor falsehood. Therein will be a running spring. Therein will be thrones raised high, and cups set at hand. And cushions set in rows, and rich carpets (all) spread out (88:1016).

\section{Existential Challenges of Heaven}

To make sense of these images from the existentialist perspective requires that we first define the term existentialism. The nomenclature is notorious for what it is not rather than for what it is. In other words, existentialism is not a body of doctrines. In fact, existentialists share a common character of opposition to any doctrine. It started as a movement against the traditional method of philosophizing represented in Plato, Aristotle and culminating in Rene Descartes. In brief, existentialists railed against the formalism and abstract and impersonal orientation of traditional philosophy that was oblivious of the real material and psychological needs of the living person. 
A human being is born, grows up and becomes a self-conscious person. It is only when she/he becomes a self-conscious person that she/he is recognized as an autonomous and moral being. Coming of age brings with it a host of freedoms and responsibilities. From the existentialist perspective, it is these freedoms and responsibilities that define what life is all about. The individual in this familiar world is confronted with choices on a daily basis: when to sleep, when to wake up, when to go to work or not go to work, etc.

Besides these routine choices we are equally confronted with situations when we have to make momentous and at times, unpleasant choices - choices whose outcomes often cannot be anticipated. For the existentialists, the hallmark of living a life is the freedom to make choices and take responsibility for the choices we make. In other words, it is about a history of the challenges that confronted the subject and how she/he strove to overcome those challenges. That is how we grade the famous and not so famous and the ignoble. It is by our achievement that we are remembered. How then are we to grade the life in Paradise, Heaven or the Kingdom of God?

From the narratives of the images of heaven presented in the three scriptures, what is striking about post-mortem existence is a life free from the pains and travails of life that are all too familiar here on earth. It is a life that apparently doesn't require any effort for enjoying perpetual bliss - a life of eternal happiness without risks, without challenges. Trapped in a perpetual cycle of ecstasy evokes the image of a subject soaked in opioid solution who drifts away on the wings of a butterfly, forever for eternity - a life without effort and no sense of achievement.

Let us borrow a page from the founder of the existentialist frame of thought, Soren Kierkegaard. In his novel titled, Either / Or, he depicts three possible forms of life that each individual is bound to choose one.

1. The aesthete: You have only one life to live, so you might as well arrange to make it enjoyable. It is true that the kind of ironic detachment this requires means that life is ultimately meaningless and that there are no serious choices, but that's just how life is.

2. The ethicist. life is neither this way nor that; it all depends on what you do with it. And that is a matter of choice, the sort of serious choice that constitutes a continuing self. You are what you make of yourself. And far from being meaningless nothing could possibly matter more.

3. The Christian: you can't successfully create yourself. We are all failures at this task. What is required is an acknowledgement of this fact, together with faith in God's forgiveness through Christ. In this way we can come to accept ourselves in spite of our unacceptability; only thus can we be free simply to be ourselves (Kierkkegaard 1987). 
Now, running through these three forms of life is the imperative of making choices that would define your person. It is the availability of choice that differentiates a person from a non-person, say, a vegetable. At least engaged in the business of making a choice rids oneself of what is considered as the greatest evil: boredom. Kierkegaard's notes as follows:

Boredom is the root of all evil. This can be traced back to the very beginning of the world. The gods were bored; therefore they created human beings. Adam was bored because he was alone; therefore Eve was created. Since that moment, boredom entered the world and grew in quantity in exact proportion to the growth of the population. Adam was bored alone; then Adam and Eve were bored together; then Adam and Eve and Cain and Abel were bored en famille. After that, the population of the world increased, and the nations were bored en masse. To amuse themselves, they hit the notion of building a tower so high that it would reach the sky. This notion is just as boring as the tower was high and is a terrible demonstration of how boredom had gained the upper hand (Kierkegaard 1987, pp. 285-286).

For the existentialist then boredom remains a major vice that must be avoided at all costs. Imagine an afterlife where virtually all sustainable choices have been made for you. There would be no need for exertion because there is virtually nothing to achieve. All our desires are fulfilled in a twinkle of an eye. And there is apparently no restraint in satisfying your desires including things such as wine, table and bed and this feast can go on forever. This is nothing short of life of sloth and indolence portrayed in John Keats "Ode on Indolence" (Vendler 1985).

One may raise a protest that such imagined afterlife depicted in the scriptures is hinged on the choice we have made on earth. Hence, the life of perpetual bliss to be enjoyed in our post-mortem existence is the reward of the choice we made to endure the pain of this life with equanimity. This protest may be right. But this flies in the face of the objective of this paper. We do not deny that God may reward good deeds with the splendour, beauty and eternal comfort in the hereafter. But the crucial question that we seek answers is: what is the nature of this eternal life in heaven? Is this life worth living, given that it is bereft of choices, risks and decision-making which characterize human existence? Our contention is that not only is such life not worth living but it is also practically inconceivable. 
Life cannot be lived in practice without the routine challenges of making choices, taking decisions and risks. In short, life cannot be lived without engaging with activities and tools that keep us frequently busy for the purposes of eschewing boredom in the world. This reminds us of one of the famous existentialist of the twentieth century, Martin Heidegger. He argues in Being and Time that being a person is necessarily not about what stuffs you are made up of. Rather, it is defined in terms of being engaged in projects, being involved with others and using tools. To live is to dwell in the world which means to be engaged with events within and outside our vicinity. It is not to be just located in the world without any engagement. Heidegger opines that:

Being-in-the-world has always dispersed itself or even split itself up into definitive ways of Being-in. The multiplicity of these is indicated by the following examples: having to do with something, producing something, attending to something, and looking after it, making use of something, giving something up and letting it go, undertaking, accomplishing, evincing, interrogating, considering, discussing, determining... (Heidegger 1967, p. 83).

These activities cited above determine our engagement with the world designed to eschew boredom. Our routine engagement with the world is what determines our being, and it is the fundamental or the essential element upon which our very life as human beings is constructed. Juxtapose this life with the life of hereafter depicted in the scriptures. How do we address the existential challenge of boredom in heaven if everything can be achieved without any human exertion? How is a life worth living in heaven without personal engagement with the world within our ken?

Let us consider another image of heaven that is often seen in many places of the scriptures. In the scriptures, heaven is cast in the patriarchal or feudalistic terms and frequently referred to as the Kingdom of God. For instance, there are about sixty-three Bible verses that make reference to the Kingdom of God and His Holy Throne. Jesus is reported to have told Pilate in the Book of John, 18:36 that "My Kingdom is not of this world".

In the Quran, the following two verses make reference to the Kingdom of God:

Say, 'O Allah! Possessor of the Kingdom! You give the Kingdom to whom You will, and You take the kingdom from whom You will”' (Quran 3:26). 
"Say, 'I seek refuge with Allah, the Lord of Mankind, the King of Mankind, the God of Mankind.... (114:1).

As noted, the reference to Kingdom envisages a feudal system where there are Kings, Lords (who are vassals to the King) knights (who are vassals to the Lords) and the serfs or peasants (who represent the people down the social ladder). The implication is that this construct of heaven is couched in feudalist terms depicting a kingdom ruled over by God, the Absolute Monarch, who will cede territories in heaven to his lords, who in turn will allow the peasant class to use tracts of land in heaven in return for loyalty. After all, this is the construct of "kingdom" we inherited from the medieval periods in Europe.

The feudalist notion of governance in heaven raises some few concerns, and we shall address these concerns in the remainder of the presentation. First, the earthly beings' status in this construct of heaven is obviously cast in stone. There would never be social mobility from serfdom to aristocracy. There would be no possibility of state transformation from a kingdom to a republic of free citizens. Consider the possibility of an afterlife of eternal existence where you will not have the freedom of dissent, no prospect of ever enjoying the status of an angel and no sense of achievement. And the frightening thing is that this state of indolence and passivity drags on forever.

Second, it contradicts the very notion of heaven that is supposed to provide an eternally blissful rest devoid of the tribulations and anguish for the righteous. The idea of the kingdom of heaven where there are serfs and lords who bear loyalty to God, the Absolute monarch, does not sit pretty well with most of the other scriptures' narratives of heaven. If heaven is a kingdom, then there is a kind of subtle admonition of the dwellers of heaven to obey the powers above and try to operate within God's commands. The implication is that even in heaven one is not a free citizen because she/he must live perpetually within the confines of God's commands. This renders the supposed freedom to be enjoyed in heaven a grand illusion. So, where lies the blissful eternal rest if in heaven dwellers will be subjected to perpetual serfdom under everlasting obedience to God, the Grand patriarch?

A third concern is that this notion of heaven fails to strike a chord with the ideal contemporary society. Though feudalism existed many centuries ago, it flourished in the medieval European societies of the $10^{\text {th }}$ and $13^{\text {th }}$ centuries CE. Our contemporary sociopolitical system is no more feudalistic; it is a republic where governance is not considered a private concern of the rulers. In the republic, as it may be found in many contemporary nations, primary positions are not inherited but are attained through democracy, oligarchy and 
aristocracy. So, how do people who presently live (or have lived) in a predominant democratically sociopolitical culture fit into this imagined feudalist political culture? Would it not sound like dying a free man and living in captivity in the afterlife for eternity? Let us ponder over this.

\section{Conclusion}

The notion of an afterlife is a subject matter that is popular with the three Abrahamic religions. The scriptures of these religions are replete with the magnificent depictions of the afterlife, especially the world-to-come (for Judaist) heaven (for Christians), and paradise (Muslims). This heavenly abode is supposed to be a place for only the righteous, who have deprived themselves of the worldly desire in search for this heavenly abode. They expect to enjoy a life of perpetual bliss, devoid of pain, anguish, tribulations and terror of this earth in this new home. Such is the splendour of heavens depicted in these scriptures. We have said in this paper that these images of heaven throw up a plethora of existential challenges. How is life in heaven worth living without all the existential challenges, like boredom, anguish, pain, disappointment, unrequited love and so on. How is life worth living under conditions where one gets everything at his disposal without exertion? We have said that such a life could at best be described as a life of the vegetable. We have also opined that the reference to heaven as a kingdom of God envisages a feudalist system where there is a king with absolute power who is perpetually worshipped by the serfs and the Knights. This view is not consistent with the narratives of the image of heaven and also does not strike a chord with the socio-political system of contemporary societies and must be jettisoned.

\section{Notes}

1. A. E. Taylor (1974, p. 64).

2. There are several books on the market that provide varied accounts of this type of near death experiences. See Alexander, E. (2012)

3. This way of conceiving afterlife is seen in 1 Corinthians 2:9 "eye has not seen, and ear has not heard, and what has not entered the human heart, (is) what God has prepared for those who love him." 


\section{References}

Alexander, E. (2012). Proof of heaven: A neurosurgeon's journey into the afterlife. New York: Simon \& Schuster.

Cohen, M. S. (1985). The Shi 'ur Qomah: Texts and Recensions. Tubingen: J.C.B. Mohr/Paul Siebeck.

Ehlmann, B. K. (2016). The theory of a natural afterlife: A newfound, real possibility for what awaits us at death. Journal of Consciousness Exploration \& Research 7(11): 931-950

Heidegger M. (1967). Being and Time. Trans. John Macquarrie and Edward Robinson. Oxford: Basil Blackwell

Kierkegaard S. (1987). Either/Or, Vol. 1 \& 2. Trans. Howard V. Hong \& Edna H. Hong. Princeton, NJ: Princeton University Press.

Taylor, A. E. (1947). The Christian hope for immortality. New York: Macmillan Vendler, H. (1985). The odes of John Keats. Harvard: Harvard University Press Wright J. E (2000). The early history of heaven. Oxford: Oxford University Press 


\title{
Lexical Gaps and Ideological Shift in the Translation of Chinua Achebe's Things Fall Apart as "Le Monde S'effondrein French'
}

\author{
Angelinus Kwame Negedu \\ University of Cape Coast, Cape Coast, Ghana.
}

\begin{abstract}
In translating Chinua Achebe's Things Fall Apart, Michel Ligny translates directly Igbo terminologies, realities and beliefs into the French language. This has contributed greatly in the preservation of the beauty and authenticity of the original text. However, the title of the novel is domesticated by Michel Ligny to present a different ideology. Within the framework of Lawrence Venuti (2004) theory of domestication and foreignization of translation, this paper examines the ideological divergence between the title of the original text and the title of the translation. The paper concludes that the ideology that the translated title projects to the French-reader is totally different from the ideology that the original title projects to the English-reader.
\end{abstract}

Keywords: domestication; foreignization; ideological shift; lexical gaps; translation.

\section{Introduction}

Things Fall Apart is a literary genre that is set during the early days of colonialism in Nigeria. It is Achebe's first novel published in 1958, a period, often referred to as the Nigerian Renaissance, when many Nigerian writers began to create literary works to shatter the stereotypical European portraits of native Africans. In other words, this dramatic upsurge of African literature during this period seeks to reject the misguided colonial accounts of Africa and to tell the real story about Africans. Before the Renaissance, most of the novels about Africa were written by Europeans. In a greater number of these novels, Africans are described as primitive, socially backward and uncivilized. 
Joseph Conrad's famous Heart of Darkness published in 1899 for instance describes Africa as a: "wild, dark and uncivilized continent".

It is beyond dispute that Achebe's novel, which portrays the clash between Nigeria's white colonial government and the traditional culture of the indigenous Igbo people, is one of the most influential novels of its time and even today to receive global critical acclaim. It has not only attracted a plethora of critique from the global stage and is still being used in academia for various pedagogical reasons (Odamtten, 2009: 161), but it has also become compulsory reading material in many schools in some English-speaking countries around the world and has been translated into many languages for example Arabic, Spanish and French, making Achebe the most translated African writer of all time. The French version was signed by Michel Ligny and was published by Présence Africaine in 1972. The publication then attracts the following comment from Mbangwana (1990: 325):

The ingenuity of Michel Ligny in translating proverbs shows clearly when he translated the title of the book Things Fall Apart as Le Monde s'effondre. The translated title is very arresting because it causes the reader to be curious by asking the questions which world is it. And what is the cause of this disintegration?

This comment is considered by Rao and Madueke (2016: 535) as very symptomatic. This implies that the translation leaves much to be desired. Having studied under Prof. Atta Britwum of the Department of French at the University of Cape Coast, I quickly reacted to the first question that this is a traditional communalistic Ibo society. However, the second question provokes series of reflections that result into this write-up. Thus, the aim of the paper is to demonstrate that the title of the original text and the title of the translation present different ideologies.

According to Newmark (2003), there cannot be any global communication without translation. This suggests that translation is very necessary for cross-cultural communication. It is a medium through which works produced in one language and culture are made available and disseminated to readers in another language and culture. Translation does not only play a prominent role in bringing human groups together and contributing to the respect for linguistic and cultural diversity but also, according to Brisset (2010), helps in the creation and renewal of literature or shaping and restructuring of a literary genre at a particular moment in history. The term translation has several meanings: the general subject field, the translated text or the act of producing the translation (Munday, 2001: 5). The 
act of reproducing a translation which involves a translator changing an original text from one language into another language is what Jakobson (2000: 114) termed as interlingual translation. The author defines it as an interpretation of verbal signs by means of some other language which he distinguishes from intralingual and intersemiotic translations. It is important to say that this type of translation is defined in different ways from different theoretical standpoints in the literature on translation.

Translation was initially defined based on formal equivalence by linguists. Catford (1965) defines translation as the replacement of textual material in one language by equivalent textual material in another language. Newmark (1988) also defines it as rendering the meaning of a text into another language in the way that the author intended the text. These suggest that textual equivalence and the author's intended meaning are crucial in translating. Cary (1962: 4) of the interpretative school also posits that:

La traduction est une opération des équivalences entre deux textes exprimés en des langues différentes, ces équivalences étant toujours et nécessairement fonction de la nature des deux textes, de leur destination, des rapports existants entre la culture des deux peuples, leur climat moral, intellectuel, affectif, fonction de toutes les contingences propres à l'époque et au lieu de départ et d'arrivée.

This means that the equivalence depends essentially on the nature and the destination of the two texts, the culture in which they are produced, their moral, intellectual and affective conditions as well as all other circumstances prevailing at the time and place of their production. This implies that the focus is not only on the textual equivalence but also the context in which the source text and the target text are produced.

Nida and Taber (2004) define translation based on functional equivalence. They consider translation as consisting of reproducing in the receptor language the closest natural equivalence of the source language message, first in terms of meaning and secondly in terms of style. This shows that the natural equivalence in meaning and style of the text is what the translator is concerned with during the act of translating. From the Skopos theoretical framework, Vermeer and Reiss (1978) consider translation as a more functional and sociocultural oriented concept. Translation is viewed not as a process of transcoding but as a specific form of human action with a purpose. For Nord (1999), it is a purposeful activity that aims at the target culture. Based on the considerations above, translation can be defined as a process that consists of reproducing the natural equivalence in terms of the 
contextual meaning and the style of a text or a message in one particular language into another language to achieve a particular communicative purpose. This process involves as well many actors including the commissioner, the translator and the editors who guarantee the correct transfer of the information into a specific language.

Geoffrey (2004) identifies four categories of translation: technical translation, business translation, interpreting and literary translation. One major issue regarding literary translation remains how to achieve an equivalent translation in the target language both in function and style. In literary texts, words are known to carry special energy and load than that found in nonliterary texts and if the translator is not extra meticulous with language use, the translation will not be a good representation of the original. Onuka, (2017: 68) explains that there are implicit information which constitute the contextual aspects of the text; that there are notional and emotional contents of the words which can hardly be perceived when they are translated literally and these can only be revealed to a translator who is sensitive to words. It goes without saying that there is no doubt among scholars of translation that literary translation presents serious challenges to translators.

Kahrizsangi1 and Haddadi1 (2017) citing Nord (2011), argue that the challenges of translation may be due to the structural differences between the source and target texts or the behavioral patterns of the source and target cultures, or even due to cross-linguistic challenges of the two languages. Literary translation becomes more difficult due to cultural and linguistic differences between various languages. Owing to the lexical, syntactic, semantic and cultural divergences between languages and the way languages express realities differently, some critics of translation maintain that literary translation is not possible. Lyons (1981: 310) argues that differences at the level of lexical structures, including most obviously lexical gaps, make translation between languages difficult and at times impossible. He observes that this could lead to cultural and linguistic untranslatability. According to Mcguire (1980: 32), cultural untranslatability is ascribed to the non-existence in the target text culture of a relevant situational feature for the source language text whereas the linguistic untranslatability refers to the absence of a syntactic or lexical substitute in the target text for a source text. This implies that cultural and lexical gaps can pose serious obstacles to translators.

\section{Lexical Gaps}

From cross-linguistic perspective, Bentivogli and Pianta (2009) maintain that lexical gaps occur whenever a language expresses a concept with a lexical unit whereas another language expresses the same concept with a free 
combination of words. This means that where one language uses a single word for instance to express a concept, another language has a phrase or more than one word to translate or express the same concept. It is possible to say that lexical gaps occur when the translator realizes that there is lack of equivalence of a concept in the target language which exists in the source language. The translation of Achebe's novel reveals a good number of lexical gaps. While cultural terms like "blacksmith" (p.27) and "jigida or waist-beads" (p.50) are rendered in the target language with their equivalents as "forgeron" (p.52), "perles" (p. 88) respectively, others like "goatskin bag" (p.45) and "snuffbottle" (p.45) are translated with a combination of words as "besace de peau de chèvre" (p.80) and "bouteille de tabac à priser" (p.80) respectively. Weise (1988: 190) also states that any gap either in the form of one-to-zero or oneto-many equivalents must be compensated by the translator's skill. There could be loss of information if lexical gaps are not well compensated for during translating and this can have serious impact not only on the quality of the text but also on the ideologies carried by the text.

\section{Defining ideology}

The term ideology was coined by Cabanis, Destutt de Tracy and their friends to represent the genetic theory of ideas. Citing Marx, Althusser (1971) explains that an ideology is the system of ideas and representations which dominate the mind of a man or a social group. According to Erikson and Tedin (2003), ideology is a set of beliefs about the proper order of society and how it can be achieved. This implies that an ideology represents a set of beliefs, ideas or representations dominant in the mind about the creation of an ideal society. These affirm Parsons' (1951) definition of ideologies as the shared framework of mental models that groups of individuals possess that provide both an interpretation of the environment and a prescription as to how that environment should be structured. In Parsons' definition, the mental models that groups of individuals possess can be said to be ideas or representations or a set of beliefs. This further means that ideologies do not only dominate the mind but are also shared. They are able to guide people understand and give true meanings to one's own environment and to act to create what they think is an ideal society. From Marxist's perspective, Tyson (1999) defines an ideology as a belief system, that is, a product of cultural conditioning. He also notes that culture cannot be separated from the socioeconomic conditions that produce it. This means that ideologies are conditioned by socio-economic realities prevailing in one's own environment. Thus, an ideology can be defined as ideas, representations or a set of beliefs 
dominant in the mind, conditioned by socio-economic realities and shared by a social group.

There are ideologies that dominate the minds of the characters in Things Fall Apart. With reference to the definition above, these ideologies can be classified into four categories such as individual characters' ideologies, communal ideologies, repressive ideologies and narrator ideologies. There could also be reader ideologies generated by the critique on the novel. Individual ideologies are beliefs that dominate the mind of a character. Characters like Okonkwo and his father Onuka have their individual ideologies. The narrator describes Okonkwo's reflections in his last year in exile as:

[...] Okonkwo knew that he would have prospered even more in Umuofia, in the land of his Fathers where men were bold and warlike. In these seven years he would have climbed to the utmost heights. And so he regretted every day of his exile (p. 117).

This shows Okonkow's belief that a man should not be effeminate, weak and unsuccessful, but strong, warlike and prosperous. His ideology is conditioned by being able to rule his household, becoming prosperous and having enough food in the barn to feed the ancestors with regular sacrifices (cf. p.37).

Communal ideologies are those set of beliefs that are shared by all the indigenes. The unwavering beliefs in and the fear of the power of the gods and the ancestors are shared by all in the Ibo tribe. When the priest of the earth goddess Ezeani, descends in his obi because he beats his wife, Okonlwo is calmed. The statement of the priest reminds him of their collective belief:

You know as well as I do that our forefathers ordained that before we plant any crops in the earth we should observe a week in which a man does not say a harsh word to his neighbor. We live in peace with our fellows to honor our great goddess of the earth without whose blessing our crops will not grow. You have committed a great evil.

This reveals the mental representation that the Ibos have about their ancestors and the gods: that living in peace with a fellow is to honour the gods so that they can in turn bless their crops. This, on the contrary indicates that their communal ideologies are not conditioned by economic realities but by the fundamental principle of morality, good conduct and respect for the gods in order to invoke their blessings. 
Repressive ideologies are those set of beliefs that come to contradict and suppress the existing ideologies of the Ibo people. When the white men arrive in the village of Mbanta, they gather a considerable number of the people and preach to them:

[...] And he told them about this new God, the Creator of all the world and all the men and women. He told them that they worshipped false gods, gods of wood and stone... He told them that the true God lived on high and that all men when they died went before Him for judgment [...] (p. 104)

This depicts that the ideologies of the white men contradict those of the Ibo people. The contradiction is that the gods of the Ibo are false whilst the God of the white man is true. It is possible to say that the repressive ideologies are conditioned by economic realities because the narration also reveals that the strange men did not only bring religion but also a system of government and trade (cf. p125, 131). After they have established their government, the reader is told that trading begins flourishing, and corruption, the great evil raises its ugly head for the first time when the Kotmen are seen taking bribe.

The narrator ideology is the ideology that the narration carries. It is the central idea that the narration projects. The whole story revolves around this idea. Okonkwo returns from exile and is discussing with Obiereka about the recent developments in Umuofia:

The white man is very clever. He came quietly and peaceably with his religion. We were amused at his foolishness and allowed him to stay. Now he has won our brothers, and our clan can no longer act like one. He has put a knife on the things that held us together and we have fallen apart. (p. 127)

This reveals the idea that the narrator presents to the reader: the white man is the one who divides them by putting a knife on what holds the Ibos together. The reader may also have his ideologies through critical reading of the novel. Ghani, Ayub and Irshad (2013) for instance posit that the idea that resonates in the novel is that Achebe presented the African culture from the native perspective and has shown that Ibo people bad their own distinct culture, history and civilization. 


\section{Foreignization or Domestication}

To be able to achieve an equivalent translation of the source text in the target language both in function and style and to surmount the challenges that the enterprise presents, scholars in Translation Studies have theorized as to how the translator may proceed in the translation of literary texts. The first group of scholars to theorize, according to Snell-Hornby (2006), are Schleiermacher and Goethe among others. According to Schleiermacher, the translator should either leave the reader in peace and move the author towards him, or leave the author and move the reader towards him. Snell-Hornby citing Lefevere (1977) explains that the two roads are so completely separate from each other that one or the other must be followed as closely as possible, and that a highly unreliable result would proceed from any mixture. SnellHornby also argues that these approaches were originally Goethe's. For Goethe, there are two maxims in translation. The first one requires that the author of a foreign nation be brought across to the new readers in such a way that they can look on him as theirs. The other one requires that translators go for the foreign and adapt themselves to its conditions, its use of language and peculiarities. Even though Schleiermacher appears to be suggesting two different approaches, he seems to project the first approach that, to be able to move the reader towards the author, the translator can translate word for word. He recommends creating a language which is "bent towards a foreign likeness, hence favouring foreignization (Snell-Hornby, 2006: 9). On the other hand Goethe recommends the middle way or the method of naturalization (i.e., domestication) when the translator is in doubt.

According to Myskja (2013), it is Lawrence Venuti who develops the distinction between the terms "domesticating" and "foreignizing" and uses them to describe two extremes of how a translator positions a translated text in the target language and in the textual environment of the target culture. In domesticating a text, the translator strives for a style that is as indistinguishable as possible from a text originally written in the target language. This involves prioritizing fluency and naturalness. According to Venuti (2004), foreignizing a text on the other hand, the translator intentionally disrupts the linguistic and genre expectations of the target language in order to mark the otherness of the translated texts. This involves discontinuities at the level of syntax, diction, or discourse. This allows the translation to be read as a translation showing where it departs from target language cultural values. To domesticate a text for it to be seen as natural, comparable to a text written in the target language means that the translator does not necessarily have to pay attention to the form and style of the original text. This implies that for a translator to succeed with the domestication approach, he needs to proceed by an oblique translation. On the 
other hand, to foreignize a text, the translator has to do a direct translation to enable the translation to be read as translation. Vinay and Darbelnet (1995) explain that direct translation involves transposing the source language message element by element into the target language through borrowing, calquing or literal translation. This becomes necessary when the translation is based on either parallel categories or on parallel concepts, and when the translator also notices lexical gaps in the target language which must be filled so that the overall impression is the same for the two messages. However, it may also happen that because of structural or metalinguistic differences, certain stylistic effects cannot be transposed into the target language without upsetting the syntactic order, or even the lexis. In this case it is understood that more complex methods like transposition, modulation, equivalence or adaptation, in other words an oblique translation has to be used which at first may look unusual but which nevertheless can permit translators a strict control over the reliability of their work.

\section{Translating the title as "Le monde s'effondre"}

"Le monde s'effondre" is a complete deviation from the original title. This does not suggest that the French version is inappropriate because deviations can be intentional (Jovanovic, 1991: 85). Whilst the narration is foreignized through direct translation, the title and the blurb are domesticated subtly to project an ideology that is different from the original. The narrator actually helps the reader understand the ideology projected by Things fall apart. The opening page of the novel has a pretext indicating that the title is adapted from W. B. Yeats' poem "The Second Coming". This places the title already in its proper context. Relating this context to the narration, it can be understood that there is a set of beliefs, embedded in the culture of the Ibos, holding intact the traditional fabric of the society. When the missionaries arrive in Mbanta, they ask for a piece of land to build their church. Having understood what the Oracle has revealed that the strange man would break their clan and spread destruction among them, the elders of the town propose the Evil Forest with the expectation that the white men will not survive up to four days or seven weeks. Unfortunately, even after the seventh week, the church continues to exist and to flourish, winning more natives to the congregation. Besides, beliefs are rife in the land that the gods were dead and impotent when three newly converts descend into the village to boast openly that they are prepared to defy them by burning all their shrines. Not only were rumours that the priest's son has killed and eaten the royal python but he is also seen defying publicly an egwugwu. 
Following these phenomena, the natives begin to think that the god of the strange man is more powerful than the gods of the land and this quickly results to a change in beliefs in the gods. It is worth noting that because there is a repressive ideology that contradicts and suppresses the beliefs of the natives, the Ibo ideologies begin to lose hold on the natives. The belief in the power of the gods and the ancestors (egwngwn), the beliefs in animals like the sacred python and the belief in the power of the Evil Forest among others are the "THINGS" that hold the Ibos together. The falling apart of these set of beliefs, shared by the people is what is suggested by the title. This can also be asserted by the conversation between Obierika and Okonkwo:

Does the white man understand our custom about land?

How can he when he does not even speak our tongue? But he says that our customs are bad... The white man is very clever. He came quietly and peaceably with his religion. We were amused at his foolishness and allowed him to stay. Now he has won our brothers, and our clan can no longer act like one. He has put a knife on the things that held us together and we have fallen apart. (p. 127)

As Obiereka remarks, the repressive ideologies are like a knife placed on the beliefs of the Ibos. This can be said to be the cause of the disintegration of a traditional communalistic Ibo society.

On the other hand, the French version is not placed in any context like the original version. It does not look like a direct translation. The translation uses the word "le monde" to translate the word "things" from the original version. Meanwhile there are words like "choses", "trucs", "machins" that can equally be used instead of "le monde" but the translator realizing the words" incapacity to convey the connotations carried by the word "things" quickly resorts to the use of the word "le monde" which of course is a way of filling the lexical hole encountered in the translation of the title. It is also important to state that the lexical gap existing in the French language for the word "things" in this context is filled in a different way by Pierre Girard in a different translation published by Editions Actes Sud in 2013 which uses "tout" instead of "le monde" in his translation to read "tout s'effondre". The use of "le monde" cannot be considered to be inappropriate since it makes reference to the world of the Ibos in the novel. It is the choice of "le monde" that calls for a perfect collocate like "s'effondrer" which renders the translation quite appropriate. It is important to note here that whereas the original title makes reference to things, the translated title makes reference to the world of the Ibo people. 
Furthermore, it is crucial to remember that a translation is meant for the reader who does not understand the language of the original text. The word "s'effondre" is from the infinitive "s'effondrer". Since this is not placed in any context like the original, it is likely to mean to the French-reader tomber sous le poids ou faute d'appui or s'écrouler, le Robert illustré (2016: 618). This translates as to fall under a weight or to fall for lack of support, or to collapse. On the other hand, to 'fall apart' to the English-reader means to break into parts or components or lose cohesion or unity ${ }^{1}$. This implies that whereas the English-reader is presented with things breaking into parts or components or losing cohesion or unity, the French-reader is presented with a world that falls under a weight or for lack of support. The things that break into parts are specifically the beliefs of the Ibos. It can be argued that even though the title of the translation seems appropriate, yet, it rather draws the attention of the French-reader to nothing specific but everything in the world of the Ibos. This also suggests that the world of the Ibos in "things fall apart" collapses not because of a change in beliefs but because it comes under a certain weight or lacks support. This is why Mbangwana (1990) raises the question as to what causes the disintegration.

The blurb of the translation is very suggestive of what Ligny projects as the cause of this disintegration. It is important to state that the blurbs of the two texts are quite different. The original blurb projects the main character Okonkwo and what has befallen him. It draws the attention of the reader to the pride, courage and tragedy of Okonkwo considered as an important man in his tribe:

The story of the tragedy of Okonkwo, an important man in the Ibo tribe in the days when the whites were first appearing on the scene... Mr. Achebe's very simple but excellent novel tells the series of events by which Okonkwo through his pride and his fear becomes exile in his tribe and returns, only to be forced into the ignominy of suicide to escape the rash courage against the white man $[\ldots]$

The translation however projects the destruction of an Ibo tribal village, the tragedy of Okonkwo aiming to become an important person in his tribe, the brutal and bloody ancestral sacrifices, uncivilized women and children cut off from the rest of the world.

Destruction de la vie tribale à la fin du siècle dernier par suite de l'arrivée des Européens ; tragédie d'un homme dont toute la vie a tendu à devenir l'un des personnages les plus importants 
de son clan mais qui finit de la façon la plus misérable ; conversion au christianisme - cette abomination - de son fils qu'a éloigné de la vie ancestrale un rite cruel et sanguinaire dont a été victime son meilleur ami d'enfance; vie quotidienne des femmes et des enfants d'un village de la forêt qui presque totalement coupé du monde extérieur, pouvait se croire le monde avec ses dieux et ses ancêtres, ses coutumes et ses interdits $[\ldots]$

It is possible to say that this is not a direct translation of the original blurb. Critical reading of the French version suggests that the disintegration of the Ibo society is due to the brutal and bloody ancestral sacrifices for example the butchering of Ikemefuna which later drives Nwoye away from the tribe to join the new religion, throwing twins into the Evil Forest after birth because they are considered evil, and women and children living in deep forest totally cut from the rest the world.

Boafo (1974) argues that the damage done to the Ibo society in Things Fall Apart is not only largely due to the incidences of Western culture but cracks in the structure of the traditional fabric made Ibo society unsuitable to resist the onslaught of imperialism. This does not suggest that Western imperialism is totally free from blame. But the translation seems to suggest otherwise. The image on the cover page of the translation showing the words of the title written boldly and scatter-logically in black contradicts the original image on the cover page showing a cock with a rope tied around its neck being spun by an unseen person and left to fall heavily on its neck. The person who is left to be determined by the curious reader is the one to blame for the disintegration. The image on the cover page of the translation affirms that the blacks are to be responsible for the collapse of the Ibo society. It is fair to say that the translation is playing a reactive role as well as a divisive one. It plays a reactive role in the sense that the one to blame for the disintegration or collapse of the traditional Ibo societies is the not the West and its culture but the Africans themselves. It is playing a divisive role in the sense that the ideology presented to the French-reader by the translation is different from that of the English-reader. It goes without saying that there is a shift from the ideology which "things fall apart" presents to the English-reader, that the natives have a set of beliefs that bind them together and that the disintegration is caused by the removal of these ideologies by repressive ideologies introduced in the land by the strange man, to the ideology that "Le monde s'effondre" presents to the French-reader, that the Ibos do not have anything that holds them together and that their world collapses due to brutal and cruel 
ancestral rites that have driven many of the natives away to join the new religion.

\section{Conclusion}

All in all, whereas "Things fall apart" draws the attention of the English-reader to the fact that there are individual and communal ideologies that hold the traditional Ibo society together, undivided and intact, and the removal of these ideologies leads to the disintegration; "Le monde s'effondre" seems to draw the attention of the French-reader to the fact that the world of the traditional Ibos in the novel collapses because there is nothing holding it together, but brutal and bloody ancestral sacrifices, women and children living in deep forests cut away from the rest of the world or civilization, rather put pressure on it to collapse. The repressive ideologies that divide the Ibo society in the novel are the same ideologies that the title "Le monde s'effondre" projects to divide readers of the translation and readers of the original text. This is indicative of the fact that the translation is playing a divisive role hence translating African literary works need to be regulated. The colleges of humanities in West Africa if not the whole of Africa have to play the lead role in the study of literary translation to determine the ideologies that each projects. This will call for the integration of doctoral programs in Translation Studies in the University curriculum to spearhead research in the area of literary translation.

\section{References}

Achebe, C. (1958). Things Fall Apart. Oxford: HEP

Achebe, C. (1972). Le monde s'effondre. Paris: Présence Africaine.

Althusser, L. (1971). Ideology and Ideological State Apparatuses. In L. Althusser (Ed.), Lenin and Philosophy and other Essays. New York: MRP

Bassnett-McGuire, S. (1980). Translation Studies. London: Methuen.

Bentivogli, L. \& Pianta, E. (2009). Looking for Lexical Gaps. Proceedings of EURALEX, Athens, Greece.

Boafo, Y. S. K. (1974). Okonkwo on the Triumph of Masculinity as a Determinant of the Fall of a Hero. Asemka. vol. 1. n 1. pp. 7 - 15.

Brisset, A. (2010). Cultural Perspectives on Translation. UNESCO ISSJ. pp. 70 -81 . 
Cary, E. (1962). Noblesse de la parole. In Babel, vol. 8. no 1, pp. 3 - 7.

Catford, J. C. (1965). A Linguistic Theory of Translation. London: Oxford University Press.

Erikson, R. S. \& Tedin, K. L. (2003). American Public Opinion (6 $6^{\text {th }}$ edition). New York: Longman.

Geoffrey, S. (2004). A Practical Guide for Translators. Toronto: Multilingual Matters Ltd.

Ghani, M., Jajja, M. A. \& Hussain, I. (2013). Things Fall Apart: Chinua Achebe Writes Back to the Centre. In The Journal of Educational Research, vol 16, $\mathrm{n}^{\circ} 1$

Jakobson, R. (1959). On Linguistics Aspects of Translation. In Venuti, L. (2004). The Translation Study Reader, pp. 113 - 118. London: Routledge.

Jovanović, M. (1991). Deviation and Translation. In TTR: Traduction, Terminologie, Rédaction, vol. 4, n 1, pp. 83-98.

Kahrizsangi1, A. A. S. \& Haddadi, M. H. (2017). An Inquiry into the Challenges of Literary

Translation to Improve Literary Translation Competence with Reference to an Anecdote by Heinrich von Kleist. Journal of Education and Learning, vol. 6, no. 3, pp. $350-357$.

Lyons, J. (1981). Language and Linguistics. Cambridge: CUP.

Munday, J. (2001). Introducing Translation Studies ( ${ }^{\text {nd }}$ edition). London: Routledge.

Newmark, P. (2003). No Global Communication without Translation. In Anderman, G. and Rogers, M. (eds.). Translating Today: Trends and Pespectives. pp. 55 - 67. England: Multilingual Matters.

Newmark, P. (1988). A Textbook of Translation. Shangai: SFLEP

Nida, E. \& Taber, C. R. (2004). The Theory and Practice of Translation. Shangai: SFLEP.

Myskja, K. (2013). Foreignisation and Resistance: Lawrence Venuti and his Critics. Nordic Journal of English Studies. vol. 12, n 2: pp. 1-23. 
Nord, C. (2006). Translating as a Purposeful Activity. A prospective Approach. In 132 TEFLIN Journal, vol. $17 . \mathrm{n}^{\circ}$ 2. pp. $131-143$.

Odamtten, H. N. K. (2009). The Significance of Things Fall Apart To African

Historiography. International Journal of Postcolonial Studies. vol.11, no 2. pp. 161 165

Onuko, T. (2017). Enhancing Literary Translation through the Interpretative Theory of

Translation (ITT)". In IOSR Journal of Humanities and Social Science (IOSR-JHSS), vol. 22 , issue 8 . pp. $67-71$

Parsons, T. (1951). The Social System. New York: Free Press.

Rao, S. \& Madueke, S. I. (2016). Le monde s'effondre ou Tout s'effondre? Traduire et retraduire Things Fall Apart en Français. In Canadian Review of Comparative Literature, pp. 187 - 194.

Snell-Hornby, M. (2006). The Turns of Translation Studies. Amsterdam: JBPC.

Tyson, L. (1999). Critical Theory Today. A User-Friendly Guide. New York \& London: Garland Publishing, Inc.

Venuti, L. (2004). The Translator's Invisibility: A bistory of translation. London: Routledge.

Vermeer, H. J. \& Reiss, K. (1984). Groundwork for a general theory of translation. Tubingen: Niemeyer.

Vinay, J. P. \& Darbelnet, J. (1995). Comparative Stylistics of French and English, a Methodology for Translating. Amsterdam: JBPC.

Weise, G. (1988). Contrastive Linguistics and the Problem of Equivalence in Translation. In Poznaň, vol. 22, pp. 187 - 194. 


\title{
Political Transformation and Development in Africa: Lessons from Achebe's Things Fall Apart.
}

\author{
Tony Talburt \\ University of Cape Coast, Cape Coast, Ghana.
}

\begin{abstract}
Drawing upon Achebe's classic work, Things Fall Apart, where Okonkwo, the principal character, refuses to accept intrusions or changes influenced by Westernisation, this paper challenges one of the central assumptions in this story, that Africa falls apart as soon as it comes in contact with Europe. Notwithstanding the overwhelmingly negative effects of the trans-Atlantic slavery systems and European colonialism on Africa (and its Diaspora), this study argues, that to a large extent, Africa's economic transformation and development could be greatly enhanced by adopting some new ideas and systems from within as well as outside the continent. This paper questions aspects of political conservatism exhibited in Okonkwo who is suspicious of fundamental changes to his society. The discussion is based on the jollof-rice principle of political hybridisation of development which proposes the amalgamation of Westernised and non-Western ideas and systems, in order to achieve economic development, rather than totally rejecting Westernisation in its entirety. The jollof-rice principle of political hybridisation is based on the idea of blending systems and ideas in much the same way that rice and tomato are combined in West Africa, to create jollof-rice. This study uses the academic discipline of international political economy in its analysis of themes of political conservatism and development in Africa, as portrayed in the Achebe's work. In contrast to Okonkwo's political conservatism, this study uses examples of Western-style democracy and state intervention in Africa to demonstrate the significance of embracing some aspects of Westernisation through political hybridisation.
\end{abstract}

Keywords: African Development; jollof-rice principle of development; political conservatism; political hybridisation. 


\section{Introduction}

In Chinua Achebe's classic work, Things Fall Apart (1986), Okonkwo, the principal character, refuses to accept ideas or systems based upon Westernisation which begins to take root in his village in Africa. He is determined to ensure the preservation of the existing status quo. Okonkwo, therefore, is regarded in this study, as a representation of a political conservative, who is resistant and suspicious of fundamental changes in society. It is the issue of conservatism and its broader links to economic development that forms the basis of this study. The study seeks to challenge this conservative approach and one of its underpinning assumptions in this story, which is that 'Africa falls apart as soon as it comes in contact with Europe'. Notwithstanding the overwhelmingly negative effects of the transAtlantic slavery and European colonialism on Africa's development, the central proposition of this work is that, to a large extent, economic development in Africa could be greatly enhanced by embracing the best of ideas and systems from within, as well as outside the continent. Therefore, drawing upon what is described here as the 'jollof-rice' principle of political hybridisation, this study suggests that African governments, in keeping with previous Far-East, Arabic and more recently, Western civilisations, need to adopt unique hybridisation of ideas and systems, to enhance the development of their people. More specifically, rather than rejecting aspects of Western ideas and systems in their entirety, as Okonkwo campaigns for in the story, this study suggests the need for a hybrid approach, in much the same way that rice and tomato, originally from different parts of the world, were combined in West Africa to create jollof-rice. The study first provides an overview the jollof-rice principle of political hybridisation, before examining specific examples of its application in a few African countries.

Achebe' classic work, Things Fall Apart (1986) can be regarded as a tragic account of an African society's destruction and destabilisation that occurs once it comes into contact with European missionaries and colonialists. This idea of the destructive nature of European colonisation on African society is perhaps best captured in the story by the quote: 'The White man has put a knife on the things that hold us together and we have fallen apart' (Achebe, 1986: 127). A number of reviewers have also discussed this novel as an example of the nineteenth century colonial disintegration of this Igbo society of Umuofia (Mongredien, 2010; The New Times, 2010). This is indeed a story of a clash between those wishing to retain African indigenous cultures, and those espousing Westernisation.

The central character in this story is Okonkwo, who is driven by the twofold desire to avoid replicating the miserable failure of his father in his own 
life, and secondly, and more important for this study, is his determination to achieve success through hard work as well as by maintaining the local traditions. This popular local hero, the greatest wrestler and warrior among the nine villages of Umuofia, fears only one thing, and that is failure itself (Achebe, 1986). Okonkwo can be seen as the main person who consistently tries his best to maintain the customs and traditions of Umuofia. Okonkwo, in this sense, displays all the main features associated with political conservatism. This ideology, is based on what Heywood (2015) describes as a desire to conserve, as well as to resist or demonstrate scepticism towards change. Two key features of political conservatism are: maintaining traditions and also the ultimate respect for the established authorities.

Okonkwo, therefore, in common with the Luddites of England and also the British landed aristocracy in the early nineteenth century, are conservatives who strongly oppose societal changes. Burke (1999), who wrote in 1790, is regarded as one of the founders of modern conservative thought, similarly opposes major societal changes taking place in France during the French Revolution of the late 1780s and early 1790s. He claims, for example, that 'kings should not owe their crown to the choice of the people' (Burke, 1999: 14-15). In other words, ultimate power should be held by the monarchs, and the populace should be totally subject to them. As far as he is concerned, 'the king is not there to obey us, but we are to obey the law in him' (Burke, 1999: 29). Whereas the people making up the Third Estate in Revolutionary France, are demanding political, economic and social changes, Burke is vehemently opposed to this, and insists on the preservation of the old order, based on the divine rights of the monarchy. Unlike the case in France where the agents of change were the people themselves, in the African society where Okonkwo lived, it is the European missionaries and colonisers who seek to implement changes. In both cases, however, despite the source from which the change derives, those with authority and privileges prefer to conserve the traditional order. Okonkwo, therefore strives to ensure the values, systems and culture of his society are preserved at all costs.

Not everyone in Umuofia, however, feels the same way as Okonkwo about the arrival of the Europeans. Okonkwo's friend Obierika, inwardly and silently, questions some of cultural practices in Umuofia such as: why Okonkwo should have been banished from the village and his entire compound burned down because of an accident. In addition, he questioned why he has to throw away his wife's twins because of obedience to local customs or traditions (Achebe, 1986: 89). Okonkwo's own son is drawn to the new Christian religion, partly because of the key questions his cultural traditions cannot answer. One of these issues is the killing of twins, once they were born (Achebe, 1986: 109). Furthermore, the Europeans have built a 
'trading store, and for the first time, palm oil and kernel became things of great price, and money flowed unto Umuofia (Achebe, 1986: 128). Here, as is discussed below, we see an example of the paradox of destruction and reconstruction that often accompanies economic development and change. In this sense, therefore, this African society is torn between two extreme positions of either totally rejecting Western ideas and systems, or being completely overtaken by them. These are clashed between political conservatism and reformers, or between africanisation versus Westernisation. Even though pan-Africanist writers such as Rodney (1988) and Diop (1974) warn of the exploitative nature of European political and economic engagement with Africa, what is being argued here, is for countries to consider adopting some of the new ideas and systems from the West and blending these with their own, to create something new.

\section{The jollof-rice principle of political hybridisation and economic development}

The jollof-rice principle asserts that appropriate and careful embracing, adaptation and use of new ideas, systems, cultures and achievements are necessary for a country to achieve structural transformation and development. This broad idea is based on the origin and manner of the creation of the West African meal of jollof-rice. This particular meal is only made possible because of the unique blend of two essential ingredients of rice and tomato, from two very different parts of the world. Rice, whether originally from the Far-East or the African variety, and tomatoes from South and Central America, are both blended during the colonial period to create an African meal. From the creation of jollof-rice, probably from Senegal, in West Africa, two important lessons are worth noting, that are applied in the succeeding discussion below, with regard to economic development in Africa. Firstly, as a result of European colonialism, Africa has been introduced or exposed to tomatoes which have not been rejected. Secondly, over a period of time, tomato has been blended and cooked with rice thereby creating a new hybridised African meal. This study builds upon the particular idea of the hybridisation of rice and tomato to create jollof-rice, by postulating that the correct balance and combination of different development ideologies and policies help to enhance structural transformation and development in every human society. Okonkwo's natural conservatism results in his resistance to the introduction of Western-based new systems that seek to undermine or threaten his worldview. This study, however, claims that for economic development to occur, some degree of exposure to, and adaptation of new ways of operating, is crucial in order for transformation and development to occur. 
There are two key phases involved in the jollof-rice principle. The first phase consists of the initial exposure and eventual acceptance of new ideas, while the second phase comprises the incorporation and hybridisation, resulting in change and development. During the first phase of initial exposure, countries are brought into contact with new cultures, ideas, systems and technologies. These forms of initial exposure, have in the past, been influenced principally by international commerce and trade, wars, conquests and settlements in foreign countries, and also through education or cultural exchanges. Through some of these means, different societies are brought into contact with one another each, though obviously, not always for altruistic reasons, as the example of Western colonisation of Africa demonstrates. The second phase of this jollof-rice principle focuses on the utilisation and incorporation of these new ideas, cultures and systems into society in order to bring about some degree of transformational change or development. It is primarily the second phase of this principle that forms the main basis of this study.

It is through such measures that other civilisations are able to make significant strides forward resulting in substantial transformation and development. From the late Middle-Ages, much of Western civilisation was initially exposed to, and later influenced by, similar patterns of exposure to systems, ideas, customs, and scientific and technological achievements from non-Western countries, particularly the Arab world. Himmelstrand et al (1994) opine that in order for Europeans to have achieved global advantage and eventual domination, they had to first be exposed to ideas and skills through interaction with Arab sailors and traders, through whom they acquired some knowledge in the area of ship-building and the related wood technology.

Stuenkel (2017) makes a similar point, asserting that the rise of Western Europe and its subsequent Western-centrism was partially brought about by the impact of Islam and Arabic contributions. Astronomy, Algebra, Trigonometry, and the decimal system, were transmitted to them, mainly by Muslim scholars in Spain (Stuenkel, 2017: 44). Some of these innovations occurred as a result of Arab and North African conquests in parts of southern Europe in the Middle-Ages. Despite the fact that much of Africa's integration in the modern global order has been based on European expansion and exploitation, McCarthy (1994) argues that Africans have been nonetheless forced to incorporate aspects of political, economic and socio-cultural changes. Parts of Western Europe were colonised and exploited by Arabs and African Moors, before later becoming colonisers of much of the modern world. Through such interchanges, commerce and travel, much of Western Europe was able to incorporate these changes in order to achieve substantial transformation and development, through a combination of delicate balancing 
of competing ideas and systems. In fact, Diop (1974) claims that, the roots of Western civilisation go back much earlier to ancient Egyptian origins. The key point, however, is that it was only through Western Europe's initial exposure to other societies that they have been able to demonstrate this first key phase of the jollof-rice principle, where countries use diverse views, skills, experiences and lessons from elsewhere for their own development.

In most societies where the elites or the powerful exist, they tend to be the main group that benefits from the maintenance of the existing status quo. Okonkwo best symbolises this in Things Fall Apart. He represents the traditional conservative class that is happy to continue with the existing order and fears changes because this would result in it losing control and power over the society. It is the traditional and conservatives like the Luddites in Britain and the Okonkwo (ites) in Africa, who generally resist structural transformation and new developments. It is only when these initial fears, suspicions and opposition to change are overcome, that the second phase of the jollof-rice principle, of hybridisation and development can occur.

Because the main theme in Achebe's work centres on the clashes between two groups over the way their society should develop, the concept of economic development needs to be briefly explained. Ayittey (2005) claims that development should not only mean a change, but also how countries use their 'existing so called primitive, backward and archaic' institutions to generate economic prosperity' (Ayittey, 2005: 89). McCarthy (1994) also views development as a process involving change, but questioned whether this should always be at the expense of 'other people changing in order to adopt the values and norms of modern, Western society' (McCarthy, 1994: 23). Rist defines development as a set of practices for the reproduction of society and transformation designed to increase the production of commodities through the use of exchange (Rist, 1997: 13). Central to these definitions of development, therefore, is the idea of transformation or change. Remaining at the same level century after century, does not signify that significant economic development is taking place. According to McCarthy, societies should believe in the notion of change or human progress in which life will not necessarily be the same as it was last year, but should continually get better (McCarthy, 1994: 25-26). To resist changes, because it comes from outside one's own culture without first considering its value or relevance, could prevent or hinder one's development.

The general pattern of economic development in post-war SubSaharan Africa has oscillated between two broad sets of policies and theoretical positions, usually through the adoption of one strategy at the exclusion of the other, thereby avoiding a hybridisation approach. One dominant or popular post war position or development strategy adopted by 
many African States was partly inspired by anti-colonial, anti-capitalist rhetoric, with strong state-centric models based either on nationalistic, or socialist/marxist perspectives. The second development position adopted by African states was the market-centric liberal approach based on the pursuit of individualism and the limited intervention on the part of governments. In other words, countries opted for an 'either or' approach between these two broad development positions (Fofack, 2015), rather than embracing a more hybrid approach.

The central feature of the jollof-rice principle of political hybridisation is the significance of combining Western and non-Western ideas and systems in order to create forms of development that is best suited to conditions in Africa. Conservative leaders and elites such as Okonkwo in the story and Burke (1999), are often reluctant to embrace too many Westernised ideas that might undermine the established order. However, in the last three decades we have begun to witness significant economic successes in some African countries based on this broad principle of blending Western and non-Western ideas and systems. The first example of this can be seen with regard to the issue of liberal democracy and development in Africa and the second example centres on the significance of state intervention and development.

\section{Political hybridisation and democracy in Africa}

The pursuit of liberal democracy is fraught with difficulties arising partly from the variations in interpretations related to this concept. Some of the key features of Western-based liberal democracy include; representative, accountable and transparent forms of governments, regular fair systems of general elections, individual freedoms, a plural society where diverse opinions, pressure groups and political parties can co-exist, and respect for the rule of law. However, there is no one perfect model of democracy to which all countries can, or should attempt to fit into. Potter (2000), refers to three major kinds of political regimes in modern societies, consisting of liberal democracies, partial democracies and authoritarian regimes. Potter (2000) however, also makes reference to a mixed type of political regime in which the accountability of government to its citizens is qualified, and where military, traditional, and other unelected establishments, interfere with the electoral process and compromise the authority of the elected government. What this means, is that, whilst there might be a semblance of democracy through elections, only certain candidates tend to be elected. There may also be some degree of restrictions on the rights of freedom of speech, or independent groups may exist, but are closely monitored by the state (Potter, 2000: 367). 
Yoder (2013), in his study of democratisation in Liberia, Sierra Leone and the Democratic Republic of the Congo, referred to at least five different levels or types of democratic regimes. The first type of democracy is what he calls Deep democracy which is where the will of all the people are enforced. This would represent the 'purest' form of liberal democracy, while the fifth type was called anarchy where there was little or no democracy and a complete breakdown of central governance, for example in Somalia. Many African countries, therefore, fall between these two levels or extremes, meaning that they like vast majority of nation-states the world over, exhibit varying degrees of democracy. Furthermore, these variations of democracy may not all conform to the ideals of Westernisation or liberal democracy.

In the early 1980s, a number of African countries embarked on development paths that were based on unique blends of different levels or aspects of Western liberal democracy. For example, Kenya, Cote d'Ivoire, Cameroon, Gabon, Malawi and Swaziland were amongst Africa's most economically successful countries up to the early 1980s, yet all six were stable single party states and managed to control political disturbances when they occurred (McCarthy, 1994: 103). The causes behind these relatively short-term signs of economic successes in these African countries up to the 1980s were very much influenced by strong government interventionist policies with less than perfect democratic systems (McCarthy, 1994: 162). According to Potter (2000) In Uganda under President Yoweri Museveni and his National Resistance movement (NRM), three elections were held between 1986 and 1996, which, according to local and foreign observes, were free, fair and open. Yet, no opposition political parties were allowed to challenge the main political party, in what became known as a system of 'no party democracy.' Due to the level of political stability that prevailed in the country during from the mid1980s through the mid-1990s, the British Labour government even decided to accept this form of democracy and refused to push for multiparty reforms in Uganda (Kasfir, 1998).

Similarly in Rwanda, after the genocide of 1994, the president introduced the traditional Gacaca system of justice rather than a Westernstyled democratic judicial system whereby perpetuators of the genocide could give their side of the story and ask for forgiveness. According to Fairbanks (2012) the National University of Rwanda found that the vast majority of people said this system was far better than any other form of justice. Since the 2000s the state has been the main player in determining what, where and how much is to be produced in the agricultural sector. The state is the main driving force behind high-value services and high-end tourism and also modern urban planning (World Bank, 2019, p. 13). This World Bank Report also claims that whilst recognising the need for a strong interventionist state soon after the 
genocide, there could be consequences for private firms and their competitiveness should this continue to the norm (World Bank, 2019: 37).

Botswana is an excellent example of a country where they insisted on an economic development strategy that mixed aspects of their own African indigenous political systems with Western models. Since the country gained political independence in 1966, through its diamond exports and a stable political system, the country has achieved remarkable economic accomplishments. According to a study by Siwawa-Ndai (1997: 343) Botswana was the fastest growing economy in the world between the years 1970-1993. Interestingly enough, the Botswana Democratic Party (BDP), formed in 1962, had, from its inception, a support base of teachers, civil servants and traditional chiefs (Acemoglu, Johnson and Robinson, 2001) and has managed to rule continuously from the mid-1960s, winning all of the eleven general elections held since 1965 until 2014. The other political parties have been unable to gain significant political foothold on power. The idea of one-party rulership, even if based on internationally observed, democratically held elections, still sits uneasy in terms of typical Western-styled system of elections. What is even more remarkable is the significance of their chieftaincy system which is this blend of the 'modern and the traditional which combines elements of continuity with elements of change' (Mohamed Salih, 2001: 162). Botswana is one of the very few African countries where there is a House of Chiefs which is a large fifteen-member body, made up of chiefs from the main tribes, that serves as an advisory body to the main Parliament (Mohamed Salih, 2001).

Ali Mazrui (cited in Ostergard et al, 2004) also supports this point of a more Afri-centirc focus in terms of democracy, when he argues that in many African countries, representativeness is often measured ethnically rather than electorally. A government is deemed to be more or less representative to the extent that it reflects the ethnic composition of the wider society. In addition, African indigenous society is based on collectivism rather than individualism. In this sense, therefore, the 'notion of individual rights is foreign to African ethnophilosophy' (McCarthy, 1994: 107). These examples help to demonstrate, that, rather than engaging in campaigns of total resistance to Western ideas and system, or rejecting fundamental changes in society, where it is appropriate, some African countries can establish political systems best suited to their needs in even if they run counter to Western orthodoxy. This idea is equally applicable to the issue of State-intervention in the economy. 


\section{Political hybridisation and state intervention in African development}

The classic Westernised approach to state intervention in the economy within a market-centric liberal economy, is normally treated with suspicion and as un-necessary interference. Some African countries have been showing that they can adopt aspects of Westernised theories of economic development by embracing state-centric policies within a laissez-faire liberal framework.

In fact, Mehmet (19990 suggests that sound theories of economic development need to be grounded in culture-specific reality and constructed with open minds to learn about cross-cultural values, institutions and environments before prescribing policy interventions. One of the flaws Mehmet saw in Westernisation was the failure of the mainstream classical liberal theorists to see the inherent contradiction between the idealism of rationalism and the mercantilism of the profit motive (Mehmet, 1999: 6). Killick (1989) also propounded similar sentiments about the supposed superiority of the state in development planning within developing countries. After pointing out that the dividing line between the roles of the public sector and the private sector is often cloudy, he further opines, that, even in Western countries where large-scale changes were needed fairly quickly, such as the conversion of a peace to a war economy, this could not be left solely to a market economy (Killick, 1989: 62). He warned of the temptation of exaggerating the appropriateness of policy prescriptions derived from mainstream theories, and urged the 'avoidance of simplistic and single-solution responses to complex problems and economic systems' (Killick, 1989: 63). Pillay (2002) considers the role of the State in economic development in two ways; the first being a 'facilitative role' and the second being a 'directive interventionist' role. Singapore, South Korea and Taiwan are examples of countries where the directive interventionist role of the state was clearly visible. With specific reference to Africa, this directive interventionist approach is also suggested by W. Arthur Lewis (1967), who recommends that public ownership and operation of industrial undertakings in African countries should be done especially in cases of public utilities and also for purposes where there are young or infant pioneering industries (Lewis, 1967: 21-22).

Mauritius serves as a good example of an African state that is embracing this hybrid approach, by incorporating changes in their economic structure in order to enhance their development. Although its economy was once based largely on sugar production that accounted for $90 \%$ of its export earnings in 1970 , by 2000 , sugar accounted for $20 \%$ of its exports and manufactured goods accounted for 70\% (Pillay, 2002: 8). It is the state that played the leading role in this transformation, through its development of the 
Export Processing Zone (EPZ) and the development of the services sector around the financial and tourism sectors. The government is also working on upskilling the labour force especially in the knowledge-based economy. The EPZs were designed, subsidised and guided by the state and by the early 1990 s over 600 were employing 90, 000 worker or nearly a third of the island's work force (Meisenhelder, 1997: 290). He further concludes that economic growth of Mauritius up to the 1990s has been the result of the guidance and intervention of the state bureaucracy rather than the unfettered market place.

In Botswana, even though the World Bank (World Bank, 2018) recognised the economic success of within the country, measured in terms of its growth rate of $5 \%$ over the last decade, this institution is still pessimistic about the country's future economic prospect, because it was deemed to be too state dependent. The problem for the World Bank is that developing countries like Botswana, are not following the traditional market-centric approach, but have adopted a hybrid alternative. Goalathe, (1997: 48)) further attests to the fact that as early as the 1980s, the boom that occurred in Botswana was due in part to substantial government intervention, where state expenditure and net lending exceeded 30\% of GDP throughout the 1980s. Goalathe (1997) further opines that although the government policy was driven by laissez-faire economics, it also clearly recognised market fragilities and weaknesses, and therefore adopted a pragmatic approach to industrial development involving appropriate state intervention. One of the most significant of these was the government's Financial Assistance Policy (FAP), introduced in 1982 to provide financial support through grants and loans to up and coming private enterprises.

Dr Akinwumi Adesina, President of the African Development Bank group, recently made a statement pointing out that 'state-intervention is crucial to drive Africa's industrialisation in order for it to become a centre for trade and manufacturing' (Adesina, 2018). He further explains that Africa could learn a lot from the South Korea example, where their economic success was achieved by the right 'vision, creativity, ingenuity, fiscal discipline and willingness to make hard decisions in order to secure its future' (Adesina, 2018). Furthermore, writers such as Chang (2005) and Shutt (1985) claim that the industrially developed countries did not get where they are through the adoption of policies and institutions that they recommend to developing countries today.

Ajakaiye and Afeikhena (2014) have made the case for a hybrid approach quite aptly by suggesting that:

in view of the success of the emerging markets, particularly those of the EAP region, in implementing a judicious and 
pragmatic combination of government intervention and market mechanisms in the process of economic growth and structural transformation, and the spate of significant government interventions in the OECD countries in dealing with the ongoing economic and financial crisis, Africa should find support for a judicious and pragmatic combination of government intervention and market mechanisms as a strategy for achieving the inclusive, poverty-reducing, and equitable growth and structural transformation that has so far proved elusive (Ajakaiye and Afeikhena, 2014: 746).

Whereas political conservatives such as Okonkwo reject Westernisation in order to preserve the existing traditions, the evidence from these emerging African countries highlights the significance of incorporating aspects of Western ideas and systems in their own development strategies.

\section{Conclusion}

Two key points emerge from the forgoing analysis. The first, in contrast to the political conservative position of Okonkwo in Things Fall Apart, is that, in order for societies to experience transformation and development, some exposure to, and adoption of, new ideas and systems is inevitable. Even though the manner in which some of these exposures was brought about were often associated with European colonialism, trade and slavery, other methods such as commerce and trade or migration are also part of this process. Some African countries have begun to embrace or incorporate economic development ideas that would normally be contradictory to each other, and garner these to their own advantage. This has enabled them to achieve substantial levels of transformation and development. The two phases of the jollof-rice principle are not only inter-related, but crucial if transformation and development are to occur.

The second point which the study makes is to challenge the assumption, in Things Fall Apart, that the adoption of Western ideas leads inevitably to the destruction and retardation of societies. What is important here, is not the wholesale continuation of traditions or the total rejection of the new, but the appropriate blending and hybridisation of these, which is at the heart of the jollof-rice principle. A few countries in Africa have not been content to accept the conservative position that all things must continue as they always have, but have move towards development pathways based on the adoption and hybridisation of aspects of Westernisation as well as nonWestern approaches. Countries like Botswana, Mauritius and Rwanda, 
demonstrate that the wholesale copying or total rejection of Western systems of liberal or deep democracy, as well as non-state intervention in their economies, might not necessarily be the answer for achieving economic development. In contrast to Okonkwo's thinking, as well as conservatives in general, this study argues that, the adoption of new ideas and systems from elsewhere plays significant roles in achieving transformation and development.

\section{References}

Acemoglu, D., \& Robinson, J. (2013). Why Nations Fail: The Origins of Power, Prosperity and Poverty. London: Profile Books Ltd.

Acemoglu, D., Johnson, S., and Robinson, J. (2001). An African Success Story: Botswana. https://economics.mit.edu/files/284 Accessed 15 February 2019.

Achebe, C. (1986). Things Fall Apart. Oxford, UK and Portsmouth, NH, USA: Heinemann Educational Publishers.

Adesina, A. (2018). State Intervention Vital to Drive Africa's Industrialisation in Ghana Business News, 21 May, https://www.ghanabusinessnews. $\mathrm{com} / 2018 / 05 / 21 /$ state-intervention-vital-to-drive-africasindustrialization-adesina/ Accessed 17 February 2019.

Ajakaiye, O., and Afeikhena J. (2014). Economic Development: The Experiences of Sub Saharan Africa, in Currie Alder, Bruce. et al., International Development: Ideas, Experience, and Prospect. Oxford University Press: pp.733-747.

Ayittey, G. (2005). Africa Unchained: The Blueprint for Africa's Future, New York and Hampshire, England: Palgrave Macmillan.

Burke, E. (1999). Reflections on the Revolution in France, Oxford: Oxford University Press.

Chang, H. (2005). Kicking Away the Ladder: Development Strategy in Historical Perspective, London: Anthem Press.

Diop, C. A. (1974). The African Origin of Civilization; Myth or Reality, Chicago, Illinois: Lawrence Hill Books.

Fairbanks, M. (2012). Rwanda is not an Authoritarian Regime The New York Times, 19 September, https://www.nytimes.com/roomfordebate/ 
2012/09/19/autocratic-leaders-who-improve-their-countries/rwanda is-not-an-authoritarian-regime Accessed 20 April 2019.

Fofack, H. (2015). The Idea of Economic Development: Views from Africa, in Mongu, C., and Lin, J.Y., The Oxford Handbook of Africa and Economics, Volume 1, Context and Concepts, Oxford, Oxford University press, pp. 271-299.

Goalathe, N. (1997). Botswana's Boom and Recession Experience: A Discussion' in Salkin. J.S. et al., Aspects of the Botswana Economy: Selected Papers, Gaborone and Oxford: Lentswe La Lesedi Publishers, in association with James Currey Publishers. pp. 37-52.

Heywood, A., 2015. Political Ideologies: An Introduction, Hampshire: Palgrave MacMillan.

Himmelstrand, U., Kinyanjui, K., and Mburugu, E. eds. (1994). African Perspectives on Development: Controversies, Dilemmas \& Openings. London: James Currey Publishers.

Kasfir, N. (1998). African Ambiguities: No Party Democracy in Uganda, in Journal of Democracy, Vol. 9 Number 2, Johns Hopkins University Press. pp. 49-61.

Killick, T. (1989). A Reaction Too Far: Economic Theory and the Role of the State in Developing Countries, London: Overseas Development Institute.

Lewis, W. A. (1967). Report on Industrialisation and the Gold Coast. Accra:

Government Printing Department.

McCarthy, S. (1994). Africa: The Challenge of Transition. London, New York: I.B. Tauris \& Co. Publishers.

Meisenhelder, T. (1997). The Development State in Mauritius. Journal of Modern African Studies. Vol. 35, No. 2 pp. 279-297.

Mohamed Salih, M.A. (2001). African Democracies and African Politics. London, Sterling, Virginia: Pluto Press.

Mongredien, P. (2010). Things Fall Apart by Chinua Achebe, in The Guardian, 31 January, https://www.theguardian.com/books/2010/jan/31/ things-fall-apart-achebe-review Accessed 24 Feb. 2019. 
Ostergard, Jr. R. (2004). et al. Power, Politics and the African Condition: Collected Essays of Ali A. Marrui. Volume 111. Trenton, NJ: Africa World Press Inc.

Pillay, P. (2002). The Role of the State in Economic Development in Southern Africa, Dialogue on Globalisation. Berlin: Friedrich-Ebert-Stiftung Department for Development Policy - Dialogue of Globalisation.

Potter, D. (2000). Democratisation, Good Governance and Development in Allen. T. and Thomas, A., ed. Poverty and Development Into the $21^{\text {st }}$ Century. Milton Keynes: The Open University in association with Oxford University Press, pp. 365-382.

Rist, G. (1997). The History of Development: From Western Origins to Global Faith. London and New York: Zed Books.

Rodney, W. (1974). How Europe Underdeveloped Africa. London: Bogle L' Overture Publications Ltd.

Shutt, H. (1985). The Myth of Free Trade: Patterns of Protectionism Since 1945. Oxford: Basil Blackwell Ltd and London: The Economist Publications Ltd.

Siwawa-Ndai, P. Industrialisation in Botswana: Evolution, Performance and Prospects in Salkin. J.S. et al, ed. (1997). Aspects of the Botswana Economy: Selected Papers, Gaborone: Lentswe La Lesedi Publishers, and James Currey Publishers. pp. 335-367.

Stuenkel, O. (2017). Post-Western World: How Emerging Powers are Remaking Global Order, Cambridge and Malden MA: Polity Press.

The New Times. (2010). Book Review: Things Fall Apart by Chinua Achebe, 22 January. https://www.newtimes.co.rw/section/read/93649 Accessed 24 February.

World Bank. (2018). The World Bank in Botswana www.worldbank.org/ en/country/botswana Accessed 17 February 2019.

World Bank. (2019). Rwanda systematic Country Diagnostic: Report no. 138100-RW 25 June, International Development Association Country Department AFCE2 Africa Region.

Yoder, J. (2013). Elections as a Stress Test of Democratisation in Societies: A Comparison of Liberia, Sierra Leone, and the Democratic Republic of the Congo in C. Veney and D. Simpson, ed. African Democracy and 
Development, Challenges for Post-Conflict African Nations. Maryland: USA and Plymouth UK: Lexington Books. pp. 109-136. 2013. 